Portland State University

PDXScholar

Dissertations and Theses

Dissertations and Theses

Winter 2-9-2015

\title{
Safety at Half-Signal Intersections in Portland, Oregon
}

Todd Robert Johnson

Portland State University

Follow this and additional works at: https://pdxscholar.library.pdx.edu/open_access_etds

Part of the Other Civil and Environmental Engineering Commons, and the Transportation Engineering Commons

Let us know how access to this document benefits you.

\section{Recommended Citation}

Johnson, Todd Robert, "Safety at Half-Signal Intersections in Portland, Oregon" (2015). Dissertations and Theses. Paper 2200.

https://doi.org/10.15760/etd.2197

This Thesis is brought to you for free and open access. It has been accepted for inclusion in Dissertations and Theses by an authorized administrator of PDXScholar. Please contact us if we can make this document more accessible: pdxscholar@pdx.edu. 
Safety at Half-Signal Intersections in Portland, Oregon

by

Todd Robert Johnson

A thesis submitted in partial fulfillment of the requirements for the degree of

Master of Science

in

Civil and Environmental Engineering

Thesis Committee:

Christopher M. Monsere, Chair

Peter Koonce

Kelly J. Clifton

Portland State University

2015 


\section{ABSTRACT}

The safety at half-signalized intersections in Portland, Oregon is analyzed in this thesis using 10 years of crash history and analysis of video that was collected at a subset of intersections. A half-signalized intersection has a standard red-yellow-green traffic signal for automobiles on the major road, a stop sign for motorists on the minor road, and a pedestrian signal with actuation for pedestrians and/or bicyclists on the minor road. Although prevalent in Canada, this type of intersection control is not typically found in the United States because the MUTCD explicitly prohibits its use. Half-signal use is limited mostly to two cities in the Pacific Northwest. In Portland, Oregon there are forty-seven intersections where half-signals are used but the last installation was in 1986; Seattle has over 100 intersections with half-signals and installs these in new locations where warranted.

To explore the safety records of these intersections in Portland, crash data from 2002-2011 was analyzed. A total of 442 crashes over the ten-year period at half-signals were observed. Sixteen of these 442 crashes involved pedestrians. In the crashes involving pedestrians, significant differences were found between the approach street of the vehicle and whether the pedestrian or driver was at fault. In the crash error reports, it was found that significantly more of the crashes involving pedestrians were 
the fault of motorists departing from the minor road who collided with pedestrians crossing the major street. Further crash analysis at half-signals was performed by developing matched comparison groups of minor stop controlled and fully signalized intersections. Crash rates were 0.158 and 0.178 crashes per million entering vehicles for 3-leg and 4-leg half-signals and these rates did not differ significantly from the minor street stop controlled and signalized comparison groups. Results from the matched comparison showed that the half-signalized group had more rear-end crashes when compared with the minor stop controlled group. This was the only result that held significance when crash rates were considered. It was also observed that the minor stop controlled group had a higher proportion of angle crashes when compared with the half-signal group but this did not influence the crash severity. Pedestrian crashes were more prevalent in the half-signal group when compared with the fully-signalized group. Pedestrian volumes were not available which would be used to determine if this significant measure is a result of higher pedestrian use at half-signals.

In addition to crash analysis, video was captured at five half-signalized intersections totaling 180 hours. Traffic volumes, pedestrian and bicycle volumes, and signal actuations were collected over a twenty-four hour period. Over this twenty-four hour period the five intersections averaged daily counts of 18613 vehicles on the major 
street, 591 vehicles on the minor street, 263 pedestrians crossing the major street, 285 pedestrians crossing the minor street, 52 bicycles on the major street, 37 bicycles on the minor street, and 126 signal actuations. Twenty-four hour observations from each of the intersections were used to study conflicts and compliance. No conflicts were observed that reflect the left-turning from the minor street pedestrian crashes that were identified in the crash history. Compliance of the half-signal by vehicles and pedestrians was comparable to compliance at fully-signalized intersections found in other studies with one exception. Across the intersections where video was collected, consisting of four 4-leg intersections and one 3-leg intersection, seven left turn on red violations were observed which had a significant impact on the time after red that red light violations were made. It is hypothesized that at half-signals vehicles on the major street make a left turn on the red signal very late into the red phase because there is not a risk of colliding with a vehicle traveling on the minor street since traffic volumes on the minor street are comparably low. The observed left turn on red violations did not put pedestrians at risk since by that point into the signal pedestrians were already clear of the intersection.

Finally, a stop compliance logistic regression model was developed at four fourleg intersections to see what factors had an effect on minor street vehicle stop 
compliance. All 166 hours of video were used to observe vehicles that arrived at the half-signal during the pedestrian phase. The dependent variable collected was whether a vehicle came to an acceptable stop. Independent variables collected included the vehicle's queue position, if it was the peak school period, if there was a vehicle across the street on the minor road, if a vehicle was stopped at the signal on the major street, if a pedestrian was present when the vehicle arrived, and the movement that the vehicle made from the minor street. Independent variables used in the model included the vehicle's queue position, if a vehicle was stopped at the signal on the major street, if a pedestrian was present, and if the vehicle made a right turn at the signal. Pedestrian presence and right turning vehicles had a positive impact on stop compliance. Vehicles being further back in the queue and cars stopped at the signal on the major street had a negative impact on stop sign compliance. In the model, pedestrian presence had the largest positive impact on stop compliance. When pedestrians were present, a motorist on the minor street was four times more likely to stop at the sign. 


\section{ACKNOWLEDGEMENTS}

I'd like to thank my family, thesis committee, and friends for their support over the years that it took to finish this thesis. My mother, father, and brother have all asked when I was going to finish this every time I traveled back to San Francisco and I thank them for their persistence. Additionally the encouraging emails from Dr. Monsere every six months asking about the status on this thesis were welcome reminders. Lastly Dr. Monsere, Dr. Clifton, Dr. Bertini, Dr. Figliozzi, and Mr. Koonce helped to spur me on annually at TRB. To the aforementioned professors and others at PSU I am very grateful to them for building the transportation program into what it is today and the benefits I have received from that education and experience. I'd also like to thank the ITS Lab at Portland State and the fellow students that I have collaborated with, learned from, and made lifelong friendships with.

This is a project that had taken me six years and multiple revisions and drafts to complete. I dedicate this M.S. thesis to my late grandmother Marian and dog Chloe both who I loved dearly and passed away during the period that I have been working on this thesis. 
Table of Contents

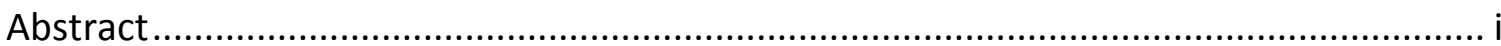

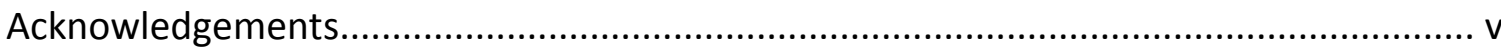

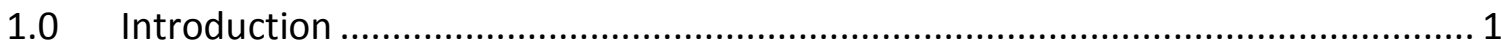

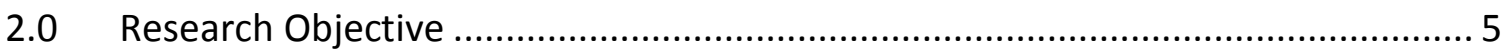

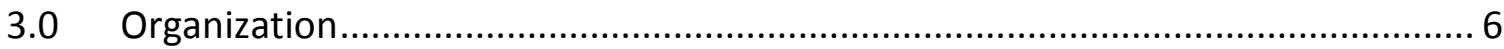

4.0 Literature Review: Safety at Half-Signals...................................................... 7

4.1 History of Half-Signals in the United States and Canada............................... 7

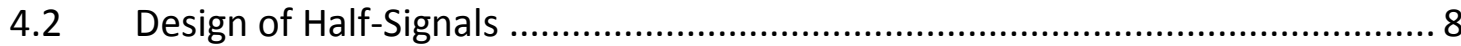

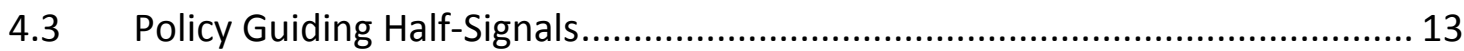

4.4 Pedestrian Safety, Vehicle Safety, and Behavior at Half-Signals .................... 19

4.4.1 Safety at Half-Signals in Seattle, WA....................................................... 21

4.4.2 Safety at Half-Signals in Seattle, WA and Lincoln, NE................................ 22

4.4.3 Safety at Half-Signals in Canada................................................................. 28

4.4.4 HAWK/Pedestrian Hybrid Beacons in Tucson, AZ ..................................... 30

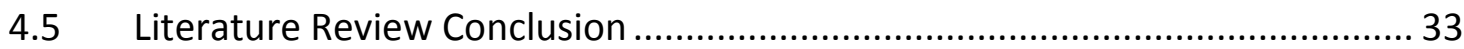

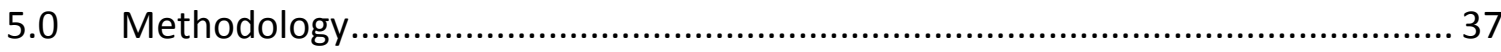

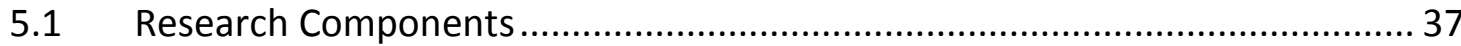

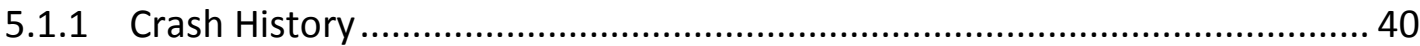

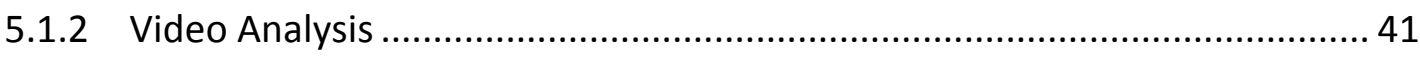

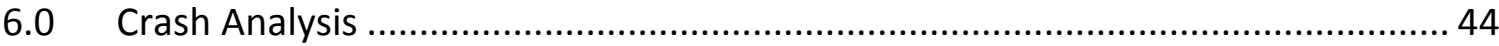

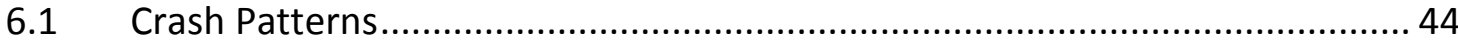

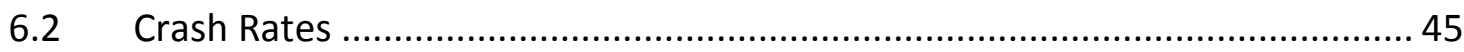

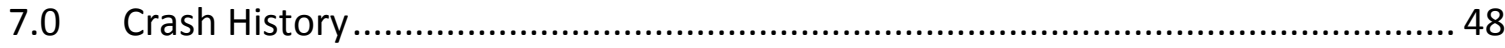

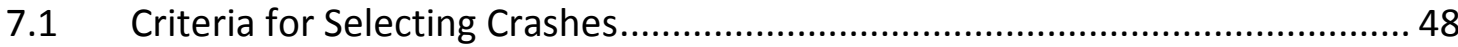

7.2 Overview of Crashes at Half-Signal Intersections........................................ 50

7.2.1 Crash Rates at Half-Signalized Intersections........................................... 55

7.2.2 Summary of Overview of Crashes and Crash Rates at Half-Signals .............. 62

7.3 Evaluation of Collision Type at Half-Signal Intersections ..............................63

7.3.1 Angle Crashes at Half-Signal Intersections .............................................. 63 


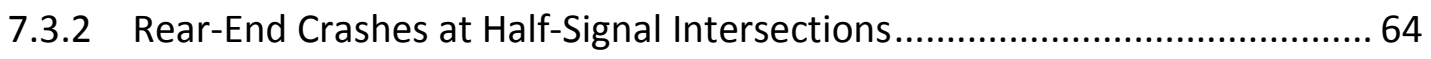

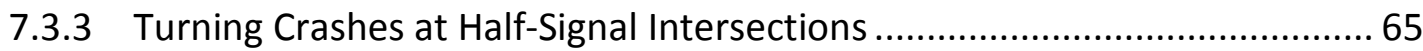

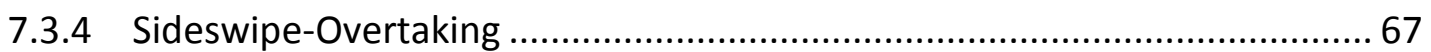

7.3.5 Bicycle and Pedestrian Crashes at Half-Signal Intersections .........................67

7.3.6 Summary of Collision Type at Half-Signalized Intersections........................ 71

7.4 Matched Comparison Group Development ............................................. 71

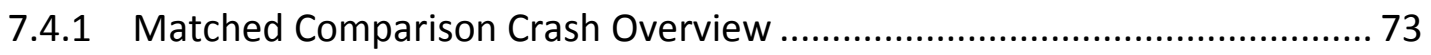

7.4.2 Angle Crashes Matched Comparison Groups ........................................... 78

7.4.3 Rear-End Crashes at Matched Comparison Groups ..................................... 79

7.4.4 Turning Crashes at Matched Comparison Groups....................................... 80

7.4.5 Bicycle and Pedestrian Crashes at Matched Comparison Groups................ 82

7.4.6 Summary of Crash History and Rates at Matched Comparison Sites........... 87

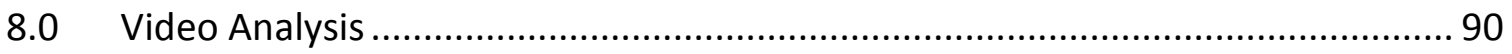

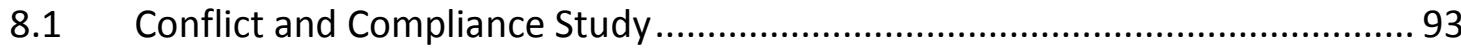

8.1.1 Conflict Study at Half-Signals in Portland, Oregon .................................... 96

8.1.2 Compliance Study at Half-Signals in Portland, Oregon............................ 103

8.2 Stop Sign Compliance Logistic Regression Model ...................................... 109

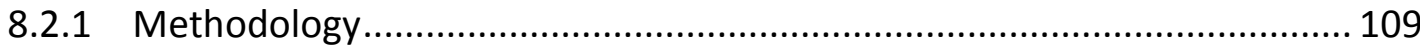

8.2.2 Stop Sign Compliance Data Summary................................................... 114

8.2.3 Establishing Dependent Variables for Stop Sign Compliance Model ......... 115

8.2.4 Logistic Regression Model at Four Half-Signals in Portland, Oregon ......... 122

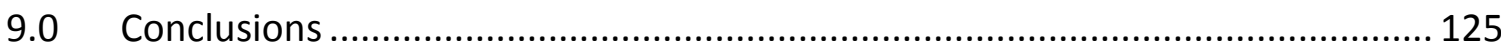

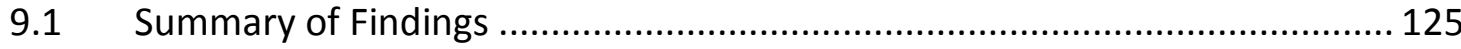

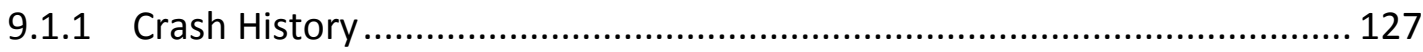

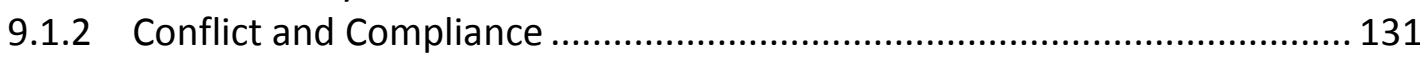

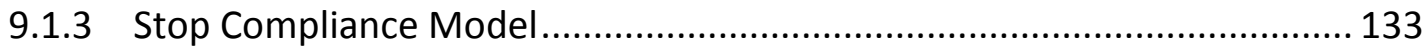

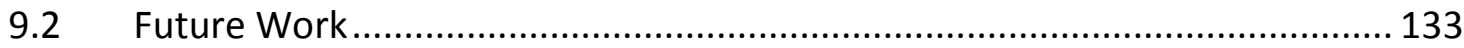

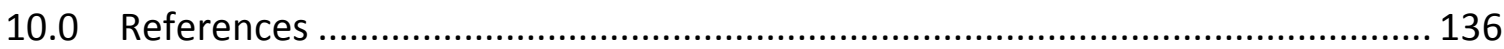

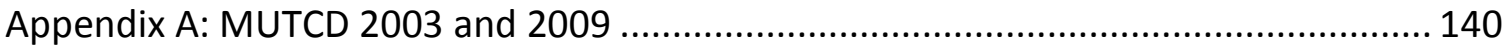

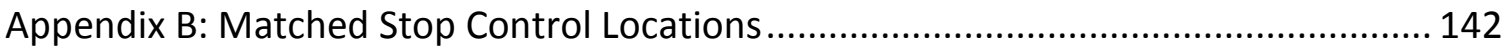

Appendix C: Matched Signal Control Locations...................................................... 143

Page vii 


\section{List of Tables}

Table 1: Crash History Results from Published Half-Signal Studies ............................... 33

Table 2: Compliance Results from Published Half-Signal Studies................................... 33

Table 3: Crash History Results from Published Pedestrian Hybrid Beacon Studies ......... 34

Table 4: Crash Severity, Collision Types, and Crash Types at Half-Signals (2002-

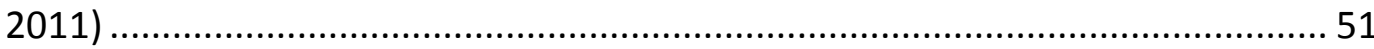

Table 5: Crashes at Half-Signals compared with Urban Minor Stop Controlled

Statewide Crash Sample (2003-2007)................................................................ 53

Table 6: Crashes at Half-Signals compared with Urban Signalized Statewide Crash

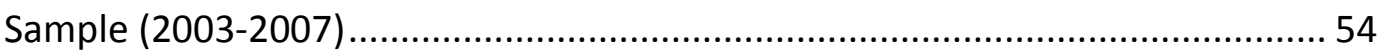

Table 7: Average Adjusted Traffic Volume Information (2002-2011) .............................. 57

Table 8: Crash Rates per million entering vehicles (MEV) at Half-Signalized

Intersections (2002-2011) ............................................................................ 58

Table 9: Crash Rates at Half Signals per MEV Compared with Statewide Urban 2-

Way-Stop Controlled Sample (2003-2007) ....................................................... 59

Table 10: Crash Rates at Half Signals per MEV Compared with Statewide Urban

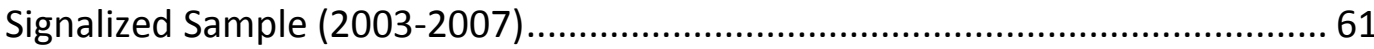

Table 11: Angle Crash Causes and Violations by Direction at 4-Leg Half-Signals

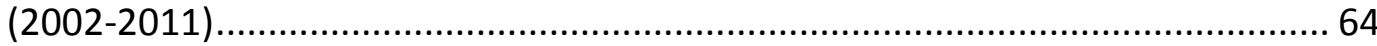

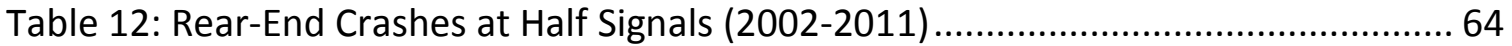

Table 13: Turning Crashes Aggregated by Turning Movement at Half Signals

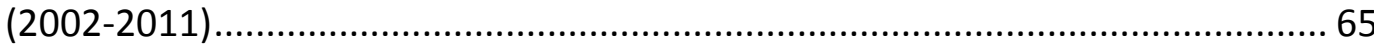

Table 14: Turning Crashes by Movement on Major Street (2002-2011)....................... 66

Table 15: Turning Crashes by Movement on Minor Street (2002-2011) ........................ 66

Table 16: Left-Turning Crashes on Major and Minor Street (2002-2011) ...................... 66

Table 17: Sideswipe-Overturning Crashes Aggregated at Half Signals (2002-2011) ........ 67

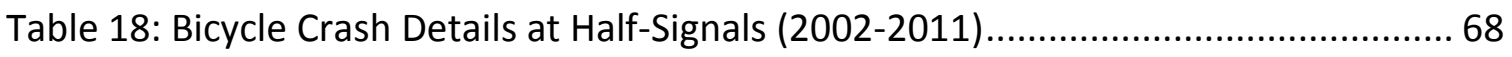

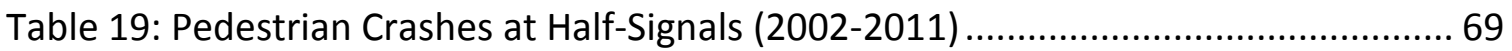

Table 20: Pedestrian Crashes Aggregated by Fault and Approach at Half Signals

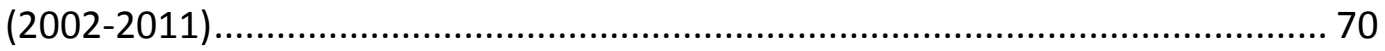

Table 21: Pedestrian Crashes Aggregated by Crash Severity and Approach at Half

Signals (2002-2011)........................................................................................ 71

Table 22: Total Crashes by Severity, Crash Type, and Collision Type at Matched

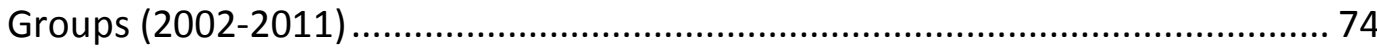

Table 23: Matched Group Adjusted Traffic Volume Information.................................. 76

Page viii 
Table 24: Crash Rate by Severity, Crash Type, and Collision Type at Matched

Groups (2002-2011) 77

Table 25: Matched Group Angle Crashes by Cause (2002-2011) .................................... 78

Table 26: Angle Crash Severity at Matched Stop Group (2002-2011)............................. 79

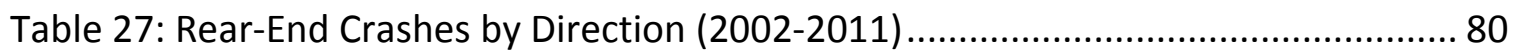

Table 28: Rear-End Crashes by Severity Type (2002-2011) ........................................ 80

Table 29: Turning Crashes at Matched Comparison Groups (2002-2011) ....................... 81

Table 30: Matched Group Turning Crashes by Movement on Major Street (2002-

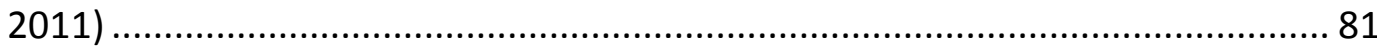

Table 31: Matched Group Turning Crashes by Movement on Minor Street (2002-

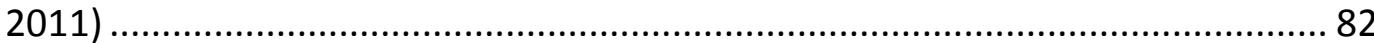

Table 32: Matched Group Left Turning Crashes on Major and Minor Street (2002-

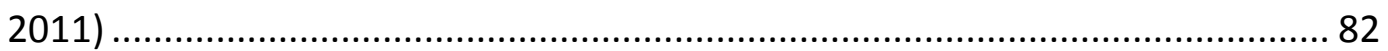

Table 33: Crashes involving Bicycles at Half and Stop Group (2002-2011) ................... 83

Table 34: Crashes Involving Bicycles at Half and Signal Group (2002-2011) ................... 84

Table 35: Pedestrian Crash Detail at Matched Stop Group (2002-2011) ....................... 85

Table 36: Pedestrian Crash Detail at Matched Signalized Group (2002-2011) ............... 86

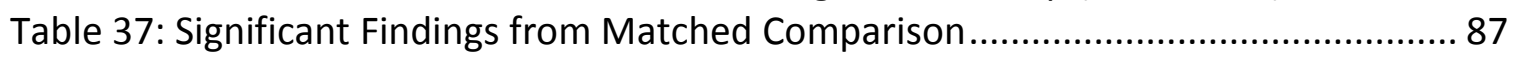

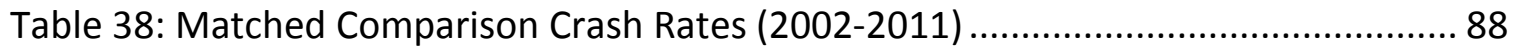

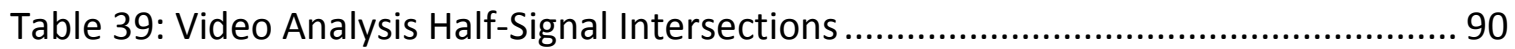

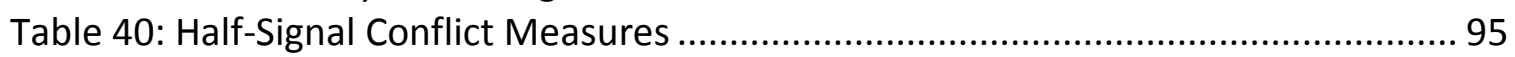

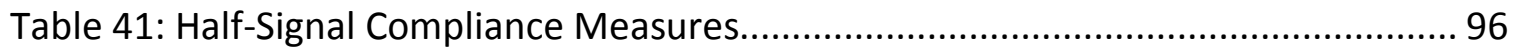

Table 42: Characteristics, Conflicts, and Counts at Five Half-Signal Locations ................ 97

Table 43: Compliance and Counts at Five Half-Signal Locations ................................. 103

Table 44: Pedestrian Signal Violation Rate ................................................................ 104

Table 45: Percent of Actuated Phases with Half-Signal Red Light Violations by

Motor Vehicles................................................................................................. 106

Table 46: Distribution of Red Light Violations by Time Elapsed after Red Onset .......... 107

Table 47: Distribution of Red Light Violations by Time Elapsed after Red Onset

without Left on Red Violations ....................................................................... 108

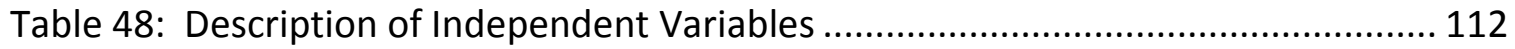

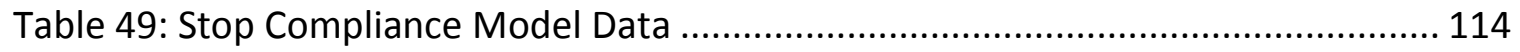

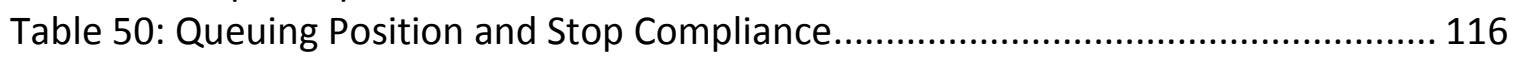

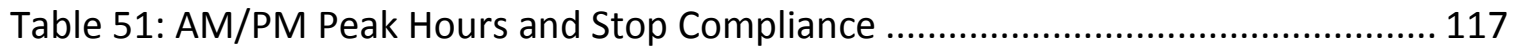

Table 52: Pedestrian Presence and Stop Compliance .............................................. 117

Table 53: Vehicle Opposite on Minor Street and Stop Compliance .............................. 118

Page ix 
Table 54: Vehicle Stopped at Signal on Major Street and Stop Compliance................. 119

Table 55: Vehicle Type and Stop Compliance............................................................. 120

Table 56: Vehicle Turning Right and Stop Compliance ............................................... 121

Table 57: Vehicle Turning Left and Stop Compliance ................................................. 121

Table 58: Vehicle Making Through Movement and Stop Compliance ......................... 122

Table 59: Logistic Regression Model and Estimates ................................................. 123

Table 60: Comparison of Relative Rates between HAWK (24) and Half Signal .............. 130 
List of Figures

Figure 1: Half-Signal Simplified Overhead Layout ......................................................... 2

Figure 2: Half-Signalized Intersection, NE Laddington and NE Glisan, Portland, OR......... 3

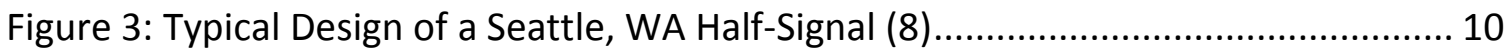

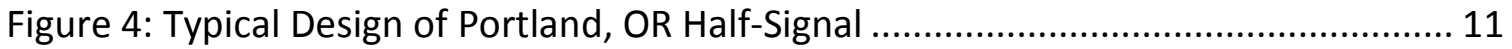

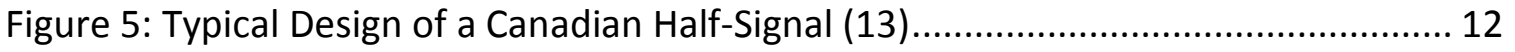

Figure 6: Pedestrian Crossing Control Warrant Chart (13) ........................................... 16

Figure 7: MUTCD Warrant 4 - 70\% Pedestrian Peak Hour Volume ................................ 17

Figure 8: MUTCD Warrant - Pedestrian Hybrid Beacons High-Speed ............................. 17

Figure 9: Major Road Motor Vehicle Compliance Performance at Pedestrian

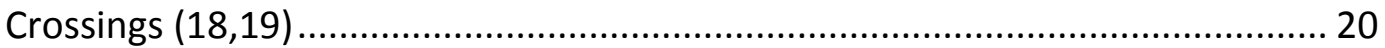

Figure 10: Urban Intersection Improvements for Pedestrian Safety: Half-Signal

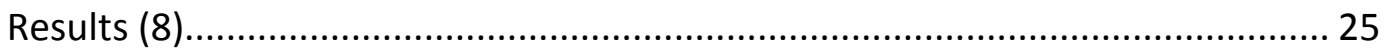

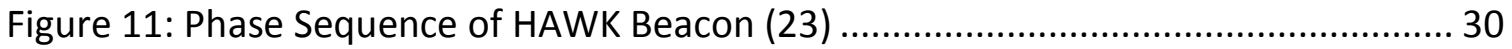

Figure 12: Traffic Count Distribution by Year ............................................................ 56

Figure 13: Sample Screen Captures from Half-Signals............................................... 92

Figure 14: Left-Turning Conflict due to queuing at SE 15th and Tacoma Portland,

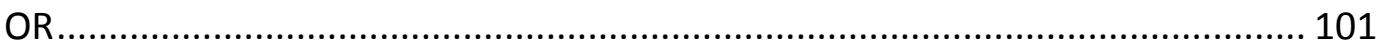

Figure 15: Pedestrian Signal Violation Rate by Hour of Day...................................... 105

Figure 16: SE Tacoma and SE 15th February 11, 2011 Peak Hours 8:00-9:00 and 14:30-15:30 


\subsection{INTRODUCTION}

Bicyclists are 1.8 times more likely than a motorist to be involved in any type crash on an individual trip (1). Per kilometer traveled pedestrians are twenty-three times more likely to be killed than car occupants and bicyclists twelve times more likely to suffer the same fate (2). These statistics suggest that the current transportation network is not conducive to pedestrian and bicycle safety. The need for a safer built environment is especially important around schools since children ages 5-15 have the highest injury rates as pedestrians $(3,4)$. Providing facilities to safely and conveniently cross busy roads is a key consideration in the network. One tool used in the past by transportation professionals at intersections and believed to create a safer pedestrian and bicycling environment is the pedestrian or "half" signal. A simplified half-signal is shown in Figure 1.

Page 1 


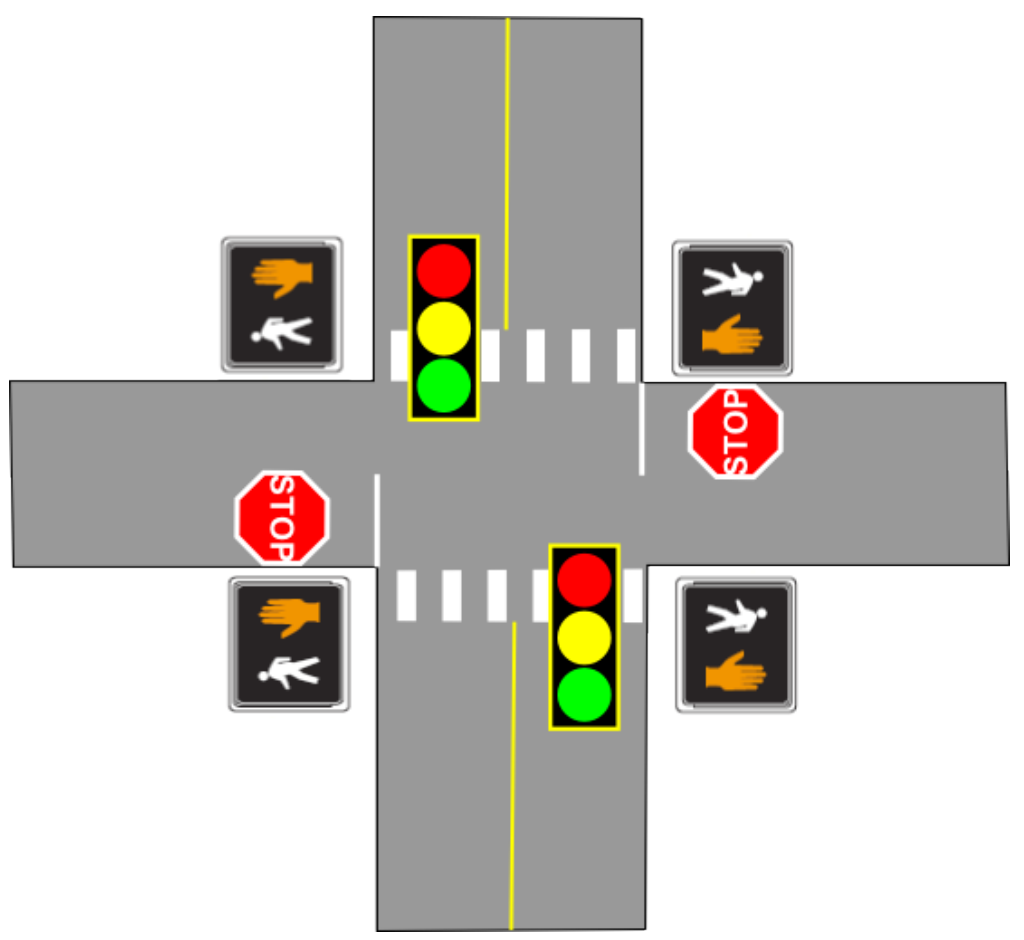

Figure 1: Half-Signal Simplified Overhead Layout

At an intersection the half-signal has a standard red-yellow-green traffic signal for automobiles on the major road, a stop sign for motorists on the minor road, and a pedestrian signal with actuation for pedestrians and/or bicyclists on the minor road. When the actuator is pressed, after some delay, traffic is stopped on the major road, pedestrians are given a walk indication, and bicyclists and motor vehicles on the minor road proceed after obeying the stop sign. Throughout the course of this thesis, the terms half-signal, pedestrian signal, and half-signalized intersection are used 
interchangeably to indicate the type of intersection as described above and shown in Figure 2.

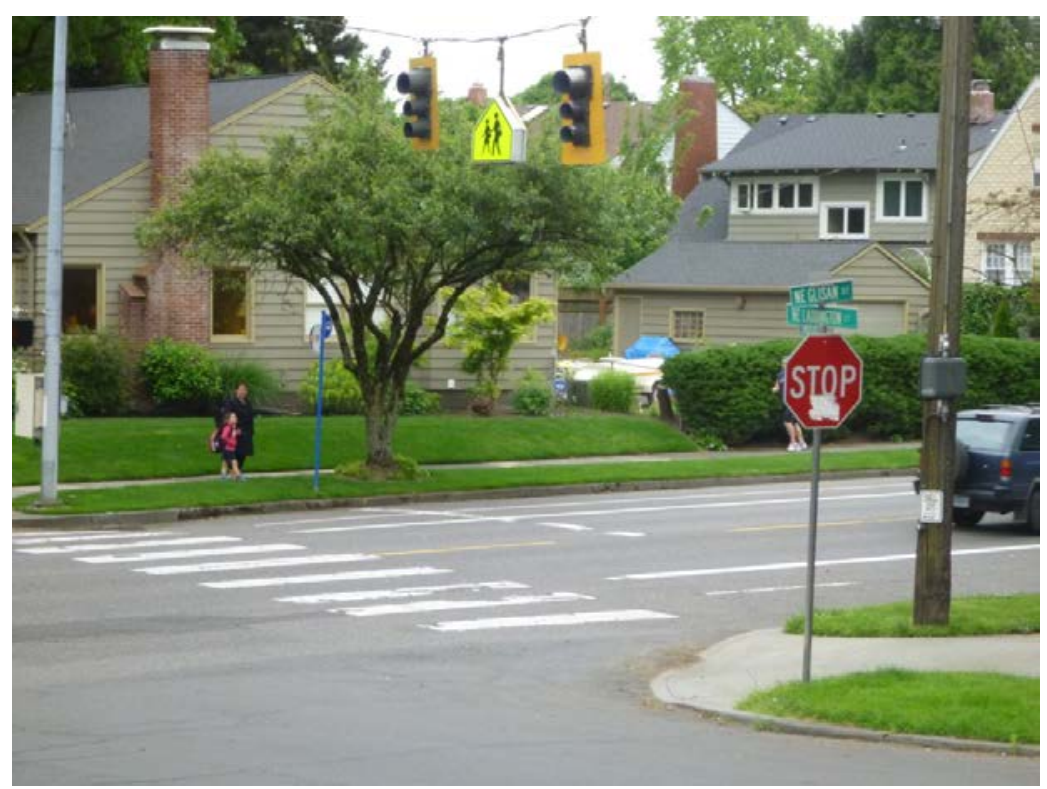

Figure 2: Half-Signalized Intersection, NE Laddington and NE Glisan, Portland, OR

Half-signals are used primarily where a high-speed, high-volume multi-lane arterial intersects a low-volume residential street. Because of low minor street vehicle volumes a full traffic signal is often not warranted where a half-signal is used. High vehicle volume on the major street, however, often results in limited gaps for pedestrians to cross the major street. Long delays for pedestrians result in riskier pedestrian behavior with pedestrians accepting smaller gaps in traffic streams. 
Half-signals are placed at intersections and not at mid-block locations since in many instances these are the most convenient and direct pathways for bicycles and pedestrians in their travel behaviors. Stop signs are utilized instead of signals on the minor roads so as to not encourage and promote motor vehicle traffic on the minor road by giving a right-of-way for motor vehicle traffic. Limiting vehicular traffic is especially important where bicycle routes intersect busy streets.

There is a concern that signalizing an intersection induces vehicle traffic on the minor street. By providing a signal, more motorists may utilize that minor street to take advantage of the ease of turning on to or crossing the major street. There are many applications where a transportation agency may want to provide safer crossings for pedestrians and/or bicyclists without encouraging vehicle traffic on the minor street. At and around school locations, in the development of bicycle routes, at commercial area street crossings, and in promoting neighborhood connectivity it may be desirable for pedestrian and cyclists to safely cross streets with high motor vehicle volumes without unreasonable delay and adding additional vehicle traffic.

Another motivation for using half-signals is the reduced cost when compared with full signalization at an intersection. 


\subsection{RESEARCH OBJECTIVE}

While half-signals have been used to implicitly improve pedestrian safety, we do not know how half-signals impact the safety of all users. The purpose of this thesis is to investigate the safety for all users of half-signalized intersections. This analysis focuses on a group of half-signalized intersections located in Portland, Oregon. The specific objectives of the work are:

1. Review and understand the crash patterns at half-signalized intersections

2. Compare the safety performance of half-signalized intersections using a matched comparison group

3. Understand operations and safety better through the use of video. 


\subsection{ORGANIZATION}

This thesis is broken into five major sections covering half-signalized

intersections as described below:

- A literature review is performed on the existing body of knowledge,

- Research steps are developed based on the findings of the literature review,

- Statistical methods used for crash video analysis are summarized,

- Crash history is reviewed at half-signalized intersections,

- Conflicts are tallied from video and a model of vehicle stopping behavior is developed, and

- Results are discussed and recommendations are given based on these results. 


\subsection{LITERATURE REVIEW: SAFETY AT HALF-SIGNALS}

The first section of this literature review outlines the history of half-signals. Since there is not a standard in the design of half-signals, varying designs and guiding policies are explained. Existing safety studies at half-signal intersections are reviewed with gaps in the literature and areas for further research identified. This literature review is limited to signalized and beacon pedestrian crossings at intersections in the United States and Canada.

\subsection{History of Half-Signals in the United States and Canada}

A precise location and date where the first half-signal was installed could not be identified in a search of the literature. Portland, Oregon's signal database identifies one half-signal at SE $39^{\text {th }}$ and SE Taylor that may have been installed as early as 1954. However most of the forty-seven half-signals currently operating in Portland were installed in the mid-1970s and no half-signals have been installed since 1986. As of 2009, 105 half-signals are currently in operation in Seattle (5). Prior to 1970, Seattle had no half-signals. Twenty half-signals were installed in the early 1970s, and two were installed in the mid-1980s (6). Since 1985, about four half-signals have been installed per year in Seattle (5). Kansas City, MO had 69 half-signals and Wichita, KS had 68 half- 
signals by 1972 (7). Both of these cities have since retrofitted locations with half-signals to full signalization or removed half-signals completely. Lincoln, NE had at least one location with a half-signalized intersection as early as 1966 (8). This location in Lincoln is currently still functioning as a half-signal. There may be other locations within the United States that at one point utilized or are still using half-signals but in reviewing literature no other locations were identified.

Like the United States, Canada began installing pedestrian/half-signals in the mid-1960s. Cities with a number of pedestrian signals at intersections in Canada include the Vancouver, British Columbia metropolitan area (including Vancouver, Richmond, Surrey, and Burnaby); Edmonton, Alberta; and Regina, Saskatchewan. The Vancouver metropolitan area has 367 pedestrian signals at intersections, Edmonton has 197, and Regina 32 as of 2002 (9). In general, across Canada, half-signalized intersections are more prevalent in the Western portion whereas jurisdictions in eastern Canada install pedestrian signals more often at midblock locations.

\subsection{Design of Half-Signals}

In the United States, the Manual on Uniform Traffic Control Devices (MUTCD) $(10,11)$ is the federal standard for signs, signals, and pavement markings to ensure consistency and uniformity. In reviewing the history of half-signals in the United States, 
patterns that emerge are directly linked with the history of the MUTCD. Most halfsignals were installed during the 1970s. During this time period a lack of guidelines led directly to different designs of half-signals in different geographic areas.

One design used in cities is shown in Figure 3. This design uses one crosswalk and one mast-arm or guide wire to support vehicular signals for both directions. This type of design was more popular due to its lower cost and was used in Lincoln, NE; Kansas City, MO; and Wichita, KS. This design is currently used in Seattle, WA. The current design in Seattle also includes signage at the unmarked pedestrian crossing that restricts crossing and directs pedestrians to use the adjacent signal and crosswalk. 


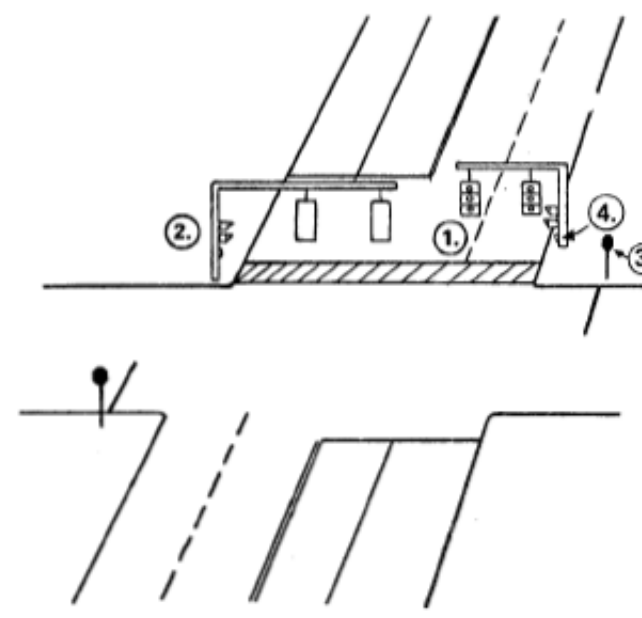

(1.)
(R)
(Y)
(G)

(2.)

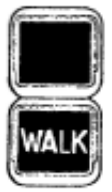

(3.) STOP

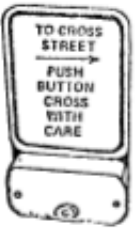

Figure 3: Typical Design of a Seattle, WA Half-Signal (8)

By contrast, the half-signal installations in Portland, OR typically have two crosswalks and a signal post and mast-arm for both directions of travel. This configuration is shown in Figure 4. Half-signals in Portland also typically have two diamond-shaped pedestrian crossing signs on the mast-arm which flash prior to, during, and after signal actuation. At these locations there are typically also roadside pole- 
mounted pedestrian crossing signs to alert motorists about the presence of pedestrians; these are not shown in Figure 4.

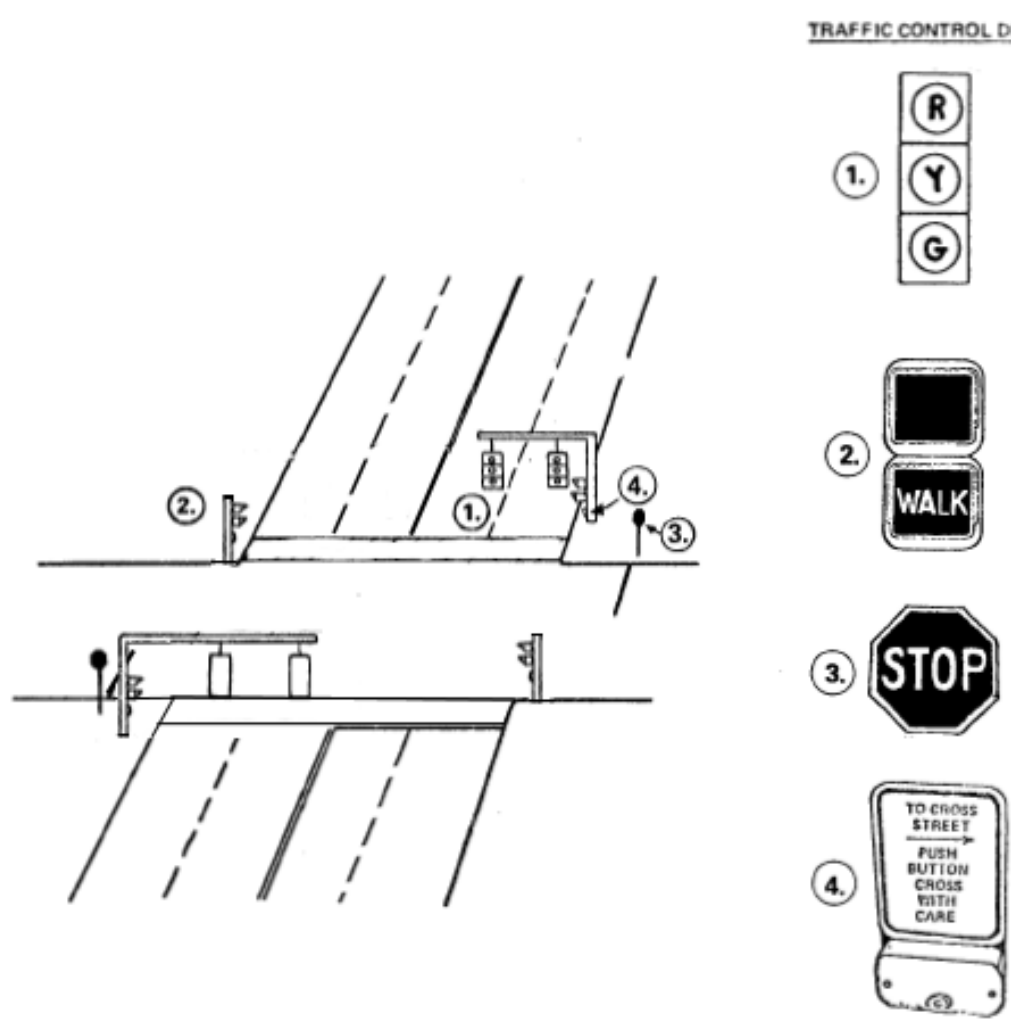

Figure 4: Typical Design of Portland, OR Half-Signal

The design of Canada's half-signals are controlled by their Pedestrian Crossing Control Manual (12). While this design still uses two signals poles, this design differs from Portland's in that typically only one pedestrian crossing is striped on the road. This design is shown below in Figure 5. One exception in the signal design across Canada is 
that British Columbia operates their pedestrian signals at intersections such that they dwell in flashing green. Flashing green is used at half-signals to convey to drivers that a particular location is a pedestrian signal, that pedestrians are present, and that all movements from the main street are permissive. Flashing green is not a valid signal display elsewhere in Canada but at one time Ontario used a rapid flashing green to signify priority for one direction at a permissive left-turn.
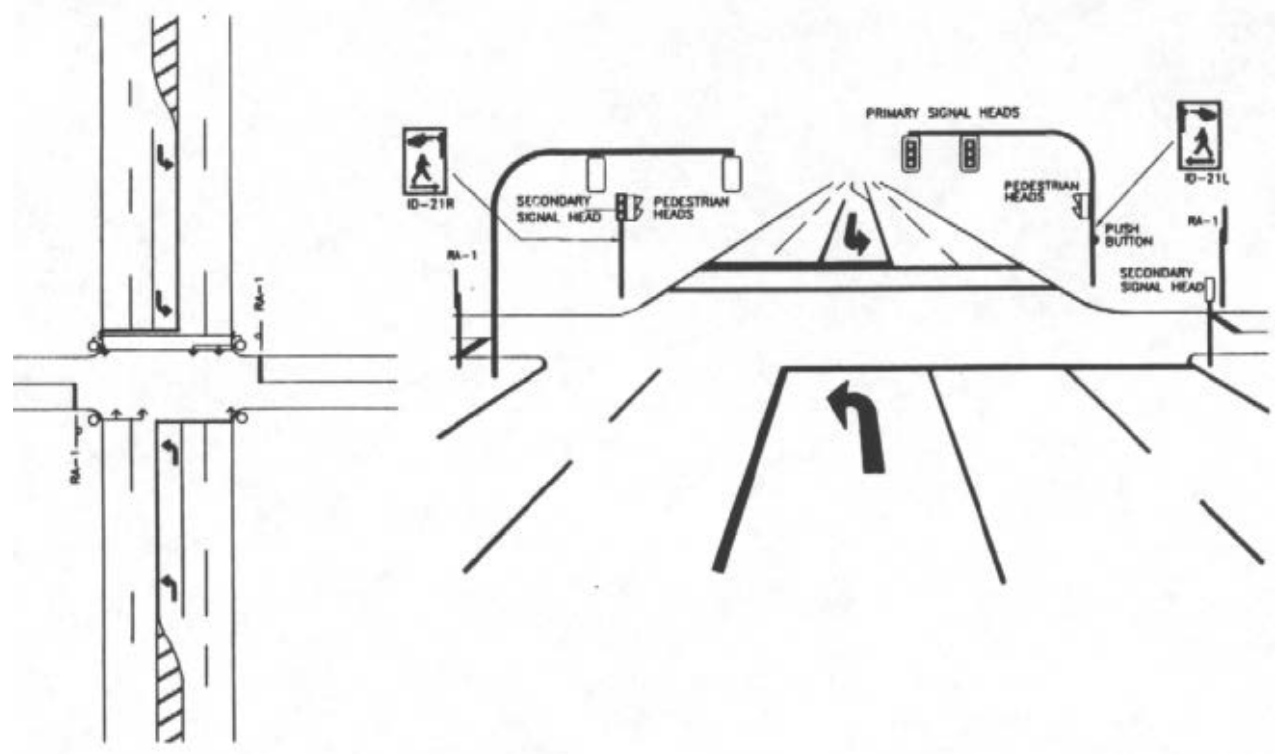

Figure 5: Typical Design of a Canadian Half-Signal (13) 


\subsection{Policy Guiding Half-Signals}

An article from the Institute of Transportation Engineers (ITE) Journal in 1965 titled "Non-Standard Traffic Signals Plague U.S. School Crossings" stated that "The lack

of a generally accepted standard, designed to fit this problem (pedestrian crossings) has left a vacuum which can only result in the continued use of non-uniform traffic control devices (14)." In 1971, the MUTCD established a school crossing warrant relating to gaps in a traffic stream that made it easier for school locations to warrant full signalization. The 1971 MUTCD also included a mandatory condition that "STOP signs shall not be erected at intersections where traffic control devices are operating" (15). The primary intention of these MUTCD additions in 1971 was to standardize school crossing locations and have crossings for pedestrians at intersections be fully signalized intersections where warranted.

At the time of the MUTCD revision in 1971, many cities already had their own non-standardized crossing types in place and sought to retrofit these into half-signals. The cities of Wichita and Kansas City requested unsuccessfully in 1972 that the 1971 MUTCD revision be reversed and that half-signals be included in the MUTCD (7). The City of Seattle also made an unsuccessful request to the National Advisory Committee on Traffic Control Devices for the adoption and trial of half-signals in 1975 (16). 
The Federal Highway Administration (FHWA) ultimately gave three reasons in 1987 through a Final Ruling in the Code of Federal Regulations (CFR) as to why halfsignals are not permitted in the MUTCD which were (16):

1. Motorists on the minor road, facing the inability to cross the major stream of traffic, could utilize the pedestrian signal, may not come to a complete stop, and not give adequate attention to pedestrians crossing the street.

2. Left-turning vehicles from the minor road that enter the intersection because they see that major road traffic is stopped could potentially become trapped in the intersection as the signal changes back to green. In this situation, there would be no clearance interval for the minor road traffic.

3. Half-signals violate driver expectancy with vehicles on the minor stop controlled leg making left turns in front of drivers who see a green ball from the traffic signal on the major road.

Since pedestrian crossings are designed to convey pedestrians safely across the road, the FHWA contends that building a device for pedestrians that has the aforementioned drawbacks is unsafe. Because of these issues, the FHWA recommends that pedestrian signals be installed at least 100 feet away from intersections (17). The drawbacks noted at half-signals appear to be based on engineering judgment and 
professional expertise rather than based on empirical evidence or research. These Final Rulings do not utilize any study or research on the safety at half-signals.

The issue of not combining stop signage and signalization is important enough to appear twice in the MUTCD. Excerpts from the MUTCD containing this text are provided in Appendix A (10),(11). Since the Final Ruling was issued in 1987, there do not appear to be any instances of new half-signals installed in any city within the United States with the exception of Seattle.

Seattle is currently the only known city in the United States that installs new half-signals at intersections. They do not follow the MUTCD on this issue citing both safety benefits and the effectiveness of these half-signals. Seattle installs half-signals at locations that meet either pedestrian or gap warrants but do not meet vehicle warrants for a full signal. On the minor road, they recommend a maximum ADT of 900-1200 vehicles or a peak hour volume of 100-150 vehicles (6).

In contrast to the United States, Canada specifies the use half-signals in their MUTCD and augments this document with their Pedestrian Crossing Control Manual (12). This document offers operational guidelines and warrants for the usage of pedestrian/half-signals at intersections and was modeled after the Pedestrian Crossing Control Manual for British Columbia (13). The key difference between the British 
Columbia Pedestrian Crossing Control Manual and the Pedestrian Crossing Control Manual is that the British Columbia version allows for flashing green use at half-signals to signify to drivers that a particular location is a pedestrian signal and that all movements from the main street should be permissive. The warrants in these Canadian manuals are shown in Figure 6. The warrant does not specify how to count the number of pedestrians per hour and whether it is a peak count or averaged over a day.

As a contrast to Figure 6, the full-signal pedestrian volume warrant for the MUTCD in the USA is shown in Figure 7. The MUTCD warrant for installing pedestrian hybrid beacons at midblock locations is shown in Figure 8.

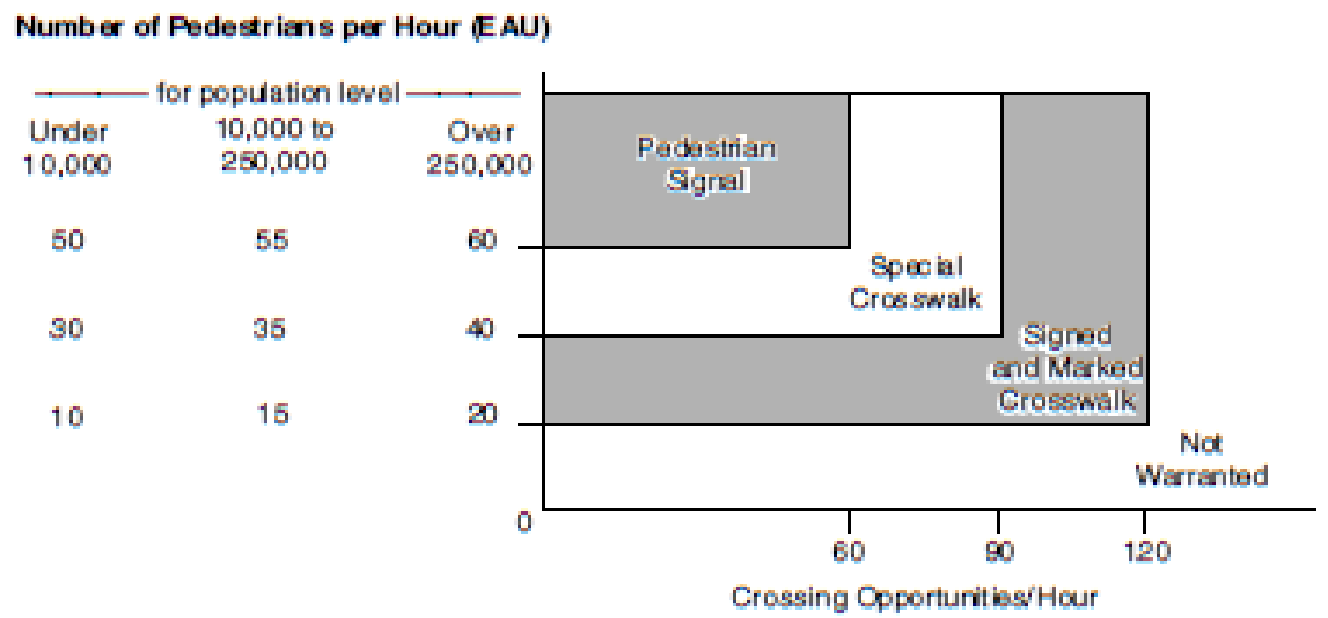

Figure 6: Pedestrian Crossing Control Warrant Chart (13) 
Figure 4C-8. Warrant 4, Pedestrian Peak Hour (70\% Factor)

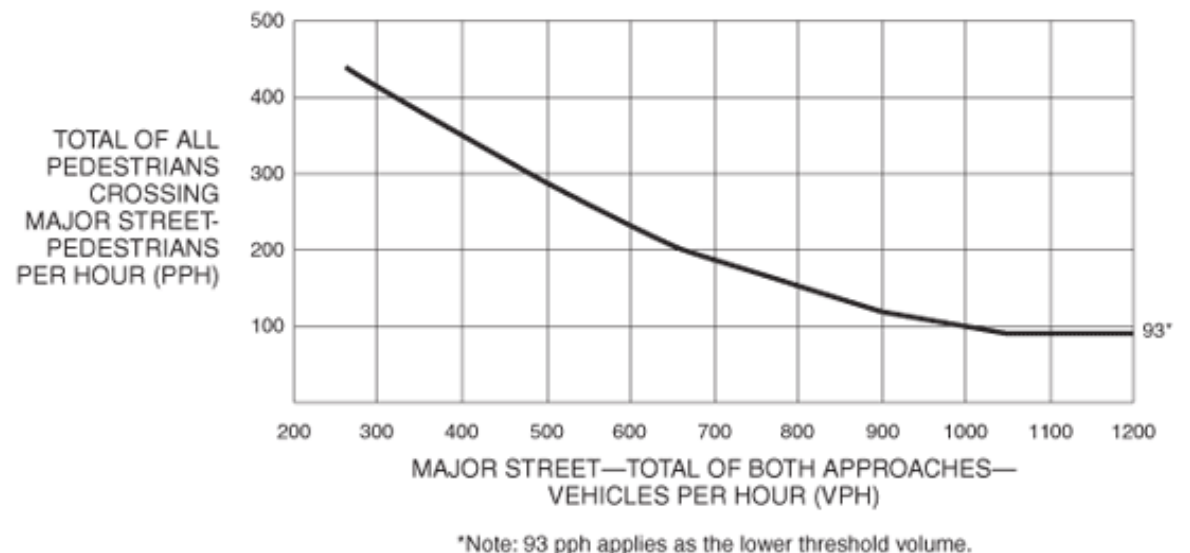

Figure 7: MUTCD Warrant 4 - 70\% Pedestrian Peak Hour Volume

Figure 4F-2. Guidelines for the Installation of Pedestrian Hybrid Beacons on High-Speed Roadways

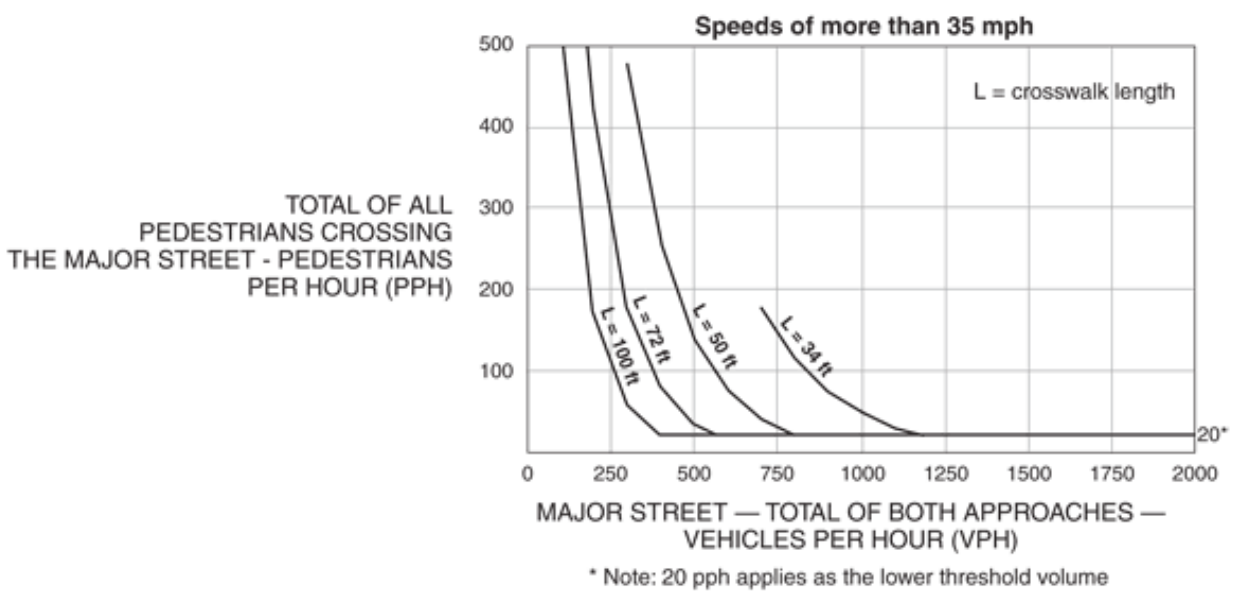

Figure 8: MUTCD Warrant - Pedestrian Hybrid Beacons High-Speed 
For a large city on a high-speed high-volume road, the half-signal warrant in Canada requires at least 60 pedestrians per hour. Under similar conditions in the United States, a full-signal needs 90 pedestrians per hour to meet the warrant and a pedestrian hybrid beacon needs 20 pedestrians per hour to meet the warrant. It is suspected that the pedestrian hybrid beacon warrant is comparatively low since these beacons are not currently placed at intersections and thus these devices are less desirable in most applications for pedestrians.

Policy guidelines between the United States and Canada differ. The Canada MUTCD augmented by the Pedestrian Crossing Control Manual currently recommends half-signals and provides warrants for their installation. By contrast, the United States MUTCD does not allow for half-signals at intersections and formalized warrants do not exist. In the United States, pedestrian warrants do exist for either placing a full-signal at an intersection or a pedestrian hybrid beacon away from an intersection. 
The three reasons given in the 1987 Final Ruling on the MUTCD as to why halfsignals are not permitted in the United States are rooted in pedestrian safety concerns, vehicle safety concerns, and concerns that these signals promote undesirable motorist behavior at intersections.

\subsection{Pedestrian Safety, Vehicle Safety, and Behavior at Half-Signals}

Half-signals have been used in cities such as Wichita, KS, Kansas City, MO, Seattle, WA Lincoln, NE, Vancouver, BC, Alberta, ON, and Portland, OR. In installing and testing half-signals these cities attempted to determine whether or not half-signals were effective and safe when compared with alternatives.

There are many pedestrian crossing treatments at intersections that have been implemented but studies show that red signal or beacon devices at marked crossings result in the highest motor vehicle yielding rates at pedestrian crossings as shown in Figure $9(18,19)$. The rates in Figure 9 were determined from video and in the field by dividing the total number of motorists actually yielding to the number of motorists that should have yielded to pedestrians at the crossing (20). 


\begin{tabular}{|c|c|c|c|c|c|c|c|c|c|}
\hline \multirow[b]{3}{*}{$\begin{array}{c}\text { Crossing } \\
\text { Treatment }\end{array}$} & \multicolumn{6}{|c|}{ TCRP D-08/NCHRP 3-71 Study } & \multirow{2}{*}{\multicolumn{3}{|c|}{$\begin{array}{l}\text { Other Studies } \\
\text { Compliance - Literature } \\
\text { Review (from Table L-1) }\end{array}$}} \\
\hline & \multicolumn{3}{|c|}{$\begin{array}{l}\text { Compliance - Staged } \\
\text { Pedestrian Crossing }\end{array}$} & \multicolumn{3}{|c|}{$\begin{array}{c}\text { Compliance - General } \\
\text { Population Pedestrian } \\
\text { Crossing } \\
\end{array}$} & & & \\
\hline & $\begin{array}{l}\text { \# of } \\
\text { Sites }\end{array}$ & $\begin{array}{l}\text { Range } \\
(\%)\end{array}$ & $\begin{array}{c}\text { Average } \\
(\%)\end{array}$ & $\begin{array}{l}\text { \# of } \\
\text { Sites }\end{array}$ & $\begin{array}{c}\text { Range } \\
(\%)\end{array}$ & $\begin{array}{c}\text { Average } \\
(\%)\end{array}$ & $\begin{array}{l}\text { \# of } \\
\text { Sites }\end{array}$ & $\begin{array}{c}\text { Range } \\
(\%)\end{array}$ & $\begin{array}{c}\text { Average } \\
(\%)\end{array}$ \\
\hline \multicolumn{10}{|c|}{ Red Signal or Beacon } \\
\hline Midblock Signal & 2 & $\begin{array}{l}97 \text { to } \\
100\end{array}$ & $99 \%$ & 4 & $\begin{array}{l}91 \text { to } \\
98\end{array}$ & $95 \%$ & NA & NA & NA \\
\hline Half Signal & 6 & $\begin{array}{c}94 \text { to } \\
100\end{array}$ & $97 \%$ & 6 & $\begin{array}{l}96 \text { to } \\
100\end{array}$ & $98 \%$ & 1 & 99 & $99 \%$ \\
\hline $\begin{array}{l}\text { HAWK Signal } \\
\text { Beacon }\end{array}$ & 5 & $\begin{array}{c}94 \text { to } \\
100\end{array}$ & $97 \%$ & 5 & $\begin{array}{l}98 \text { to } \\
100\end{array}$ & $99 \%$ & 1 & 93 & $93 \%$ \\
\hline \multicolumn{10}{|c|}{ Active When Present } \\
\hline $\begin{array}{l}\text { In-Roadway } \\
\text { Warning Lights }\end{array}$ & NA & NA & NA & NA & NA & NA & 11 & $\begin{array}{l}8 \text { to } \\
100\end{array}$ & $66 \%$ \\
\hline $\begin{array}{l}\text { Overhead } \\
\text { Flashing Beacon } \\
\text { (Pushbutton } \\
\text { Activation) }\end{array}$ & 3 & $\begin{array}{c}29 \text { to } \\
73\end{array}$ & $47 \%$ & 4 & $\begin{array}{c}38 \text { to } \\
62\end{array}$ & $49 \%$ & 10 & $\begin{array}{c}13 \text { to } \\
91\end{array}$ & $52 \%$ \\
\hline $\begin{array}{l}\text { Overhead } \\
\text { Flashing Beacon } \\
\text { (Passive } \\
\text { Activation) }\end{array}$ & 3 & $\begin{array}{c}25 \text { to } \\
43\end{array}$ & $31 \%$ & 3 & $\begin{array}{c}61 \text { to } \\
73\end{array}$ & $67 \%$ & NA & NA & $74 \%$ \\
\hline $\begin{array}{l}\text { Pedestrian } \\
\text { Crossing Flags }\end{array}$ & 6 & $\begin{array}{c}46 \text { to } \\
79\end{array}$ & $65 \%$ & 4 & $\begin{array}{l}72 \text { to } \\
80\end{array}$ & $74 \%$ & NA & NA & NA \\
\hline
\end{tabular}

Notes: "NA" indicates that data were not collected or available in the literature. The "Range" column represents the range of motorist yielding for all sites with the treatment.

The "Average" column represents the average value of motorist yielding for all sites with the treatment.

Figure 9: Major Road Motor Vehicle Compliance Performance at Pedestrian Crossings $(18,19)$

For pedestrian safety, high motorist compliance is a desirable characteristic of a pedestrian crossing but it does not give the complete picture of the safety at half- 
signals. While few studies exist on half-signals and safety, what follows is a review of existing literature pertaining to half-signals and one study on HAWK beacons.

\subsubsection{Safety at Half-Signals in Seattle, WA}

The first known study on the safety performance at half-signals was performed by a City of Seattle traffic engineer in 1974 (7). Prior to 1971, Seattle's actuated pedestrian school crossings were designed with a center suspended signal that dwelled in flashing amber to the major road and flashing red to the side streets. Upon pedestrian actuation, the signal would immediately display solid green to the major road and solid red to the side streets. After this it would cycle through a 60 second fixed cycle allowing pedestrian crossings typically halfway through that cycle before returning back to dwell in flashing amber. After a number of serious crashes under this configuration and concerns for pedestrian safety, the City of Seattle looked towards existing half-signals in Portland, Oregon and installed similar configurations beginning in 1971 (7). Pedestrian signals were placed at 18 previous minor stop controlled intersections and crashes $7 \frac{1}{2}$ to 30 months before and after the installation of these half-signals were analyzed.

Results showed that there were 30 crashes before the installation of half-signals with four of these crashes involving pedestrians. There were 28 crashes after installation with none of these crashes involving pedestrians. This study found that the reduction in total 
pedestrian crashes from four before half-signal installation to zero afterwards was significant using a chi-square contingency table with a $95 \%$ confidence interval. This study also determined that automobile crashes were not significantly increased nor reduced. From these results the study surmised that the potential for conflict is extremely low at half-signals where residential streets have traffic volumes up to 1,000 average annual daily traffic (AADT). Seattle updated this report in 1988 (6) when the City had 22 half-signals in operation. These intersections saw a sixty-five percent reduction in pedestrian crashes, from 49 to 18 , over the duration of the study and a ten percent reduction in vehicle crashes from 470 to 425 over an average of $14 \frac{1}{2}$ years before and $14 \frac{1}{2}$ years after the installation of these 22 half-signals. A third update in 2001 looked at 19 more recently installed half-signals that had been in operation for at least seven years in Seattle and found on average a total crash reduction of twenty percent (21).

\subsubsection{Safety at Half-Signals in Seattle, WA and Lincoln, NE}

Shortly after the first study on half-signals by Seattle in 1974 and as a result of a request by the City of Seattle to the National Advisory Committee on Uniform Traffic Control Devices (NAC) a national study from Petzold and Nawrocki in 1977 analyzed five alternative pedestrian crossing designs used around school areas (8). These five designs included: 
1. An overhead "WATCH FOR PEDESTRIANS" sign with flashing beacon on the major road and a Stop sign on the minor road,

2. A flashing red beacon on the major road and a flashing yellow signal on the minor road,

3. A flashing green signal on the major road and Stop sign on the minor road,

4. A signal on the major road and Stop sign on the minor road, i.e. half-signal, and

5. A crossing guard at a minor stop controlled intersection.

The Petzold and Nawrocki study included a cross-sectional safety evaluation where these five intersections were evaluated and compared with comparable fullysignalized intersections in two different cities. In the case of the half-signal, the two cities analyzed were Lincoln, NE and Seattle, WA. Petzold and Nawrocki (8) recognized in their study that a before/after analysis for each of the five types of pedestrian crossings would have been ideal, however the costs of upgrading stop signs or the political issues with downgrading a fully-signalized intersection made this type of study infeasible. As a compromise, a cross-sectional study was used. There is always a concern with using cross-sectional comparisons between different sites to determine the safety effects of a design. Hauer (22) makes the case that cross-sectional studies are ineffective because too many variables change from one intersection to another and the subjective ways in 
which control sites are chosen make it difficult to truly evaluate the safety impacts of a specific change. Petzold and Nawrocki selected comparison sites nearby to the halfsignal sharing the same major road (8) to minimize extraneous variables. This study included field testing and evaluation of the aforementioned urban pedestrian crossing designs along with user understanding surveys.

During field testing and evaluation of the Petzold and Nawrocki study, three visits were made to each half-signal and control fully-signalized site. Compliance and behavior were observed for 6 hours at each visit. The results from this study are shown in Figure 10. 
Summary of Results

(Sg-44) Signal \& Stop Sign Vs Full Signalization (Semi-Actuated)

\begin{tabular}{|c|c|c|c|c|}
\hline \multicolumn{2}{|c|}{ City } & \multirow{2}{*}{$\frac{\text { Lincoln }}{E^{* *}}$} & \multirow{2}{*}{$\begin{array}{c}\text { Seattle } \\
E^{*}\end{array}$} & \multirow{2}{*}{$\frac{\text { Trend }}{E}$} \\
\hline \multirow{5}{*}{$\left|\begin{array}{l}B \\
E \\
H \\
A \\
V \\
I \\
O \\
R \\
A \\
L\end{array}\right|$} & $\begin{array}{l}\text { Hesitation } \\
\text { or } \\
\text { Reversal }\end{array}$ & & & \\
\hline & $\begin{array}{l}\text { Turning } \\
\text { Vehicle } \\
\text { Conflict } \\
\end{array}$ & n.s. & n.s. & n.s. \\
\hline & $\begin{array}{l}\text { Vehicle } \\
\text { Hazard }\end{array}$ & n.s. & n.s. & n.s. \\
\hline & $\begin{array}{l}\text { Rear. } \\
\text { End } \\
\text { Conflict }\end{array}$ & n.s. & n.s. & n.s. \\
\hline & $\begin{array}{c}\text { Angle } \\
\text { Conflict }\end{array}$ & $C^{*}$ & n.s. & n.s. \\
\hline \multirow{3}{*}{\begin{tabular}{|c|} 
\\
\\
$C$ \\
$O$ \\
$M$ \\
$P$ \\
$\mathrm{~L}$ \\
$\mathrm{I}$ \\
$\mathrm{A}$ \\
$\mathrm{N}$ \\
$\mathrm{C}$ \\
$\mathrm{E}$ \\
\end{tabular}} & $\begin{array}{l}\text { Leave Curb } \\
\text { on Permissive } \\
\text { Interval }\end{array}$ & $E^{* *}$. & $E^{* *}$ & $E$ \\
\hline & $\begin{array}{l}\text { Leave Curb } \\
\text { on Prohibited } \\
\text { Interval }\end{array}$ & $E^{* *}$ & $E^{* *}$ & $E$ \\
\hline & $\begin{array}{c}\text { Violation of } \\
\text { Major Street } \\
\text { Prohibited Phase }\end{array}$ & $E^{*}$ & n.s. & n.s. \\
\hline $\begin{array}{l}\mathrm{C} \\
\mathrm{O} \\
\mathrm{S} \\
\mathrm{T}\end{array}$ & $\begin{array}{c}\text { Cost Ratio } \\
\text { (E/C) }\end{array}$ & 0.40 & 0.50 & 0.45 \\
\hline \multirow{4}{*}{$\begin{array}{l}U \\
\mathrm{~N} \\
\mathrm{D} \\
\mathrm{E} \\
\mathrm{R} \\
\mathrm{S} \\
\mathrm{T} \\
\mathrm{A} \\
\mathrm{N} \\
\mathrm{D} \\
\mathrm{I} \\
\mathrm{N} \\
\mathrm{G}\end{array}$} & Question $1^{A}$ & - & $83 \%$ & $83 \%$ \\
\hline & Question $2^{\mathrm{A}}$ & $67 \%$ & $94 \%$ & $81 \%$ \\
\hline & Question $3^{A}$ & $67 \%$ & $66 \%$ & $67 \%$ \\
\hline & Question 4A & $50 \%$ & $49 \%$ & $50 \%$ \\
\hline
\end{tabular}

Note: $\quad t=$ Crossing guard present when school children are crossing.

$E=$ Difference in favor of experimental, school-pedestrian crossing design.

$\mathrm{C}=$ Difference in favor of control, full signalization.

$\mathrm{ns}=$ No significant difference between experimental and control condition.

$\therefore=$ Significant at the 0.05 level.

Cost Ratio = Ratio of installation costs for experimental and control conditions.

Question 1 At he intersection you just passed, were there any traffic control devices?

Question 2 At the interction you just passed, what is the purpose of the traffic control device?

What causes the traffic control device to turn red?

What causes the trafic control device to turn red?

$A=$ Percent of drivers answering question correctly.

Appendices contain the Data Summeries that support this table.

Figure 10: Urban Intersection Improvements for Pedestrian Safety: Half-Signal Results (8) 
In general, the vehicle behavior measures used in this study, including rear-end conflicts and angle conflicts, occurred at very low rates. At one half-signal site in Lincoln, $\mathrm{NE}$, there were significantly more angle conflicts at half-signals when compared with the fully signalized control. The authors note that the rate of occurrence of these angle conflicts was very low at $0.05 \%$ of the major street traffic volume. Angle conflicts, the authors observed, happened most often when motorists from the minor stop controlled road would enter the intersection while the major road traffic was stopped when the signal changed to green. Red-light violations in the study did not differ between fullysignalized locations and half-signalized locations. Pedestrian reversal and hesitation happened significantly less frequently at the half-signalized intersection than at fullysignalized intersections. The authors hypothesize that this is due to drivers being aware that the half-signal is for pedestrians and therefore drivers do not "challenge" pedestrians while crossing. This hypothesis, however, was not overwhelmingly confirmed in their administered intercept survey which found a $66 \%$ correct response from motorists when asked "what causes the traffic device to turn red" and 50\% correct response when asked "what controls traffic on the minor street at this intersection". These surveys were administered to 44 motorists combined in Seattle and Lincoln as vehicles were stopped at the particular intersection in question. Compliance rates of 
pedestrians, measured as the percentage of pedestrians obeying the walk signal at halfsignals, were higher when compared with fully-signalized intersections. Lastly, this study performed a delay study and found that the delay per vehicle was greater on the major and minor roads during peak pedestrian volumes at half-signals when compared with the fully-signalized intersections. During off-peak hours of pedestrian demand, the delay per vehicle was much less at half-signalized intersections.

Petzold and Nawrocki conclude that the half-signal design, the flashing green design (half-signal dwelling in flashing green), or using a crossing guard have operating characteristics that are more desirable than full signalization. This study found that the flashing green signal did not have a significant effect on vehicle behaviors when compared with steady green operations and therefore the authors recommend halfsignals or crossing guards to enhance safety around schools. Per this study, half-signals were recommended when distribution patterns of pedestrians are consistent throughout the day and a crossing guard is recommended when pedestrians are mainly only crossing for several hours during the day. Both treatments were recommended at intersections with a minimum AADT of 7,000-10,000 combined on both approaches on the major street and a maximum AADT from 900-1,200 on the local residential minor street. 


\subsubsection{Safety at Half-Signals in Canada}

Shifting the focus from the United States to Canada, a study from 2002 by Voss and Parks analyzed minor street stop compliance at half-signals in the Vancouver, B.C. area (23). In this study, twelve half-signalized intersections were observed during the midday and afternoon each for 4-5 hours total. This study exclusively looked at left-turn and through movement stop sign violations from the minor road. Rolling stops that the "trained field crew considered to be acceptable in today's society" were not counted as stop sign violations. Average stop sign violation rates were found to be $28 \%$ during the midday peak and $34 \%$ during the afternoon peak. The authors conclude that a stop sign violation rate of less than $10 \%$ in their professional opinions does not indicate significant non-compliance. Since 10 out of the 12 half-signals had stop sign non-compliance rates greater than $10 \%$, these half-signals are designed to "promote the abuse of traffic control facilities". This study does not look at non-compliance rates at stop signs in general.

The study by Voss and Parks prompted a larger effort by the Canadian Institute of Transportation Engineers (CITE) to look into the usage and safety of half-signals throughout Canada (9). As part of this study, a survey was administered to jurisdictions throughout Canada to determine the use of half-signals throughout Canada. Locations 
with half-signals at intersections include Vancouver, Richmond, Surrey, and Burnaby in British Columbia; Edmonton, Alberta; Calgary, Alberta; Halifax, Nova Scotia; Gatineau, Quebec; and Regina, Saskatchewan. As part of this study a survey was administered by the Insurance Corporation of British Columbia (ICBC) to 604 households to determine motorist understanding on the flashing green indication in British Columbia. Results from this survey showed that $74 \%$ of motorists and $76 \%$ of pedestrians have not encountered confusion while using flashing green half-signalized intersections.

As part of the CITE study, data were collected two years after the study on stop sign compliance from Voss and Parks. The same methodology as the Voss and Parks study was used by CITE in collecting violations of through and left turning vehicles. The CITE study found that as traffic volumes on both the major and minor streets increased, minor street stop sign non-compliance increased at half-signal intersections.

The CITE study also used a simple a before/after study at twenty-five half-signals in the City of Hamilton, Ontario in 2003. The time period of pedestrian signal collision information ranged between fifteen months and five years. Average collision rates changed from 0.30 collisions per million entering vehicles (MEV) before half-signals were installed to 0.23 collisions per MEV after the installation of half-signals. Pedestrian 
collision rates changed from 0.03 collisions per million entering vehicles (MEV) before half-signal installation to 0.01 collisions per MEV after half-signal installation.

\subsubsection{HAWK/Pedestrian Hybrid Beacons in Tucson, AZ}

A traffic beacon that fills the same niche at intersections as the half-signal is the high intensity activated crosswalk, HAWK beacon, or pedestrian hybrid beacon. The

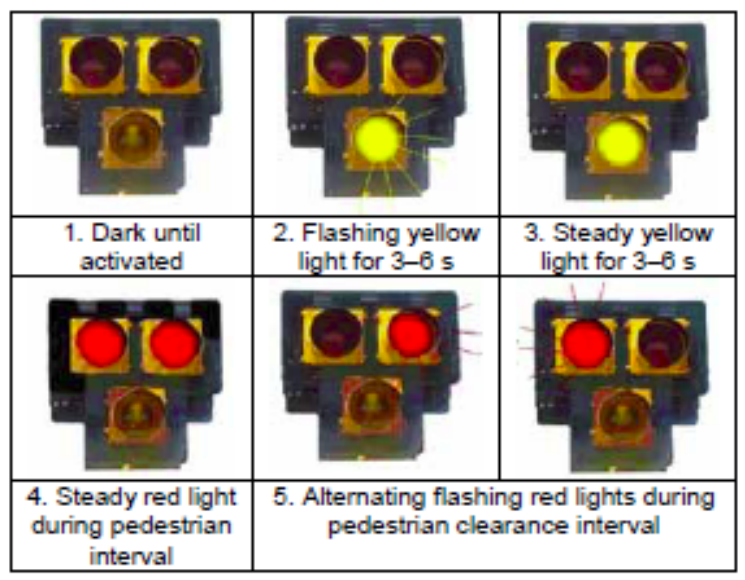

Figure 11: Phase Sequence of HAWK Beacon (23) beacon device is shown in Figure 11.

Operationally the pedestrian

hybrid beacon dwells in dark until a

pedestrian actuates the signal. Upon

actuation, the yellow light flashes and

then changes to solid yellow. Following these phases the top two lights change

to solid red for the pedestrian interval. After the pedestrian interval the top two lights blink flashing red to allow automobiles on the major road to proceed if no pedestrians are present. This flashing red phase reduces delay to motorists while also providing a clearance interval for pedestrians. A beacon is used since they do not have a legal requirement for vehicles to stop whereas signals do have this legal requirement. 
A study from Fitzpatrick and Park looked at 21 intersections with HAWK beacons in Tucson, AZ (24). The study assessed the safety performance of these intersections with 19-36 months of before and after crash data. To account for regression-to-themean effects, changes in traffic volume, weather effects, or other unexplained variations the Empirical Bayes (EB) method, as pioneered by Hauer (25) in traffic safety studies, was used to evaluate the safety performance of HAWK beacons. In order to perform the EB method, a larger reference group of 71 signalized and unsignalized intersections within $1 / 4$ mile of the HAWK sites and another reference group of 102 unsignalized intersections within 2 miles of each HAWK signal were developed. At these reference groups and as well at the 21 HAWK intersection locations, two-hour pedestrian volumes and vehicle volumes were collected which were later adjusted into daily counts and AADT. These reference groups were treated as control sites and general trends in crash history were accounted for in the HAWK group using the EB method. This allowed for a better estimation of any crash reduction effects when compared to the simple before/after study. Using this methodology, the authors determined that installing HAWK signals led to a $29 \%$ reduction in total crashes and a $69 \%$ reduction in pedestrian crashes at a $95 \%$ significance level. HAWK beacons in this study had a crash rate between $0.223-0.618$ crashes per million entering vehicles and 
pedestrians. Nearby minor stop controlled and signalized intersections used in reference groups had crash rates between $0.150-0.430$ and $0.716-1.788$ crashes per million entering vehicles and pedestrians respectively. The first number in the crash rate above reflects crashes matching street names and having an intersection related field tagged. The second crash rate number includes only crashes with matching street names. The authors of this paper stated that the actual average crash rate for each group is likely somewhere between these ranges.

The results from the Fitzpatrick and Park study led to the inclusion of pedestrian hybrid beacons in the 2009 MUTCD (10). In the MUTCD it is recommended that these beacons are placed at least 100 feet from intersections even though all pedestrian hybrid beacons in the Fitzpatrick and Park study were located at intersections. There are still concerns with pedestrian hybrid beacons specifically regarding the safety implications of the beacon resting in dark, driver compliance during the flashing red phase, a concern that since the pedestrian hybrid beacons in Tucson were not installed in random locations that the realized crash reduction would not hold true at other locations, and a concern that drivers on the minor streets exit their vehicles at intersections to actuate the signal in order to achieve a sufficient gap in traffic to complete turning movements (26). 


\subsection{Literature Review Conclusion}

Results from the publications dealing with half-signals and safety are presented in Table 1 and Table 2.

Table 1: Crash History Results from Published Half-Signal Studies

\begin{tabular}{|l|l|l|l|l|c|c|c|}
\hline Location & Year & $\begin{array}{l}\text { \# of } \\
\text { sites }\end{array}$ & Study Type & $\begin{array}{l}\text { Time } \\
\text { Period } \\
\text { yr }\end{array}$ & $\begin{array}{l}\Delta \text { in Ped } \\
\text { Crashes from } \\
\text { Before/After }\end{array}$ & $\begin{array}{l}\Delta \text { in Auto } \\
\text { Crashes from } \\
\text { Before/After }\end{array}$ & $\begin{array}{l}\text { Half Signal } \\
\text { Crash Rate } \\
\text { (per MEV) }\end{array}$ \\
\hline $\begin{array}{l}\text { Seattle,WA } \\
(7)\end{array}$ & 1974 & 18 & $\begin{array}{l}\text { Simple } \\
\text { Before/After }\end{array}$ & $\begin{array}{l}0.6-2.5 \\
\mathrm{yr}\end{array}$ & $-100 \%^{1^{*}}$ & $+8 \%$ & 0.525 \\
\hline $\begin{array}{l}\text { Seattle, WA } \\
(6)\end{array}$ & 1988 & 22 & $\begin{array}{l}\text { Simple } \\
\text { Before/After }\end{array}$ & $14.5 \mathrm{yr}$ & $-65 \%$ & $-10 \%$ & N/A \\
\hline $\begin{array}{l}\text { Seattle, WA } \\
(21)\end{array}$ & 2001 & 19 & $\begin{array}{l}\text { Simple } \\
\text { Before/After }\end{array}$ & $4-16 \mathrm{yr}$ & N/A & $-20.4 \%$ & N/A \\
\hline Canada (9) & 2003 & 25 & $\begin{array}{l}\text { Simple } \\
\text { Before/After }\end{array}$ & $\begin{array}{l}3.25-5 \\
\mathrm{yr}\end{array}$ & $-66 \%$ & $-23 \%$ & 0.230 \\
\hline
\end{tabular}

${ }^{1}$ Total number of pedestrian crashes went from 4 in the before period to 0 in the after period.

*Significant at the $95 \%$ confidence interval level

Table 2: Compliance Results from Published Half-Signal Studies

\begin{tabular}{|l|l|l|l|l|l|c|c|}
\hline Location & Year & $\begin{array}{l}\text { \# of } \\
\text { sites }\end{array}$ & Study Type & $\begin{array}{l}\text { Time } \\
\text { Period } \\
\text { hours }\end{array}$ & $\begin{array}{l}\text { Motor Vhcl } \\
\text { Stop Non- } \\
\text { Compliance }\end{array}$ & $\begin{array}{l}\text { Motor Vhcl } \\
\text { Signal Non- } \\
\text { Compliance }\end{array}$ & $\begin{array}{l}\text { Ped Signal } \\
\text { Non- } \\
\text { Compliance }^{2}\end{array}$ \\
\hline $\begin{array}{l}\text { Seattle, WA } \\
\text { Lincoln,NE(8) }\end{array}$ & 1977 & 2 & Compliance & $\begin{array}{l}\mathbf{9} \text { hours } \\
\text { at each }\end{array}$ & $6.7-15.5 \%$ & $0.02-0.07 \%$ & $6.7-9.0 \%$ \\
\hline $\begin{array}{l}\text { Vancouver, } \\
\text { B.C. (23) }\end{array}$ & 2000 & 12 & $\begin{array}{l}\text { Stop } \\
\text { Compliance }\end{array}$ & $\begin{array}{l}\mathbf{5} \text { hours } \\
\text { at each }\end{array}$ & $0-64 \%$ & N/A & N/A \\
\hline Canada (9) & 2002 & 16 & $\begin{array}{l}\text { Stop } \\
\text { Compliance }\end{array}$ & $\begin{array}{l}\mathbf{4} \text { hours } \\
\text { at each }\end{array}$ & $0-66 \%$ & N/A & N/A \\
\hline $\begin{array}{l}\text { Seattle, WA } \\
\text { Portland, OR } \\
\text { (18,19) }\end{array}$ & 2006 & 6 & $\begin{array}{l}\text { Yielding } \\
\text { Behavior }\end{array}$ & $\begin{array}{l}\mathbf{4} \text { hours } \\
\text { at each }\end{array}$ & N/A & N/A & N/A \\
\hline
\end{tabular}

${ }^{1}$ Motor vehicle signal non-compliance is the number of vehicles entering on red compared to the major street traffic

${ }^{2}$ Ped signal non-compliance is a violation by pedestrians during the prohibited phase of the ped signal 
Table 3: Crash History Results from Published Pedestrian Hybrid Beacon Studies

\begin{tabular}{|l|c|c|l|l|c|c|c|}
\hline Location & Year & $\begin{array}{l}\text { \# of } \\
\text { sites }\end{array}$ & Study Type & $\begin{array}{l}\text { Time } \\
\text { Period } \\
\text { yr }\end{array}$ & $\begin{array}{l}\Delta \text { in Ped } \\
\text { Crashes from } \\
\text { Before/After }\end{array}$ & $\begin{array}{l}\Delta \text { in Auto } \\
\text { Crashes from } \\
\text { Before/After }\end{array}$ & $\begin{array}{l}\text { Crash Rate } \\
\text { (per MEV\&P) }\end{array}$ \\
\hline $\begin{array}{l}\text { Tucson, AZ } \\
\text { (24) }\end{array}$ & 2009 & 21 & $\begin{array}{l}\text { Empirical } \\
\text { Bayes } \\
\text { Before/After }\end{array}$ & $1.6-2 \mathrm{yr}$ & $-59 \%^{*}$ & $-14 \%^{*}$ & $0.223-0.618$ \\
\hline
\end{tabular}

*Significant at the $95 \%$ confidence interval level

There are seven published studies involving half-signalized intersections: four are simple before/after studies, one is a cross-sectional study, one is a behavioral study, and one looks into yielding behavior.

Results from cross-section studies cannot typically be compared with other cross-section studies since methods used to pick comparison groups are different and subjectively chosen $(22,27,28)$. In a cross-section study it is difficult to isolate the element of what has changed at a particular intersection and this lends to skepticism that these studies provide useful, robust, and repeatable results (27).

There are a number of concerns with these simple before/after studies that have to this date been performed at half-signals. None of the before/after studies performed at half-signals take into account pedestrian volumes. Pedestrian volume has been found to be the most influential factor in explaining the variation in counts of pedestrian crashes by Zeeger, et al. (29). In defense of these before/after studies, it is assumed that pedestrian volumes increase after the installation of a signal and therefore any 
reduction in pedestrian crashes combined with an increase in pedestrian volumes signify that half-signals are safer for pedestrians. More of a concern is that these before/after studies do not take into account regression-to-the-mean effects (25). The concern is that locations chosen for pedestrian signals may have been chosen as a reactionary response because of recent crashes. After the installation of a half-signal, the intersection would experience a reduction of crashes regardless of treatment as the average number of crashes at that intersection would normalize to the true average of its crash count. Since half-signals are installed nearby schools the regression-to-themean effect may be less of a concern since these sites were not chosen reactively because of crashes but were more likely chosen because of location. The report from Fitzpatrick et al. (24) at pedestrian hybrid beacons does account for regression-to-themean effects. There are no studies to date at half-signals that account for the regression-to-the-mean effect.

While there are indications that half-signals are beneficial to pedestrian safety, the simple before/after study may not be a robust method to predict the safety effectiveness of a modification (22). Furthermore, a review committee from the MUTCD raises the concern of minor street motorists failing to come to a complete stop and not giving adequate attention to pedestrians crossing the street at half-signals. It is 
important to note that these issues also occur at the HAWK signals in the study from Fitzpatrick in Tucson but these issues have not been evaluated at HAWK or half-signal locations (26). Gaps in the literature at half-signalized intersections also suggest that motorist-motorist and motorist-pedestrian interactions at half-signals have not been studied. These gaps indicate that a video analysis of driver and vehicle behavior and the conflicts thereof will be a beneficial tool in evaluating the relative safety at half-signals. 


\subsection{METHODOLOGY}

Portland, Oregon currently has 47 half-signals located at intersections, all of which were installed prior to 1987. Most of these half-signals were placed around school zones but 16 of the 47 are located in commercial areas. As of 2011, Portland had two HAWK signals at intersections and the city is questioning whether to transition existing half-signals to HAWK signals or to continue utilizing half-signals. In this paper, the safety at half-signals is evaluated.

\subsection{Research Components}

Crash patterns and crash rates at half-signals are summarized as a first step in evaluating the safety at half-signals. Direct diagnostic and pattern-recognition techniques are utilized in a method similar to what is used by Konokov and Janson $(30,31)$. It is understood that the observational before/after study is $(22)$ the best tool in evaluating the effects of a modification to an intersection because it allows for that particular modification to be isolated. Unfortunately, undertaking an observational before/after study in Portland is not possible since vehicle and pedestrian volumes are not available from forty years ago prior to the installation of these half-signals. This 
study simply compares crash history between different sets of intersections over the same time period.

After exploring the crash patterns, two matched pair groups, one consisting of similar signalized intersections and one with similar minor stop controlled intersections, are developed for use in a cross section analysis. The two sets of paired intersections are developed using a method similar to what was used by Zeeger in a study performed on the safety of marked crosswalks (29). Guidance in choosing similar sites when using a cross section study is not clearly defined and this is typically left up to the researcher's judgment and experience. Hauer (22) argues that using a group of comparison locations to attempt to isolate the effects of a transportation modification will often lead to varying or incorrect results.

With results from both the crash summary and cross-section analysis, we determine if certain types of crashes are more likely or less likely to occur at half-signals. These results are then corroborated or not by looking at video footage collected at selected half-signals.

In the video analysis we identify conflicts that are unique in the operation of half-signalized intersections. Since stop compliance has already been deemed an issue in both the study by Parks and Voss (23) and has been raised as a concern by the MUTCD 
National Advisory Committee on Traffic Control Devices (17), video analysis will allow for us to determine what lends itself to motorist non-compliance of the STOP sign.

The steps undertaken in this research are summarized below:

1. Crash History

a. Crash Pattern Summary

i. Direct Diagnostic Analysis with Statewide Intersection Sample

b. Cross Sectional Matched Pair Analysis

i. Half-signal crash data comparison with matched minor stop controlled intersections

ii. Half-signal crash data comparison with matched signalized intersections

2. Video Analysis
a. Conflict Analysis
b. Stop-Compliance Model 


\subsubsection{Crash History}

Crash records are available for 17 years from 1995 to 2011 . There is a concern when using older crash records that environmental conditions and land-use patterns change which could influence crash patterns. To avoid the aforementioned effects but to gather a large sample size we use ten years of crash history data from the years 20022011.

\subsubsection{Direct Diagnostic Analysis}

A statewide sample of 500 intersections in Oregon developed by Monsere et al (32) is used to determine crash patterns that would be expected at a typical intersection. Crash patterns at half-signalized intersections are compared with this statewide sample to determine any differences in crash patterns using the direct diagnostic method. The statewide sample was chosen with a mostly random stratified sampling plan from a statewide GIS layer but limited to only intersections which had recent minor road traffic volume counts. In this dataset, 298 intersections are utilized that are located in urban areas. Of these intersections, 55 are 3-leg signalized, 77 are 3leg minor stop controlled, 106 are 4-leg signalized, and 60 are 4-leg minor stop controlled. One issue with the statewide sample is that signalized intersections were 
chosen mostly at random irrespective of traffic volumes and turning bay configurations. As such, the majority of signalized intersections in the statewide sample have left-turn and right-turn bays which might be indicative of higher traffic volumes on the minor road. It was anticipated that the statewide sample is not the ideal comparison group for half-signals and this led to the development of the matched pair comparison sites.

\subsubsection{Cross Sectional Matched Pair Analysis}

In developing matched pair comparison sites, one minor stop controlled intersection and one signalized intersection that best fit with a particular half-signalized intersection were identified primarily based on proximity and geometry considerations. There were instances where half-signals did not have good matches and these halfsignalized intersections and corresponding crash history were removed from this portion of the analysis.

\subsubsection{Video Analysis}

If half-signals are considered from the perspective of a motorist on the major road, a unique circumstance occurs when vehicles from the minor road turn left or proceed straight while the major road still has a green signal. If half-signals are considered from the perspective of a motorist on the minor road, a unique circumstance 
occurs when the pedestrian walk phase is actuated and motorists on the major road are stopped at the signal. Video cameras were setup at five half-signalized intersections to observe both of these unique situations. The cameras captured 263 hours in total with each intersection having at least one full 24-hour period of video.

From this video footage, conflicts on the major and minor road are recorded and motorist stop compliance is analyzed on the minor road in a logistic regression model.

\subsubsection{Conflict Study}

The conflict study tabulates conflicts for one full day at each of the 5 halfsignalized intersections where video was captured. To some extent this study replicates the study by Petzold and Nawrocki (8) using the same conflict metrics they had established at half-signals. Additional conflict metrics, if any, come from any significant findings in the crash history analysis.

\subsubsection{Logistic Regression Model}

Parks and Voss (23) and by the MUTCD National Advisory Committee on Traffic Control Devices (17) have suggested that non-compliance of the stop sign on the minor road is a safety concern for pedestrians at half-signals. 
A logistic regression model is used to determine which, if any, conditions during the pedestrian phase of the half-signal show significant changes in motorist stop sign compliance. Conditions are observed such as vehicle turning movement, the presence of queued vehicles, and if pedestrians are crossing the street. A logit regression model is developed for each of the five intersections where video was captured individually and also developed for the five intersections as a whole. 


\subsection{CRASH ANALYSIS}

For the crash history and video analysis to follow, statistical methods used to determine significant differences between comparison groups are outlined below.

\subsection{Crash Patterns}

To determine the probability of a certain crash happening or not, crashes are viewed as a sequence of independent Bernoulli trials each with the outcome of a specific type of crash either occurring or not occurring. This procedure is described by Kononov and Janson (31). The probability that $X$ or more crashes of a particular type will be observed out of $n$ Bernoulli trials is given by the cumulative distribution of the binomial equation:

$$
P(X \geq x)=\sum_{i=0}^{x} \frac{n !}{(n-i) ! i !} p^{i}(1-p)^{n-i}
$$

\section{Equation 1}

Where: $\quad x=$ observed number of crashes of a particular type

$$
\begin{aligned}
& n=\text { total observed number of crashes of all types } \\
& p=\text { expected probability of a crash of a particular type }
\end{aligned}
$$

Conversely, the probability that $x$ or fewer crashes of a particular type will be observed out of $n$ Bernoulli trials is given by the cumulative binomial equation: 


$$
P(X \leq x)=1-\sum_{i=0}^{x-1} \frac{n !}{(n-i) ! i !} p^{i}(1-p)^{n-i}
$$

\section{Equation 2}

To establish confidence intervals for the binomial equation, because often there are very few crashes at half-signalized intersections, the "exact" or Clopper-Pearson method with upper and lower bounds as shown in Equation 3 and Equation 4 is used (33).

$$
\sum_{i=x}^{n}\left(\begin{array}{c}
n \\
i
\end{array}\right) p_{L B}{ }^{i}\left(1-p_{L B}\right)^{n-i}=\alpha / 2
$$

\section{Equation 3}

$$
\sum_{i=0}^{i}\left(\begin{array}{c}
n \\
i
\end{array}\right) p_{U B}^{i}\left(1-p_{U B}\right)^{n-i}=\alpha / 2
$$

\section{Equation 4}

The lower bound probability and upper bound probabilities in these equations can be solved using an F-distribution for the desired alpha level of .05 (34). The statistical package $\mathrm{R}$ with the package "mlogit" is used to develop confidence intervals and test for significance using these methods.

\subsection{Crash Rates}

A two-tailed student's t-test is used for crash rates since these data have continuous non-integer values. A two-tailed test is utilized since it is desirable to 
determine whether there are differences between reference groups. Since sample sizes are different between the half-signal set and the statewide Oregon sample, we assume unequal variances. This is a more conservative approach which means that greater differences between sets of data are necessary to determine significant differences. Equations used to determine the $t$ statistic and degrees of freedom are given by Equation 5 and Equation 6.

$$
T=\frac{\mu_{1}-\mu_{2}}{\sqrt{\frac{s_{1}^{2}}{n_{1}}+\frac{s_{2}^{2}}{n_{2}}}}
$$

\section{Equation 5}

$$
d f=\frac{\left(\frac{s_{1}^{2}}{n_{1}}+\frac{s_{2}^{2}}{n_{2}}\right)^{2}}{\frac{\left(\frac{s_{1}^{2}}{n_{1}}\right)^{2}}{n_{1}-1}+\frac{\left(\frac{s_{2}^{2}}{n_{2}}\right)^{2}}{n_{2}-1}}
$$

\section{Equation 6}

Fisher's exact test is used for contingency tables when evaluating crash types in depth since the count data of crashes at half-signals is often small and thus the contingency tables under evaluation are not large. The statistic software program $\mathrm{R}$ with the package "stats" is used to evaluate contingency tables and determine p-values. 
General equations for the exact test are not shown here but Weisstein offers a good summary (35). 


\subsection{CRASH HISTORY}

The Oregon Department of Transportation's (ODOT) Crash Analysis and Reporting (CAR) Unit compiles crash data from individual driver and police crash reports. These reports are submitted to the Department of Motor Vehicles (DMV) as required by Oregon state law. From 1997 until 2003 Oregon law required that crashes involving a fatality, bodily injury, and/or damage to property in excess of $\$ 1,000$ be reported. Starting in 2004, crashes resulting in a fatality, bodily injury, a vehicle being towed, or damage to property in excess of $\$ 1,500$ were required to be reported (36). It is unknown what effect these changes to crash reporting limits have on our dataset which uses crashes from 2002-2011. In Oregon submittal of crash reports that meet the aforementioned limits are solely the responsibility of the individual drivers involved in the crash.

\subsection{Criteria for Selecting Crashes}

In this analysis three methods were used to identify specific intersection crashes in the Oregon statewide crash database.

On state highways, the highway number and milepost of the intersection \pm .01 miles ( 50 feet) were queried. 
On city and/or county owned streets, crashes were queried that occurred within 50 feet of the intersection in question. Unlike crashes that happen on highways city streets do not typically have corresponding mileposts. Therefore at locations on city streets, crashes were queried using two pieces of information. Oregon crash data has fields set aside for street names and street numbers. Street numbers are 5 digit unique codes for streets within a city and county. It is ODOT protocol to code crashes so that the street with the 5-digit lower street number is placed in the main street field and the street with the higher 5-digit street number is placed in the intersecting street field (36). However, it was discovered that this rule is not routinely followed and it was necessary sometimes to query crashes with the higher numbered street number in the main street field. It was also necessary to query by street name to find crashes were street numbers had been miscoded. This presented a problem since the street names have prefixes and suffixes which were often not consistent. Different combinations of prefixes and suffixes with the street name were queried and results were manually filtered to ensure consistency.

The Oregon crash database also has an intersection related field that is marked when crashes occur outside of the limits of an intersection but are related to a movement or control of traffic at a nearby intersection. When this field was flagged, 
crashes within 250 feet of an intersection on city streets or within $\pm .05 \mathrm{mi}$ ( $264 \mathrm{ft}$ ) of an intersection on state highways were used in this analysis.

Additional filtering involved removing driveway-related crashes that occurred from 0 to 50 feet from the intersection. While these may be associated with intersection crashes, it was determined that these types of crashes might be influenced more by land-use patterns than by signal operations.

To finalize the database, individual crashes were manually inspected to ensure that crashes were queried that met the desired criteria and were located at the intersection of interest. Crashes that did not meet these criteria were removed from this analysis.

\subsection{Overview of Crashes at Half-Signal Intersections}

While each intersection is unique, for this analysis, every half-signalized intersection crash is included and it is overlooked whether the intersection is skewed, has turning legs, is serving a commercial area or a school area, has a different approach speed on the major road, and/or other geometric and operational differences. Halfsignalized intersections are only aggregated by the number of legs under this analysis. Crashes were queried from 2002-2011 to look at general trends in crash severity, 
collision type, and crash type as shown in Table 4. Crash and collision types with fewer than five total crashes were tallied into its respective "other" category.

Table 4: Crash Severity, Collision Types, and Crash Types at Half-Signals (2002-2011)

\begin{tabular}{|c|c|c|c|c|c|}
\hline & \multirow{3}{*}{$\begin{array}{r}\text { 3Leg } \\
20\end{array}$} & \multirow{3}{*}{$\begin{array}{r}\text { 4Leg } \\
26\end{array}$} & \multirow{3}{*}{$\begin{array}{r}\text { 6Leg } \\
1\end{array}$} & \multirow{3}{*}{$\begin{array}{c}\text { TOTAL } \\
47\end{array}$} \\
\hline & & & & & \\
\hline & \# of Half-Signals & & & & \\
\hline \multirow{3}{*}{ 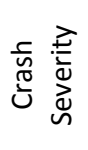 } & Fatal & 1 & 2 & 0 & 3 \\
\hline & Injury ${ }^{1}$ & 81 & 124 & 5 & 210 \\
\hline & Property Damage Only & 86 & 139 & 4 & 229 \\
\hline \multirow{6}{*}{$\begin{array}{l}\stackrel{0}{2} \\
\stackrel{2}{2} \\
\frac{0}{0} \\
\frac{\overline{0}}{\overline{0}}\end{array}$} & Angle & 7 & $66^{*}$ & 1 & 74 \\
\hline & Pedestrian & 6 & 10 & 0 & 16 \\
\hline & Rear-End & 71 & 101 & 6 & 178 \\
\hline & Sideswipe - Overtaking & 11 & 15 & 0 & 26 \\
\hline & Turning Movement & $64 *$ & 58 & 1 & 123 \\
\hline & Other & 9 & 15 & 1 & 25 \\
\hline \multirow{10}{*}{$\begin{array}{l}\stackrel{0}{2} \\
\stackrel{2}{2} \\
\frac{c}{n} \\
\frac{0}{v}\end{array}$} & Bicycle & 6 & 6 & 0 & 12 \\
\hline & Entering at angle - all others & 39 & $95 *$ & 1 & 136 \\
\hline & Fixed Object & 3 & 6 & 0 & 9 \\
\hline & Opposite direction-one left, one straight & 16 & 21 & 1 & 38 \\
\hline & Pedestrian & 6 & 10 & 0 & 16 \\
\hline & Parking Vehicle & 6 & 15 & 1 & 22 \\
\hline & Same direction - one stopped & 68 & 93 & 5 & 166 \\
\hline & Same direction - one turn, one straight & 9* & 2 & 0 & 11 \\
\hline & Same direction - both straight & 9 & 12 & 0 & 21 \\
\hline & Other & 5 & 5 & 1 & 11 \\
\hline
\end{tabular}

${ }^{1}$ Injuries include Type A, Type B, and Type $\mathrm{C}$ which are incapacitating, non-incapacitating, and minor injury crashes respectively.

*indicates statistical difference at $95 \%$ or higher confidence level

In Table 4, 3-leg and 4-leg crash proportions are compared to each other, omitting analysis on the 6-leg intersection due to the small sample size. Using a negative binomial test to compare 3-leg and 4-leg intersections, we note that at 3-leg 
intersections there are significantly more turning movement crashes and crashes occurring between vehicles where one vehicle is moving straight and the other is turning. There are proportionally more angle crashes at 4-leg half-signalized intersections. Angle crashes by definition occur when vehicles that are making through movements from intersecting streets collide. There should not be any angle crashes at 3-leg intersections since the vehicle from the minor street should always be making a turning movement and not a through movement.

To determine if 3-leg intersections are coded improperly specifically at halfsignals or if this is something consistent across Oregon's crash database a previously developed set of minor road stop controlled urban intersections from Monsere et al. (32) is used for comparison. Since this set of intersections is intended to be a representative sample of crashes throughout Oregon, severity, crash type, and collision type measures at 3-leg and 4-leg half-signal intersections are also compared. Note that comparisons with statewide dataset use 5 years of crash history which differs from the rest of this analysis where 10 years of crash history are utilized. 
Table 5: Crashes at Half-Signals compared with Urban Minor Stop Controlled Statewide Crash Sample (2003-2007)

\begin{tabular}{|c|c|}
\hline & \# of Intersections \\
\hline & \# of Crashes \\
\hline \multirow{3}{*}{ 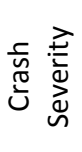 } & Fatal \\
\hline & Injury \\
\hline & Property Damage Only \\
\hline \multirow{6}{*}{ 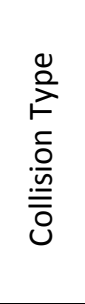 } & Angle \\
\hline & Pedestrian \\
\hline & Rear-End \\
\hline & Sideswipe - Overtaking \\
\hline & Turning Movement \\
\hline & Other \\
\hline \multirow{10}{*}{ 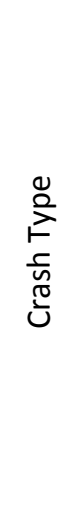 } & Bicycle \\
\hline & Entering at angle - all others \\
\hline & Fixed Object \\
\hline & Opp direction- 1 turn, 1 straight \\
\hline & Pedestrian \\
\hline & Parking Vehicle \\
\hline & Same direction - one stopped \\
\hline & Same direction -1 turn, 1 straight \\
\hline & Same direction - both straight \\
\hline & Other \\
\hline
\end{tabular}

\begin{tabular}{|r|r|}
\hline \multicolumn{1}{|l|}{$\begin{array}{r}\text { 3Leg } \\
\text { Half }\end{array}$} & $\begin{array}{r}\text { 3Leg Urban } \\
\text { Minor Stop } \\
\text { Statewide }\end{array}$ \\
\hline 20 & 77 \\
\hline 84 & 318 \\
\hline $0.0 \%$ & $0.3 \%$ \\
\hline $45.2 \%$ & $47.8 \%$ \\
\hline $54.8 \%$ & $51.9 \%$ \\
\hline $2.4 \%$ & $3.8 \%$ \\
\hline $0.0 \%$ & $0.6 \%$ \\
\hline $\mathbf{4 5 . 2 \% *}$ & $31.1 \%$ \\
\hline $9.5 \% *$ & $3.1 \%$ \\
\hline $36.9 \%$ & $\mathbf{5 3 . 5 \%}$ \\
\hline $6.0 \%$ & $7.9 \%$ \\
\hline $2.4 \%$ & $2.8 \%$ \\
\hline $22.6 \%$ & $\mathbf{3 7 . 1 \%} *$ \\
\hline $1.2 \%$ & $5.3 \%$ \\
\hline $8.3 \%$ & $12.3 \%$ \\
\hline $0.0 \%$ & $0.6 \%$ \\
\hline $\mathbf{6 . 0 \% *}$ & $0.0 \%$ \\
\hline $\mathbf{4 2 . 9 \% *}$ & $28.6 \%$ \\
\hline $\mathbf{6 . 0 \% *}$ & $2.2 \%$ \\
\hline $7.1 \%$ & $6.0 \%$ \\
\hline $3.6 \%$ & $5.0 \%$ \\
\hline \hline
\end{tabular}

\begin{tabular}{|c|c|}
\hline $\begin{array}{l}\text { 4Leg } \\
\text { Half }\end{array}$ & $\begin{array}{l}\text { 4Leg Urban } \\
\text { Minor Stop } \\
\text { Statewide }\end{array}$ \\
\hline 26 & 60 \\
\hline 133 & 283 \\
\hline $0.8 \%$ & $0.0 \%$ \\
\hline $46.6 \%$ & $45.6 \%$ \\
\hline $52.6 \%$ & $54.4 \%$ \\
\hline $26.3 \%$ & $29.7 \%$ \\
\hline $5.3 \% *$ & $1.8 \%$ \\
\hline 39.1\%* & $28.3 \%$ \\
\hline $3.0 \%$ & $2.8 \%$ \\
\hline $20.3 \%$ & $33.6 \% *$ \\
\hline $6.0 \% *$ & $3.9 \%$ \\
\hline $2.3 \%$ & $0.7 \%$ \\
\hline $35.3 \%$ & $45.9 \% *$ \\
\hline $1.5 \%$ & $2.1 \%$ \\
\hline $9.8 \%$ & $12.0 \%$ \\
\hline $5.3 \% *$ & $1.8 \%$ \\
\hline $4.5 \% *$ & $1.4 \%$ \\
\hline $36.8 \% *$ & $26.1 \%$ \\
\hline $0.0 \%$ & $4.9 \% *$ \\
\hline $3.0 \%$ & $3.2 \%$ \\
\hline $1.9 \%$ & $1.7 \%$ \\
\hline
\end{tabular}

*indicates statistical significant more crashes at $95 \%$ or higher confidence level

Crash data from utilized.

Table 5 indicate that when compared with minor stop controlled intersections, half-signalized intersections exhibit proportionally more pedestrian, rear-end, and sideswipe-overtaking crashes. Minor stop controlled intersections on the other hand tend to show proportionally more angle and turning movement crashes. 
Table 6: Crashes at Half-Signals compared with Urban Signalized Statewide Crash Sample (2003-2007)

\begin{tabular}{|c|c|}
\hline & \# of Intersections \\
\hline & \# of Crashes \\
\hline \multirow{3}{*}{ 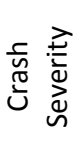 } & Fatal \\
\hline & Injury \\
\hline & Property Damage Only \\
\hline \multirow{6}{*}{ 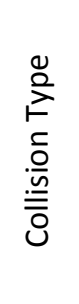 } & Angle \\
\hline & Pedestrian \\
\hline & Rear-End \\
\hline & Sideswipe - Overtaking \\
\hline & Turning Movement \\
\hline & Other \\
\hline \multirow{10}{*}{$\begin{array}{l}0 \\
\stackrel{0}{2} \\
\frac{1}{n} \\
\frac{0}{U}\end{array}$} & Bicycle \\
\hline & Entering at angle - all others \\
\hline & Fixed Object \\
\hline & Opp direction- 1 turn, 1 straight \\
\hline & Pedestrian \\
\hline & Parking Vehicle \\
\hline & Same direction - one stopped \\
\hline & Same direction -1 turn, 1 straight \\
\hline & Same direction - both straight \\
\hline & Other \\
\hline
\end{tabular}

\begin{tabular}{|c|c|}
\hline $\begin{array}{l}\text { 3Leg } \\
\text { Half }\end{array}$ & $\begin{array}{c}\text { 3Leg Urban } \\
\text { Signalized } \\
\text { Statewide }\end{array}$ \\
\hline 20 & 55 \\
\hline 84 & 743 \\
\hline $0.0 \%$ & $0.1 \%$ \\
\hline $45.2 \%$ & $43.3 \%$ \\
\hline $54.8 \%$ & $56.5 \%$ \\
\hline $2.4 \%$ & $4.7 \%$ \\
\hline $0.0 \%$ & $0.8 \%$ \\
\hline $45.2 \%$ & $54.0 \%$ \\
\hline $9.5 \% *$ & $4.6 \%$ \\
\hline $36.9 \%$ & $29.2 \%$ \\
\hline $6.0 \%$ & $6.7 \%$ \\
\hline $2.4 \%$ & $1.5 \%$ \\
\hline $22.6 \%$ & $19.4 \%$ \\
\hline $1.2 \%$ & $3.5 \%$ \\
\hline $8.3 \%$ & $8.9 \%$ \\
\hline $0.0 \%$ & $0.8 \%$ \\
\hline $6.0 \% *$ & $0.7 \%$ \\
\hline $42.9 \%$ & $51.7 \%$ \\
\hline $6.0 \% *$ & $1.9 \%$ \\
\hline $7.1 \%$ & $6.2 \%$ \\
\hline $3.6 \%$ & $5.5 \%$ \\
\hline
\end{tabular}

\begin{tabular}{|c|c|}
\hline $\begin{array}{l}\text { 4Leg } \\
\text { Half }\end{array}$ & $\begin{array}{c}\text { 4Leg Urban } \\
\text { Signalized } \\
\text { Statewide }\end{array}$ \\
\hline 26 & 106 \\
\hline 133 & 2659 \\
\hline $0.8 \%$ & $0.2 \%$ \\
\hline $46.6 \%$ & $43.1 \%$ \\
\hline $52.6 \%$ & $56.7 \%$ \\
\hline $26.3 \% *$ & $17.7 \%$ \\
\hline $5.3 \% *$ & $1.7 \%$ \\
\hline $39.1 \%$ & $47.2 \% *$ \\
\hline $3.0 \%$ & $4.4 \%$ \\
\hline $20.3 \%$ & $25.9 \%$ \\
\hline $6.0 \% *$ & $3.1 \%$ \\
\hline $2.3 \%$ & $1.6 \%$ \\
\hline 35.3\%* & $26.8 \%$ \\
\hline $1.5 \%$ & $1.3 \%$ \\
\hline $9.8 \%$ & $10.0 \%$ \\
\hline $5.3 \% *$ & $1.7 \%$ \\
\hline $4.5 \% *$ & $0.4 \%$ \\
\hline $36.8 \%$ & $45.0 \% *$ \\
\hline $0.0 \%$ & $2.6 \% *$ \\
\hline $3.0 \%$ & $5.9 \%$ \\
\hline $1.9 \%$ & $1.7 \%$ \\
\hline
\end{tabular}

*indicates statistical significant more crashes at $95 \%$ or higher confidence level

Trends in both utilized.

Table 5 and Table 6 show proportionally a higher distribution of pedestrian crashes and parking vehicle crashes. Both of these results are expected since half-signals are used primarily around schools and more dense commercial areas where there are more pedestrians and more ingress and egress for parking. The other trend found in 
these tables is that minor stop controlled intersections show a proportionally higher distribution of rear-end crashes than half-signals. This is an expected result.

Since traffic volumes are significant factors in explaining crashes at intersections (37), the previous comparison with the Oregon statewide dataset is repeated with traffic volumes to develop crash rates.

\subsubsection{Crash Rates at Half-Signalized Intersections}

Traffic volume counts on major and minor roads were not available for all intersections. Of the 47 half-signalized intersections, 35 had traffic volumes for all approaching streets. Traffic counts were often not available at the specific intersection so nearby traffic volumes were used provided that they were on the shared street within ten blocks of the intersection and that there was not a collector or arterial road in between the traffic count and the intersection in question. Sources used to obtain traffic volumes included the City of Portland through the web-based portlandmaps.com and their GIS layer, ODOT, and Google search queries. Due to the variety of sources, traffic counts varied in the year that the count was performed. Traffic counts collected varied from 2000 to 2012 and the distribution of years for major and minor streets are shown in Figure 12. A majority of traffic counts on the minor street were obtained from a Portland Bureau of Transportation (PBOT) GIS layer with counts from 2007. 


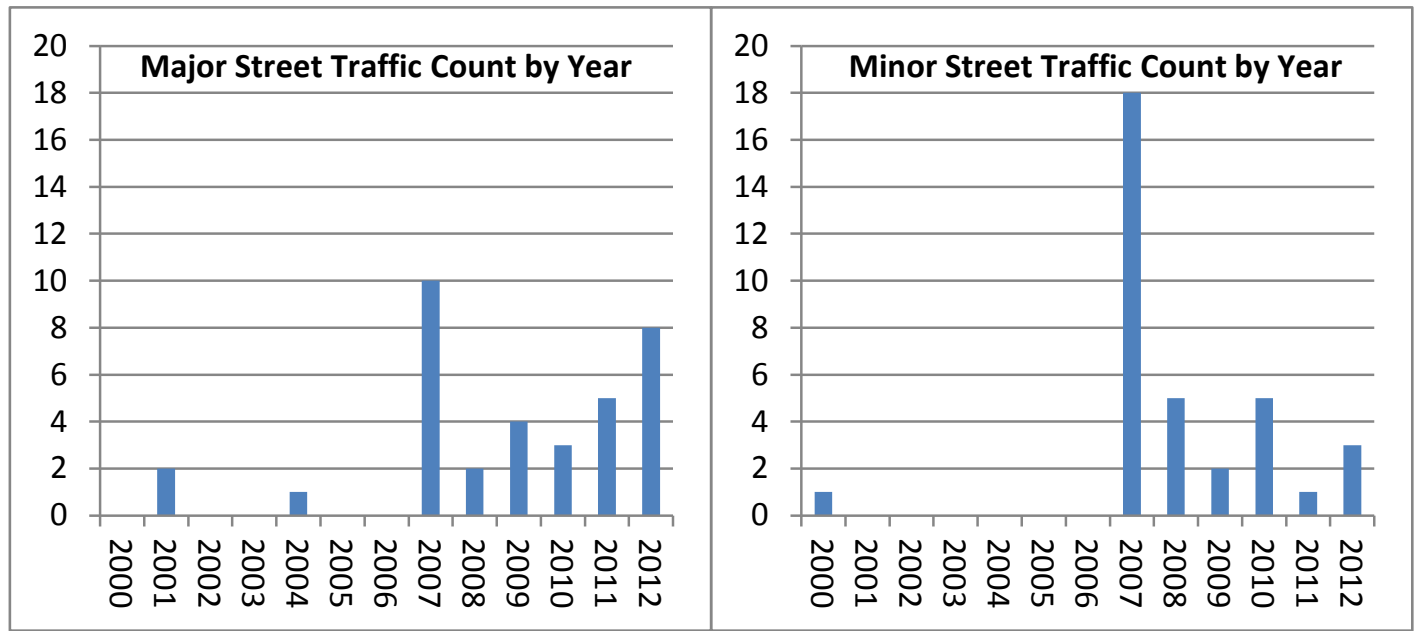

Figure 12: Traffic Count Distribution by Year

To normalize counts, average daily traffic (ADT) counts were adjusted for the year that the count was performed by utilizing ODOT transportation volume tables (38). These tables allowed ADT counts at half-signals to be adjusted and averaged over the analysis period. Traffic counts trends in the ODOT tables were selected at one intersection in N, NE, SE, and SW Portland and used respectively to adjust counts at halfsignals according to its location. A summary of adjusted averaged traffic volume information is presented in Table 7. 
Table 7: Average Adjusted Traffic Volume Information (2002-2011)

\begin{tabular}{|l|r|r||r|r|}
\cline { 2 - 5 } \multicolumn{1}{c|}{} & \multicolumn{2}{c||}{ 3-Leg Half } & \multicolumn{2}{c|}{ 4-Leg Half } \\
\hline Intersections with volume data & \multicolumn{2}{|c|}{10} & \multicolumn{2}{c|}{25} \\
\hline Mean & Major & Minor & Major & Minor \\
\hline Standard Deviation & 16,179 & 560 & 14,278 & 758 \\
\hline Maximum & 3,823 & 375 & 6,812 & 453 \\
\hline Minimum & 23,282 & 1,316 & 26,790 & 1,992 \\
\hline
\end{tabular}

With traffic volume information, crash rates were developed at half-signalized intersections using the standard formula:

Crash rate per million entering vehicles $=\frac{C * 10^{6}}{V * D}$

$C=$ number of crashes in study period

$V=$ sum of volumes entering from all approaches, in vehicles per day (usually AADT)

$D=$ number of days in study period

\section{Equation 7: Crash Rate}

Crash rates are developed individually for each intersection and then averaged. Crash rates for half-signals with available traffic counts over the 10 year analysis period are developed and shown in Table 8Table 7. 
Table 8: Crash Rates per million entering vehicles (MEV) at Half-Signalized Intersections (2002-2011)

\begin{tabular}{|l|l|r|r|r|}
\cline { 3 - 4 } \multicolumn{2}{c|}{} & $\begin{array}{r}\text { 3Leg } \\
\text { Half }\end{array}$ & $\begin{array}{r}\text { 4Leg } \\
\text { Half }\end{array}$ & Total \\
\hline \hline & $\begin{array}{l}\text { \# of Half Signal Intersections with Traffic } \\
\text { Volume Available }\end{array}$ & 10 & 25 & 35 \\
\hline & $\begin{array}{l}\text { Total Crashes per Million Entering } \\
\text { Vehicles (MEV) }\end{array}$ & 0.158 & 0.178 & 0.163 \\
\hline
\end{tabular}

Crash rates are compared with the urban statewide Oregon dataset. Crash rates at half-signals in Table 9 and Table 10 vary slightly from what is shown in Table 8 because the period of analysis is ten years in Table 7Crash rates are developed individually for each intersection and then averaged. Crash rates for half-signals with available traffic counts over the 10 year analysis period are developed and shown in Table 8Table 7.

Table 8 and five years in the ensuing tables. 
Table 9: Crash Rates at Half Signals per MEV Compared with Statewide Urban 2-Way-Stop Controlled Sample (2003-2007)

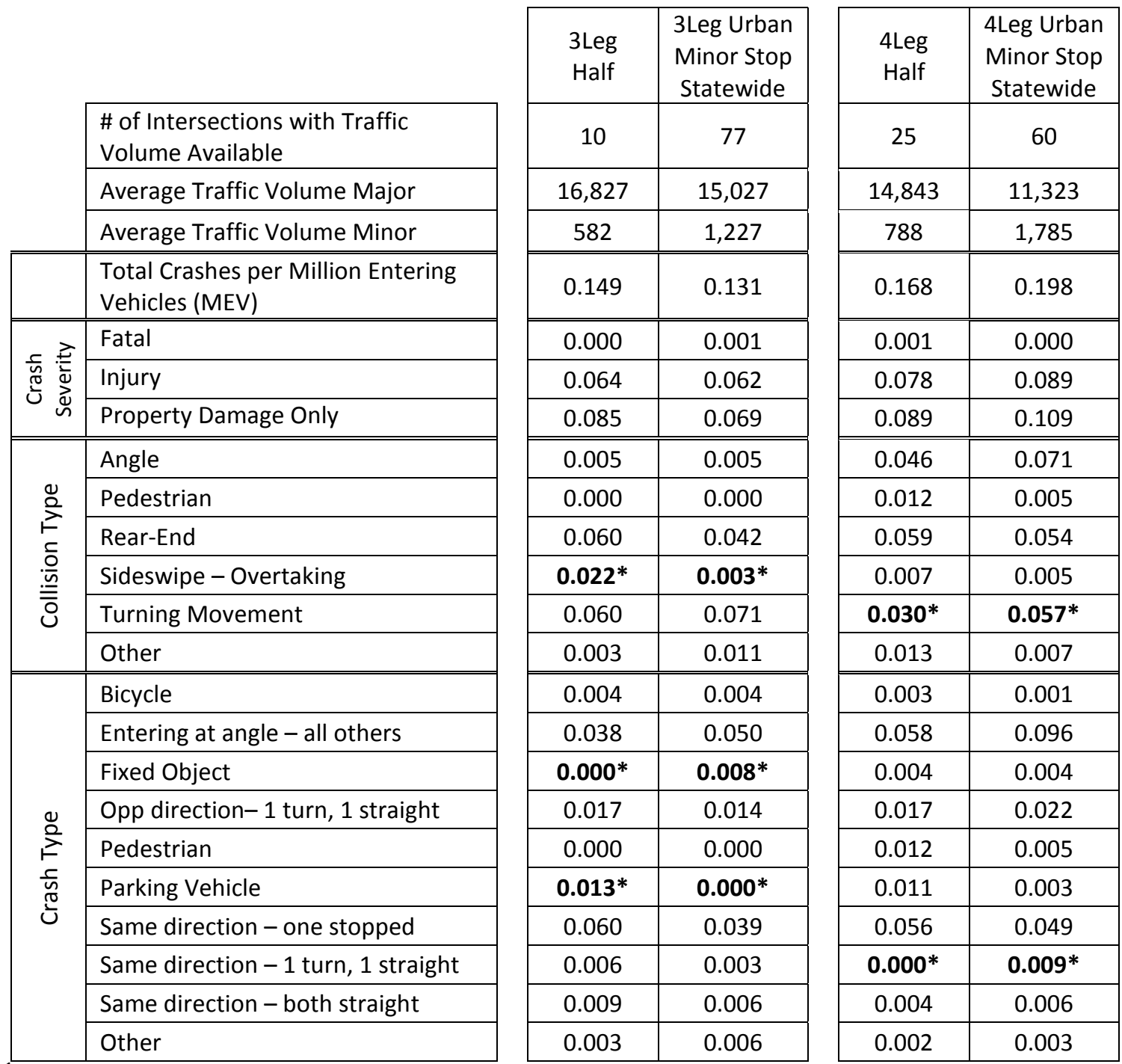

${ }^{1}$ Injuries include Type $\mathrm{A}$, Type $\mathrm{B}$, and Type $\mathrm{C}$ which are incapacitating, non-incapacitating, and minor injury crashes respectively.

*indicates statistical difference at $95 \%$ or higher confidence level 
Using the student's t-test to compare crash rates between half-signalized intersections and minor stop controlled intersections, it is noted that there is no significant difference between overall crash rates. There is a significantly higher rate of sideswipe-overtaking crashes at 3-leg half-signals and a higher rate of turning movement crashes at 4-leg minor stop controlled intersections. At all half-signal locations there is a significantly higher rate of parking maneuver crashes. This could be due to half-signals being utilized more frequently in commercial and school zones with frequent ingress and egress. 
Table 10: Crash Rates at Half Signals per MEV Compared with Statewide Urban Signalized Sample (20032007)

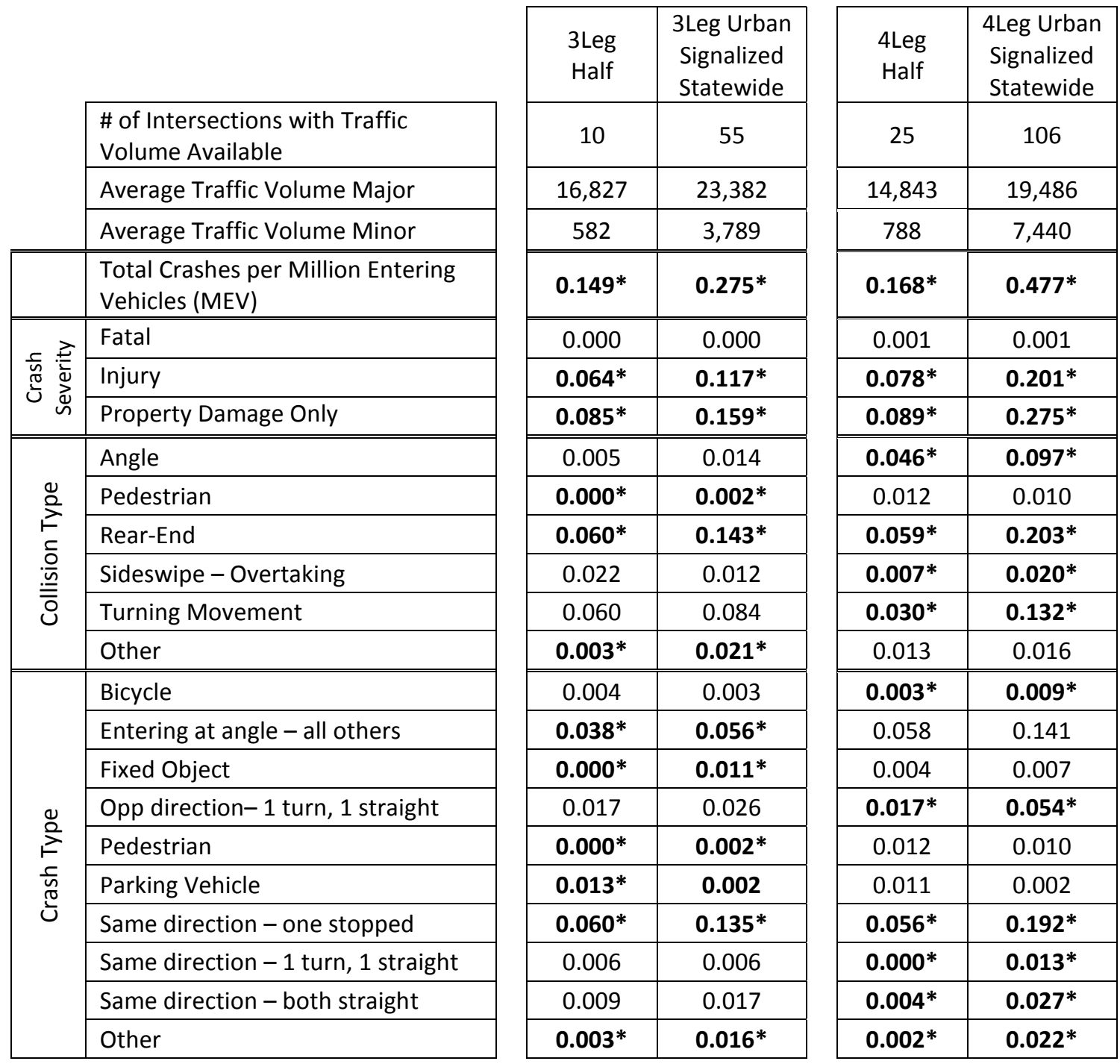

*indicates statistical difference at $95 \%$ or higher confidence level 
Looking at the results from comparing the statewide sample at signalized intersections and half signals, it is apparent that these datasets are not similar. Signalized intersections in the statewide sample have roughly 10 times the volume of traffic on the minor road and this increases complexity at the intersection which leads to higher crash rates at signalized intersections. It is clear that a comparison group with lower minor street traffic is needed to obtain useful results when comparing half-signals to signalized intersections.

\subsubsection{Summary of Overview of Crashes and Crash Rates at Half-Signals}

Results from comparing the crash history at half-signalized intersections to statewide samples at minor stop controlled and signalized intersections did not point to any consistent trends. It is notable that the datasets do not match up very well and this was anticipated

Crash rates at half-signalized intersections determined from the 35 intersections with traffic volume available were 0.158 and 0.178 respectively for 3-leg and 4-leg halfsignals. These rates are analogous with rates in Hamilton, Ontario (9) where researchers found an average crash rate of 0.23 crashes per million entering vehicles at twenty-five half-signals. However, the methodology of the study in Ontario is unknown and Hamilton uses the design with one marked crossing and one unmarked crossing at their 
intersections. The crash rates at half-signals in Portland, OR are also comparable to crash rates of 0.223-0.618 per million entering vehicles and pedestrians found at twenty-one pedestrian hybrid beacons in Tucson, AZ (24). These pedestrian hybrid beacons also only marked one side of the intersection crossing. While caution must be placed in directly comparing crash rates spatially removed from one another because crash reporting criteria differ, these crash rates do exhibit similar patterns.

\subsection{Evaluation of Collision Type at Half-Signal Intersections}

In this section, crashes at half-signalized intersections are looked into in depth. Specifically angle, rear-end, sideswipe-overtaking, turning, bicycle, and pedestrian crashes are evaluated to identify trends.

\subsubsection{Angle Crashes at Half-Signal Intersections}

Angle crashes are crashes that occur between vehicles traveling on crossing paths. In order to be classified as an angle crash in the Oregon crash database (36), both vehicles must be making straight movements through the intersection and not be turning at the time of the crash. The cause of angle crashes and whether they occur on the major or minor street at 4-leg half-signalized intersections are presented in Table 11. 
Table 11: Angle Crash Causes and Violations by Direction at 4-Leg Half-Signals (2002-2011)

\begin{tabular}{|l|c|c|c|}
\cline { 2 - 4 } \multicolumn{1}{c|}{} & Major & Minor & TOTAL \\
\hline Angle - Did not Yield Right of Way & $?$ & $?$ & 44 \\
\hline Angle - Passed Stop Sign & 0 & 4 & 4 \\
\hline Angle - Disregard Traffic Signal & 18 & 0 & 18 \\
\hline
\end{tabular}

It is not apparent what the category "Did Not Yield Right of Way" indicates. Eight of these forty-four "Did not Yield Right of Way" crashes had one vehicle that "proceeded after stopping for a stop sign". Without knowing more information about these "Did not Yield Right of Way" crashes, it is not useful at this moment to examine patterns based on these data.

\subsubsection{Rear-End Crashes at Half-Signal Intersections}

Rear-end crashes are aggregated by approach and the number of approach legs and shown in Table 12.

Table 12: Rear-End Crashes at Half Signals (2002-2011)

\begin{tabular}{|l|c|c||c|}
\cline { 2 - 4 } \multicolumn{1}{c|}{} & 3Leg & 4Leg & TOTAL \\
\hline Major approach & 69 & 94 & 163 \\
\hline Minor approach & 2 & 7 & 9 \\
\hline \hline TOTAL & 71 & 101 & 172 \\
\hline
\end{tabular}

Insignificant at $\alpha=.05 p=0.3098$

It is evident that rear-end crashes principally occur on the major road where the traffic signal is located. Using Fisher's exact test, we do not note any significant 
differences between 3-leg and 4-leg intersections and the respective number of crashes on major and minor approaches. Crash causes listed for these rear-end crashes are all related to driving behaviors. Following too closely, traveling too fast for conditions, improper driving, and inattention are coded the causes of all of these rear-end crashes.

\subsubsection{Turning Crashes at Half-Signal Intersections}

Turning crashes aggregated by approach and turning movement are shown in Table 13.

Table 13: Turning Crashes Aggregated by Turning Movement at Half Signals (2002-2011)

\begin{tabular}{|l|c|c||c|}
\cline { 2 - 4 } \multicolumn{1}{c|}{} & 3Leg & 4Leg & TOTAL \\
\hline Major Road Vehicle Turning Left & 25 & 23 & 48 \\
\hline Major Road Vehicle Turning Right & 5 & 2 & 7 \\
\hline Major Road Vehicle U-Turn & 2 & 1 & 3 \\
\hline Minor Road Vehicle Turning Left & 24 & 26 & 50 \\
\hline Minor Road Vehicle Turning Right & 4 & 4 & 8 \\
\hline Minor Road Vehicle U-Turn & 0 & 0 & 0 \\
\hline Both Vehicles Turning Left & 4 & 2 & 6 \\
\hline \hline TOTAL & 64 & 58 & 122 \\
\hline
\end{tabular}

In Table 13 it is not surprising that the quantity of left turning vehicle crashes from the major and minor streets have similar numbers. While traffic volumes are much lower on the minor street than the major street, it is expected that the number of vehicles turning onto and from the minor street is comparable and thus similar numbers 
of conflicts likely occur. Results from Table 13 are separated into contingency tables in Table 14, Table 15, and Table 16 individually analyzing major street, minor street, and left-turn turning crashes.

Table 14: Turning Crashes by Movement on Major Street (2002-2011)

\begin{tabular}{|l|c|c||c|}
\cline { 2 - 4 } \multicolumn{1}{c|}{} & 3Leg & 4Leg & TOTAL \\
\hline Major Vehicle Turning Left & 25 & 23 & 48 \\
\hline Major Vehicle Turning Right & 5 & 2 & 7 \\
\hline Major Vehicle U-Turn & 2 & 1 & 3 \\
\hline \hline TOTAL & 32 & 26 & 58 \\
\hline
\end{tabular}

Insignificant at $\alpha=.05 p=0.6586$

Table 15: Turning Crashes by Movement on Minor Street (2002-2011)

\begin{tabular}{|l|c|c||c|}
\cline { 2 - 4 } \multicolumn{1}{c|}{} & 3Leg & 4Leg & TOTAL \\
\hline Minor Vehicle Turning Left & 24 & 26 & 50 \\
\hline Minor Vehicle Turning Right & 4 & 4 & 8 \\
\hline Minor Vehicle U-Turn & 0 & 0 & 0 \\
\hline \hline TOTAL & 28 & 30 & 58 \\
\hline
\end{tabular}

Insignificant at $\alpha=.05 p=1$

Table 16: Left-Turning Crashes on Major and Minor Street (2002-2011)

\begin{tabular}{|l|c|c||c|}
\cline { 2 - 4 } \multicolumn{1}{c|}{} & 3Leg & 4Leg & TOTAL \\
\hline Major Vehicle Turning Left & 25 & 23 & 48 \\
\hline Minor Vehicle Turning Left & 24 & 26 & 50 \\
\hline \hline TOTAL & 49 & 49 & 98 \\
\hline
\end{tabular}

Insignificant at $\alpha=.05 p=1$ 


\subsubsection{Sideswipe-Overtaking}

Sideswipe-overtaking crashes are aggregated by approach and the number of intersection legs and shown in Table 17.

Table 17: Sideswipe-Overturning Crashes Aggregated at Half Signals (2002-2011)

Insignificant at $\alpha=.05 p=0.1134$

\begin{tabular}{|l|c|c||c|}
\cline { 2 - 4 } \multicolumn{1}{c|}{} & 3Leg & 4Leg & TOTAL \\
\hline Major Approach & 11 & 11 & 22 \\
\hline Minor Approach & 0 & 4 & 4 \\
\hline \hline TOTAL & 11 & 15 & 26 \\
\hline
\end{tabular}

Half of these twenty-six sideswipe-overtaking crashes are parking maneuver crashes. Even with these parking crashes, there is still not a correlation to major or minor streets.

\subsubsection{Bicycle and Pedestrian Crashes at Half-Signal Intersections}

Because there are so few crashes at half-signals involving bicycles and pedestrians, details for each crash are provided in Table 18. 
Table 18: Bicycle Crash Details at Half-Signals (2002-2011)

\begin{tabular}{|c|c|c|c|c|c|c|}
\hline Location & $\begin{array}{l}\text { Int } \\
\text { Legs }\end{array}$ & $\begin{array}{l}\text { Collision } \\
\text { Type }\end{array}$ & Severity & $\begin{array}{l}\text { Vehicle } \\
\text { Street }\end{array}$ & $\begin{array}{l}\text { Bicycle } \\
\text { Street }\end{array}$ & Description \\
\hline $\begin{array}{l}\text { SW Barbur } \\
\text { SW Hooker }\end{array}$ & 3 & L-TURN & INJ-B & Major & Major & $\begin{array}{l}\text { Bicycle passed veh improperly, } \\
\text { struck by opposing L-Turn vehicle }\end{array}$ \\
\hline $\begin{array}{l}\text { SW Broadway } \\
\text { SW Harrison }\end{array}$ & 3 & L-TURN & INJ-C & Major & Major & Vehicle Did Not Yield ROW \\
\hline $\begin{array}{l}\text { SW Bv-Hillsdale } \\
\text { SW 25th }\end{array}$ & 3 & L-TURN & INJ-B & Major & Major & Vehicle Did Not Yield ROW \\
\hline $\begin{array}{l}\text { SE Hawthorne } \\
\text { SE 16th }\end{array}$ & 4 & L-TURN & INJ-B & Major & Major & Vehicle Did Not Yield ROW \\
\hline $\begin{array}{l}\text { NE Sandy } \\
\text { NE 50th }\end{array}$ & 4 & ANGL & PDO & Minor & Major & $\begin{array}{l}\text { Bicycle Riding Opposite Traffic on } \\
\text { Street }\end{array}$ \\
\hline $\begin{array}{l}\text { SE Tacoma } \\
\text { SE 15th }\end{array}$ & 4 & ANGL & INJ-C & Major & Minor & $\begin{array}{l}\text { Driver had sun in eyes. Bicycle } \\
\text { had ROW }\end{array}$ \\
\hline $\begin{array}{l}\text { SE Milwaukie } \\
\text { SE Tolman }\end{array}$ & 3 & R-TURN & INJ-B & Minor & Major & $\begin{array}{l}\text { Bicycle Riding Opposite Traffic on } \\
\text { Sidewalk }\end{array}$ \\
\hline $\begin{array}{l}\text { SE Sandy } \\
\text { SE 70th }\end{array}$ & 3 & R-TURN & INJ-C & $\begin{array}{l}\text { Minor } \\
\text { (drivewy) }\end{array}$ & Major & $\begin{array}{l}\text { Bicycle Riding Opposite Traffic on } \\
\text { Sidewalk }\end{array}$ \\
\hline $\begin{array}{l}\text { SE 15th } \\
\text { SE Shaver }\end{array}$ & 4 & L-TURN & PDO & Major & Minor & Vehicle Did Not Yield ROW \\
\hline $\begin{array}{l}\text { SE 17th } \\
\text { SE Umatilla }\end{array}$ & 4 & L-TURN & PDO & Minor & Minor & Vehicle Did Not Yield ROW \\
\hline $\begin{array}{l}\text { SE Foster } \\
\text { SE 78th }\end{array}$ & 3 & ANGL & INJ-B & Major & Minor & Vehicle Disregarded Signal \\
\hline $\begin{array}{l}\text { NE } 42^{\text {nd }} \\
\text { NE Alberta Ct }\end{array}$ & 4 & ANGL & INJ-B & Minor & Major & Vehicle Did Not Yield ROW \\
\hline
\end{tabular}

Eight of the twelve bicycle crashes during the observation period place fault on the driver. With addition detail unavailable it is not possible to determine whether these right-of-way violation crashes with bicycles stem from something inherently dangerous at a half-signal or not.

Individual pedestrian crashes at half-signals are presented in Table 19. 
Table 19: Pedestrian Crashes at Half-Signals (2002-2011)

\begin{tabular}{|c|c|c|c|c|c|}
\hline Location & $\begin{array}{l}\text { Int } \\
\text { Legs }\end{array}$ & $\begin{array}{l}\text { Severity } \\
\text { (\# Ped) }\end{array}$ & Vehicle Movement & Ped Location & $\begin{array}{l}\text { Failure to Yield } \\
\text { Right of Way Fault }\end{array}$ \\
\hline $\begin{array}{l}\text { SE Foster } \\
\text { SE 78th }\end{array}$ & 3 & INJ-A & Through from MAJ & Inside X-Walk & Driver \\
\hline $\begin{array}{l}\text { SW Barbur } \\
\text { SW Hooker }\end{array}$ & 3 & INJ-A & Through from MAJ & Inside X-Walk & Pedestrian \\
\hline $\begin{array}{l}\text { SE 17th } \\
\text { SE Umatilla }\end{array}$ & 4 & $\begin{array}{l}\text { INJ-B } \\
(2)\end{array}$ & Left-Turn from MNR & Inside X-Walk & Driver \\
\hline $\begin{array}{l}\text { N Lombard } \\
\text { N Reno }\end{array}$ & 4 & INJ-B & Through from MAJ & Inside X-Walk & Pedestrian \\
\hline $\begin{array}{l}\text { SE Caesar Chavez } \\
\text { SE Taylor }\end{array}$ & 4 & INJ-B & Through from MAJ & Inside X-Walk & Driver \\
\hline $\begin{array}{l}\text { N Lombard } \\
\text { N John }\end{array}$ & 4 & INJ-B & Left Turn from MNR & Inside X-Walk & Driver \\
\hline $\begin{array}{l}\text { N Lombard } \\
\text { N John }\end{array}$ & 4 & INJ-B & Left Turn from MNR & Inside X-Walk & Driver \\
\hline $\begin{array}{l}\text { NE Sandy } \\
\text { NE 50th }\end{array}$ & 4 & INJ-B & Left-Turn from MNR & Inside X-Walk & Driver \\
\hline $\begin{array}{l}\text { NE Sandy } \\
\text { NE 50th }\end{array}$ & 4 & INJ-C & Left-Turn from MNR & Inside X-Walk & Driver \\
\hline $\begin{array}{l}\text { SE Hawthorne } \\
\text { SE 16th }\end{array}$ & 4 & FAT & Through from MAJ & Inside X-Walk & $\begin{array}{l}\text { Pedestrian } \\
\text { (Vehicle Speeding) }\end{array}$ \\
\hline $\begin{array}{l}\text { SE Foster } \\
\text { SE 64th }\end{array}$ & 3 & INJ-B & Left-Turn from MAJ & $\begin{array}{l}\text { Minor Road } \\
\text { X-Walk }\end{array}$ & Driver \\
\hline $\begin{array}{l}\text { SE Foster } \\
\text { SE 78th }\end{array}$ & 3 & INJ-C & Through from MAJ & Inside X-Walk & Pedestrian \\
\hline $\begin{array}{l}\text { N Fesenden } \\
\text { N Burr }\end{array}$ & 4 & INJ-B & Backing & Sidewalk & Driver \\
\hline $\begin{array}{l}\text { NW Everett } \\
\text { NW 20th }\end{array}$ & 3 & INJ-C & $\begin{array}{l}\text { Right-Turn from } \\
\text { MNR }\end{array}$ & Inside X-Walk & Driver \\
\hline $\begin{array}{l}\text { NE Sandy } \\
\text { NE 50th }\end{array}$ & 4 & $\begin{array}{l}\text { INJ-B } \\
(2)\end{array}$ & Left-Turn from MNR & Inside X-Walk & Driver \\
\hline $\begin{array}{l}\text { SE } 92^{\text {nd }} \\
\text { SE Main }\end{array}$ & 3 & $\begin{array}{l}\text { INJ-C } \\
(2)\end{array}$ & Left-Turn from MNR & Inside X-Walk & Driver \\
\hline
\end{tabular}

From these data, a contingency table is created to compare the originating approach of the striking vehicle and which road user did not yield right-of-way. The 
pedestrian crashes that do not occur in the marked major street crossing are shown in light grey in Table 19 and these crashes are omitted from Table 20.

Table 20: Pedestrian Crashes Aggregated by Fault and Approach at Half Signals (2002-2011)

\begin{tabular}{|c|c|c|c|}
\hline & \multicolumn{2}{|c|}{ Fault } & \\
\hline & Ped & Driver & TOTAL \\
\hline Vehicle Originates from Major Road & 4 & 2 & 6 \\
\hline Vehicle Originates from Minor Road & 0 & 8 & 8 \\
\hline TOTAL & 4 & 10 & 14 \\
\hline
\end{tabular}

Significant at $\alpha=.05 p=0.01499$

Significant differences are found when comparing the street that the colliding vehicle originated from and which road user could be held at fault for the crash. All of the crashes at half-signals where a vehicle departed from the minor road are the fault of the driver on the minor road. These crashes occurred when pedestrians had the walk phase and this is the concern that the FHWA mentions when stating that "motorists on the minor road facing the inability to cross... may not give adequate attention to pedestrians crossing the street". This phenomenon may not necessarily be exclusive to half-signals as the same crash patterns could occur at minor stop controlled intersections with marked pedestrian crossings.

Pedestrian crash severity and the direction from which the vehicle originates are shown in Table 21. While this may not be the ideal test primarily due to higher speeds 
on the major road, it is noted that the $p$-value is close to 0.05 in Table 21 indicating that there may be a correlation between the control on the approach and pedestrian crash severity.

Table 21: Pedestrian Crashes Aggregated by Crash Severity and Approach at Half Signals (2002-2011)

Insignificant at $\alpha=.05 p=0.0549$

\begin{tabular}{|l|c|c||c|}
\cline { 2 - 4 } \multicolumn{1}{c|}{} & \multicolumn{2}{c|}{ Vehicle Direction } & \\
\cline { 2 - 4 } \multicolumn{1}{c|}{} & MAJ & MNR & TOTAL \\
\hline Fatality and Injury A & 3 & 0 & 3 \\
\hline Injury B + C & 3 & 8 & 11 \\
\hline \hline TOTAL & 6 & 8 & 14 \\
\hline
\end{tabular}

\subsubsection{Summary of Collision Type at Half-Signalized Intersections}

While evaluating collision types at half-signalized intersection, significant differences in the fault of the road user and the approach street of the vehicle in crashes involving pedestrians were found. There may also be a correlation in pedestrian crashes between the control on the approach street and the severity of the crash. In order to test these findings, comparison groups are developed and evaluated with the previously evaluated collision types.

\subsection{Matched Comparison Group Development}

To develop matched comparison groups an attempt was made to match each half-signal with both a minor stop controlled and a fully signalized intersection that 
shares either the major street or the minor street. If an intersection match was not found within two miles of the half-signal along the major or minor street with the same number of approach lanes, same posted approach speed, same zoning, similar intersection offset, same skew, same one-way status, same number of turning bays, and similar pedestrian refuge then that half-signal was omitted from this section of analysis. Wherever possible, in matching up intersections the same number and placement of transit stops, number of marked crossings, type of marked crossings, and similar traffic volumes were sought. Crash Modification Factors (CMFs) were referenced when choosing between different potential matched pairs to ultimately decide which intersection was a best fit (39).

Comparison groups were limited to those where entering vehicle volume data were available. At signalized locations, ten matched locations were originally identified; however, four of these locations had higher than ideal volumes on the minor road and were removed from this analysis. At minor stop controlled intersections, potential sites were reduced from 35 to 20 paired intersections because of difficulties in obtaining minor road volumes. Matched groups and corresponding adjusted traffic volumes are listed in detail in Appendices B and C. 
One of the weaknesses in using comparison groups to study safety effects is that the same location with the same environment is not used like it would be in a beforeafter study. By choosing intersections within two miles and on the same major roads as the half-signals in consideration, unaccounted for and hard to measure differences are minimized. Statistical significance is tested using Fisher's test for crash counts and the Student's or t-test for crash rates.

\subsubsection{Matched Comparison Crash Overview}

Crashes are tabulated for paired groups of half-signal/minor stop controlled and half-signal/fully signalized groups. Crash counts aggregated by severity, crash, and collision type are shown in Table 22. 
Table 22: Total Crashes by Severity, Crash Type, and Collision Type at Matched Groups (2002-2011)

\begin{tabular}{|c|c|}
\hline & \# of Intersections \\
\hline & \# of Crashes \\
\hline \multirow{3}{*}{ 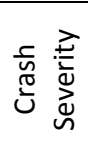 } & Fatal \\
\hline & Injury \\
\hline & Property Damage Only \\
\hline \multirow{6}{*}{ 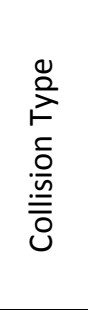 } & Angle \\
\hline & Pedestrian \\
\hline & Rear-End \\
\hline & Sideswipe - Overtaking \\
\hline & Turning Movement \\
\hline & Other \\
\hline \multirow{10}{*}{ 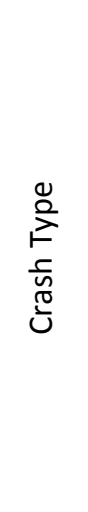 } & Bicycle \\
\hline & Entering at angle - all others \\
\hline & Fixed Object \\
\hline & Opp direction- 1 turn, 1 straight \\
\hline & Pedestrian \\
\hline & Parking Vehicle \\
\hline & Same direction - one stopped \\
\hline & Same direction - 1 turn, 1 straight \\
\hline & Same direction - both straight \\
\hline & Other \\
\hline
\end{tabular}

\begin{tabular}{|c|c|}
\hline \multicolumn{2}{|c|}{ Matched Stop Group } \\
\hline Half & Stop \\
\hline 19 & 19 \\
\hline 176 & 159 \\
\hline \hline $0.0 \%$ & $0.6 \%$ \\
\hline $46.0 \%$ & $40.3 \%$ \\
\hline $54.0 \%$ & $59.1 \%$ \\
\hline \hline $21.0 \%$ & $25.2 \%$ \\
\hline $2.3 \%$ & $3.8 \%$ \\
\hline $42.0 \% *$ & $27.0 \%$ \\
\hline $6.3 \%$ & $4.4 \%$ \\
\hline $22.7 \%$ & $33.3 \% *$ \\
\hline $5.7 \%$ & $6.3 \%$ \\
\hline \hline $2.8 \%$ & $1.9 \%$ \\
\hline $31.3 \%$ & $39.0 \% *$ \\
\hline $2.2 \%$ & $3.1 \%$ \\
\hline $6.1 \%$ & $13.2 \% *$ \\
\hline $2.2 \%$ & $3.8 \%$ \\
\hline $6.1 \%$ & $3.8 \%$ \\
\hline $39.1 \% *$ & $25.2 \%$ \\
\hline $2.2 \%$ & $1.9 \%$ \\
\hline $2.8 \%$ & $4.4 \%$ \\
\hline $5.0 \%$ & $3.8 \%$ \\
\hline
\end{tabular}

\begin{tabular}{|c|c|}
\hline \multicolumn{2}{|c|}{ Matched Signal Group } \\
\hline Half & Signal \\
\hline 6 & 6 \\
\hline 93 & 114 \\
\hline $0.0 \%$ & $0.0 \%$ \\
\hline $46.2 \%$ & $39.5 \%$ \\
\hline $53.8 \%$ & $60.5 \%$ \\
\hline $25.8 \%$ & $32.5 \%$ \\
\hline $5.4 \% *$ & $0.9 \%$ \\
\hline $34.4 \%$ & $28.9 \%$ \\
\hline $4.3 \%$ & $6.1 \%$ \\
\hline $25.8 \%$ & $22.8 \%$ \\
\hline $4.3 \%$ & $8.8 \%$ \\
\hline $1.1 \%$ & $3.5 \%$ \\
\hline $36.6 \%$ & $41.2 \%$ \\
\hline $1.1 \%$ & $1.8 \%$ \\
\hline $14.0 \%$ & $10.5 \%$ \\
\hline $5.4 \% *$ & $0.9 \%$ \\
\hline $3.2 \%$ & $2.6 \%$ \\
\hline $31.2 \%$ & $28.1 \%$ \\
\hline $0.0 \%$ & $0.9 \%$ \\
\hline $5.4 \%$ & $6.1 \%$ \\
\hline $2.2 \%$ & $4.4 \%$ \\
\hline
\end{tabular}

*indicates statistical significant more crashes at $95 \%$ or higher confidence level

From these crash data, the half-signalized group has a higher proportion of rear-

end crashes but the minor stop controlled group has a higher proportion of turning

crashes when compared with each other in Table 22. Results also suggest that crashes

involving pedestrians are more frequent at the half-signal group when compared to the

signalized group but the sample size of crashes involving pedestrians is very small. The 
relative volume of pedestrians at the signalized versus half-signalized group are unknown.

\subsubsection{Crash Rates at Half-Signalized Intersections}

Crash rates are developed using the same methodology as described earlier in this paper. Traffic volumes were adjusted for the year that the count was performed by utilizing ODOT transportation volume tables (38). These ODOT tables allowed ADT counts at half-signals to be adjusted and averaged over the 10 -year analysis period from 2002-2011. For each intersection, the total number of crashes over the 10 year analysis is divided by the total number of entering vehicles. Matched group information and adjusted average traffic volumes for these groups are shown in Table 23. For the signal group, the minor volumes at the half-signals are roughly $1 / 2$ the signalized minor volumes. 
Table 23: Matched Group Adjusted Traffic Volume Information

\begin{tabular}{|l|r|r|r|r|r|r|r|r|}
\cline { 2 - 9 } \multicolumn{1}{c|}{} & \multicolumn{4}{c|}{ Matched Stop Group } & \multicolumn{4}{c|}{ Matched Signal Group } \\
\cline { 2 - 10 } \multicolumn{1}{c|}{ Half } & \multicolumn{2}{c|}{ Stop } & \multicolumn{3}{c|}{ Half } & \multicolumn{2}{c|}{ Signal } \\
\hline $\begin{array}{l}\text { Intersections with } \\
\text { Traffic Volume Data }\end{array}$ & \multicolumn{2}{c|}{19} & \multicolumn{2}{c|}{19} & \multicolumn{2}{c|}{6} & \multicolumn{2}{c|}{6} \\
\hline & Major & Minor & Major & Minor & Major & Minor & Major & Minor \\
\hline Mean & 13262 & 687 & 12349 & 810 & 14141 & 1035 & 14995 & 2055 \\
\hline Standard Deviation & 5917 & 516 & 5848 & 851 & 9681 & 507 & 5717 & 1296 \\
\hline Maximum & 25252 & 1992 & 24836 & 3783 & 26790 & 1686 & 23086 & 3851 \\
\hline Minimum & 3780 & 117 & 3780 & 159 & 4405 & 201 & 6419 & 685 \\
\hline
\end{tabular}

Using these volume data, crash rates are shown per million entering vehicles

(MEV) for the matched intersection sets in Table 24. 
Table 24: Crash Rate by Severity, Crash Type, and Collision Type at Matched Groups (2002-2011)

\begin{tabular}{|c|c|c|c|c|c|}
\hline & & \multicolumn{2}{|c|}{ Matched Stop Group } & \multicolumn{2}{|c|}{ Matched Signal Group } \\
\hline & & Half & Stop & Half & Signal \\
\hline & $\begin{array}{l}\text { \# of Intersections with Traffic } \\
\text { Volume Available }\end{array}$ & 19 & 19 & 6 & 6 \\
\hline & Average Traffic Volume Major & 13262 & 12349 & 14141 & 14995 \\
\hline & Average Traffic Volume Minor & 687 & 810 & 1035 & 2055 \\
\hline & $\begin{array}{l}\text { Total Crashes per Million Entering } \\
\text { Vehicles (MEV) }\end{array}$ & 0.181 & 0.155 & 0.254 & 0.320 \\
\hline \multirow{3}{*}{ 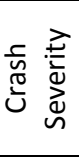 } & Fatal & 0.000 & 0.001 & 0.000 & 0.000 \\
\hline & Injury & 0.085 & 0.062 & 0.122 & 0.131 \\
\hline & Property Damage Only & 0.097 & 0.092 & 0.133 & 0.189 \\
\hline \multirow{6}{*}{$\begin{array}{l}\stackrel{0}{2} \\
\stackrel{2}{z} \\
\frac{0}{0} \\
\stackrel{.0}{\overline{0}}\end{array}$} & Angle & 0.042 & 0.049 & 0.073 & 0.117 \\
\hline & Pedestrian & 0.006 & 0.005 & 0.017 & 0.002 \\
\hline & Rear-End & $0.069 *$ & 0.038 & 0.074 & 0.085 \\
\hline & Sideswipe - Overtaking & 0.013 & 0.006 & 0.013 & 0.020 \\
\hline & Turning Movement & 0.042 & 0.043 & 0.059 & 0.067 \\
\hline & Other & 0.010 & 0.014 & 0.018 & 0.031 \\
\hline \multirow{10}{*}{$\begin{array}{l}\stackrel{0}{2} \\
\stackrel{2}{\Xi} \\
\frac{c}{n} \\
\frac{0}{U}\end{array}$} & Bicycle & 0.006 & 0.003 & 0.002 & 0.010 \\
\hline & Entering at angle - all others & 0.058 & 0.067 & 0.095 & 0.141 \\
\hline & Fixed Object & 0.005 & 0.009 & 0.007 & 0.008 \\
\hline & Opp direction- 1 turn, 1 straight & 0.015 & 0.015 & 0.036 & 0.034 \\
\hline & Pedestrian & 0.006 & 0.005 & 0.017 & 0.002 \\
\hline & Parking Vehicle & 0.011 & 0.007 & 0.012 & 0.008 \\
\hline & Same direction - one stopped & $0.066^{*}$ & 0.035 & 0.065 & 0.082 \\
\hline & Same direction - 1 turn, 1 straight & 0.004 & 0.003 & 0.000 & 0.002 \\
\hline & Same direction - both straight & 0.006 & 0.006 & 0.016 & 0.020 \\
\hline & Other & 0.004 & 0.004 & 0.009 & 0.014 \\
\hline
\end{tabular}

*indicates statistical significant more crashes at $95 \%$ or higher confidence level

Results suggest that the half-signal group has a statistically significant higher rear-end crash rate when compared with the minor stop controlled group. No significant differences were found when comparing the half-signal and fully signalized groups. 
Unintentionally, the crash rates at half-signals in the matched stop group of 0.181 crashes per MEV and 0.254 per MEV in the matched signalized group are higher than crash rates in the full set of thirty-five half-signal intersections which has 0.163 crashes per MEV. Pedestrian crash rates in the half-signal group were higher than the signalized group but due to a very small count of crashes, a few intersections having most of the pedestrian crashes, and a low overall number of compared intersections, significant differences were not found.

\subsubsection{Angle Crashes Matched Comparison Groups}

Relevant angle crash causes are listed for signalized and minor stop controlled matched groups in Table 25.

Table 25: Matched Group Angle Crashes by Cause (2002-2011)

\begin{tabular}{|l|c|c|c|c|}
\cline { 2 - 5 } \multicolumn{1}{c|}{} & \multicolumn{2}{c|}{$\begin{array}{c}\text { Matched } \\
\text { Minor Stop Group }\end{array}$} & \multicolumn{2}{c|}{ Matched Signal Group } \\
\cline { 2 - 5 } \multicolumn{1}{c|}{} & Half & Stop & Half & Signal \\
\hline Angle - Did not Yield Right of Way & $59.5 \%$ & $91.9 \%$ & $45.9 \%$ & $10.8 \%$ \\
\hline Angle - Passed Stop Sign & $5.4 \%$ & $13.5 \%$ & $10.8 \%$ & $0.0 \%$ \\
\hline Angle - Disregard Traffic Signal & $35.1 \%$ & $0.0 \%$ & $8.1 \%$ & $86.5 \%$ \\
\hline \hline Total \# of Crashes & 37 & 39 & 24 & 36 \\
\hline
\end{tabular}

Significant at $\alpha=.05 p=0.00003$ (Stop Group) $p=0.000000002$ (Signal Group)

Without knowing in detail what "Did not Yield Right of Way" indicates, in the matched stop group six of these crashes in the stop group and three of the crashes in 
the half-signal group occurred where the vehicle proceeded after stopping. One crash in the half-signal subset from the matched signalized group is identified as proceeding after stopping. Crash severity is tabulated in Table 26 to determine if the inclusion of a signal has an effect on crash severity.

Table 26: Angle Crash Severity at Matched Stop Group (2002-2011)

\begin{tabular}{|l|c|c|c|c|}
\cline { 2 - 5 } \multicolumn{1}{c|}{} & \multicolumn{2}{c|}{ Matched Stop Group } & \multicolumn{2}{c|}{ Matched Signal Group } \\
\cline { 2 - 5 } \multicolumn{1}{c|}{} & Half & Stop & Half & Signal \\
\hline FAT + INJA & $5.4 \%$ & $2.5 \%$ & $0.0 \%$ & $0.0 \%$ \\
\hline INJB + INJC & $51.4 \%$ & $37.5 \%$ & $50.0 \%$ & $43.2 \%$ \\
\hline PDO & $43.2 \%$ & $60.0 \%$ & $50.0 \%$ & $56.8 \%$ \\
\hline \hline Total \# of Crashes & 37 & 40 & 24 & 37 \\
\hline
\end{tabular}

Insignificant at $\alpha=.05 p=0.3933$ (Stop Group) $p=0.7929$ (Signal Group)

No significant differences were found when comparing crash severity and the control of the intersection in angle crashes.

\subsubsection{Rear-End Crashes at Matched Comparison Groups}

Rear-end crashes and the street on which the crash occurred are shown in Table 27. 
Table 27: Rear-End Crashes by Direction (2002-2011)

\begin{tabular}{|l|c|c|c|c|}
\cline { 2 - 5 } \multicolumn{1}{c|}{} & \multicolumn{2}{c|}{ Matched Stop Group } & \multicolumn{2}{c|}{ Matched Signal Group } \\
\cline { 2 - 5 } \multicolumn{1}{c|}{} & Half & Stop & Half & Signal \\
\hline Major approach & $91.9 \%$ & $93.0 \%$ & $90.6 \%$ & $90.9 \%$ \\
\hline Minor approach & $8.1 \%$ & $7.0 \%$ & $9.4 \%$ & $9.1 \%$ \\
\hline \hline Total \# of Crashes & 74 & 43 & 32 & 33 \\
\hline
\end{tabular}

Insignificant at $\alpha=.05 p=1$ (Stop Group) $p=1$ (Signal Group)

Table 28: Rear-End Crashes by Severity Type (2002-2011)

\begin{tabular}{|l|c|c|c|c|}
\cline { 2 - 5 } \multicolumn{1}{c|}{} & \multicolumn{2}{c|}{ Matched Stop Group } & \multicolumn{2}{c|}{ Matched Signal Group } \\
\cline { 2 - 5 } \multicolumn{1}{c|}{} & Half & Stop & Half & Signal \\
\hline FAT + INJA & $1.4 \%$ & $0.0 \%$ & $0.0 \%$ & $0.0 \%$ \\
\hline INJB + INJC & $52.7 \%$ & $48.8 \%$ & $37.5 \%$ & $45.5 \%$ \\
\hline PDO & $45.9 \%$ & $51.2 \%$ & $62.5 \%$ & $54.5 \%$ \\
\hline \hline Total \# of Crashes & 74 & 43 & 32 & 33 \\
\hline
\end{tabular}

Insignificant at $\alpha=.05 p=0.8166$ ((Stop Group) $p=0.617$ (Signal Group)

No significant differences are determined when evaluating crash severity

between stop and half-signal and half and fully signalized groups in Table 28.

\subsubsection{Turning Crashes at Matched Comparison Groups}

Turning crashes at matched comparison groups are shown in Table 29 below. 
Table 29: Turning Crashes at Matched Comparison Groups (2002-2011)

\begin{tabular}{|l|c|c|c|c|}
\cline { 2 - 4 } \multicolumn{1}{c|}{} & \multicolumn{2}{c|}{ Matched Stop Group } & \multicolumn{2}{c|}{ Matched Signal Group } \\
\cline { 2 - 4 } \multicolumn{1}{c|}{} & Half & Stop & Half & Sig \\
\hline \hline Major Vehicle Turning Left & $32.5 \%$ & $45.3 \%$ & $50.0 \%$ & $76.9 \%$ \\
\hline Major Vehicle Turning Right & $5.0 \%$ & $7.5 \%$ & $4.2 \%$ & $0.0 \%$ \\
\hline Major Vehicle U-Turn & $5.0 \%$ & $0.0 \%$ & $0.0 \%$ & $0.0 \%$ \\
\hline Minor Vehicle Turning Left & $47.5 \%$ & $37.7 \%$ & $37.5 \%$ & $15.4 \%$ \\
\hline Minor Vehicle Turning Right & $5.0 \%$ & $5.7 \%$ & $4.2 \%$ & $7.7 \%$ \\
\hline Minor Vehicle U-Turn & $0.0 \%$ & $0.0 \%$ & $0.0 \%$ & $0.0 \%$ \\
\hline Both Vehicles Turning Left & $5.0 \%$ & $3.8 \%$ & $4.2 \%$ & $0.0 \%$ \\
\hline \hline Total \# of Crashes & 40 & 53 & 24 & 26 \\
\hline
\end{tabular}

Vehicle movements from the minor and major roads are compared in Table 30 and Table 31. Because left-turning movements crashes appear to be prevalent, these crashes are aggregated by the road from which the left turn is made and tested in Table 32.

Table 30: Matched Group Turning Crashes by Movement on Major Street (2002-2011)

\begin{tabular}{|l|c|c|c|c|}
\cline { 2 - 5 } \multicolumn{1}{c|}{} & \multicolumn{2}{c|}{ Matched Stop Group } & \multicolumn{2}{c|}{ Matched Signal Group } \\
\cline { 2 - 5 } \multicolumn{1}{c|}{} & Half & Stop & Half & Sig \\
\hline Major Vehicle Turning Left & $76.5 \%$ & $85.7 \%$ & $92.3 \%$ & $100.0 \%$ \\
\hline Major Vehicle Turning Right & $11.8 \%$ & $14.3 \%$ & $7.7 \%$ & $0.0 \%$ \\
\hline Major Vehicle U-Turn & $11.8 \%$ & $0.0 \%$ & $0.0 \%$ & $0.0 \%$ \\
\hline \hline Total \# of Crashes & 17 & 28 & 13 & 20 \\
\hline
\end{tabular}

Insignificant at $\alpha=.05 p=0.6657$ (Stop Group) $p=0.3939$ (Signal Group) 
Table 31: Matched Group Turning Crashes by Movement on Minor Street (2002-2011)

\begin{tabular}{|l|c|c|c|c|}
\cline { 2 - 5 } \multicolumn{1}{c|}{} & \multicolumn{2}{c|}{ Matched Stop Group } & \multicolumn{2}{c|}{ Matched Signal Group } \\
\cline { 2 - 5 } \multicolumn{1}{c|}{} & Half & Stop & Half & Sig \\
\hline Minor Vehicle Turning Left & $90.5 \%$ & $87.0 \%$ & $90.0 \%$ & $66.7 \%$ \\
\hline Minor Vehicle Turning Right & $9.5 \%$ & $13.0 \%$ & $10.0 \%$ & $33.3 \%$ \\
\hline Minor Vehicle U-Turn & $0.0 \%$ & $0.0 \%$ & $0.0 \%$ & $0.0 \%$ \\
\hline \hline Total \# of Crashes & 21 & 23 & 10 & 6 \\
\hline
\end{tabular}

Insignificant at $\alpha=.05 p=1$ (Stop Group) $p=0.5179$ (Signal Group)

Table 32: Matched Group Left Turning Crashes on Major and Minor Street (2002-2011)

\begin{tabular}{|l|c|c|c|c|}
\cline { 2 - 5 } \multicolumn{1}{c|}{} & \multicolumn{2}{c|}{ Matched Stop Group } & \multicolumn{2}{c|}{ Matched Signal Group } \\
\cline { 2 - 5 } \multicolumn{1}{c|}{} & Half & Stop & Half & Sig \\
\hline Major Vehicle Turning Left & $54.2 \%$ & $54.5 \%$ & $57.1 \%$ & $83.3 \%$ \\
\hline Minor Vehicle Turning Left & $79.2 \%$ & $45.5 \%$ & $42.9 \%$ & $16.7 \%$ \\
\hline \hline Total \# of Crashes & 24 & 44 & 21 & 24 \\
\hline
\end{tabular}

Insignificant at $\alpha=.05 p=0.2412$ (Stop Group) $p=0.0977$ (Signal Group)

\subsubsection{Bicycle and Pedestrian Crashes at Matched Comparison Groups}

Individual bicycle crashes are presented in Table 33 and Table 34. 
Table 33: Crashes involving Bicycles at Half and Stop Group (2002-2011)

\begin{tabular}{|c|c|c|c|c|c|c|c|}
\hline & Location & $\begin{array}{l}\text { Int } \\
\text { Legs }\end{array}$ & $\begin{array}{l}\text { Collision } \\
\text { Type }\end{array}$ & Severity & $\begin{array}{l}\text { Vehicle } \\
\text { Street }\end{array}$ & $\begin{array}{l}\text { Bicycle } \\
\text { Street }\end{array}$ & Description \\
\hline \multirow{6}{*}{$\begin{array}{l}\frac{0}{3} \\
0 \\
\frac{0}{0} \\
\frac{4}{\pi} \\
\frac{\pi}{1}\end{array}$} & $\begin{array}{l}\text { SE Milwaukie } \\
\text { SE Tolman }\end{array}$ & 3 & R-TURN & INJ-B & Minor & Major & $\begin{array}{l}\text { Bicycle Riding Opposite } \\
\text { Traffic on Sidewalk }\end{array}$ \\
\hline & $\begin{array}{l}\text { SE Tacoma } \\
\text { SE 15th }\end{array}$ & 4 & ANGL & INJ-C & Major & Minor & $\begin{array}{l}\text { Driver had sun in eyes. } \\
\text { Bicycle had ROW }\end{array}$ \\
\hline & $\begin{array}{l}\text { SE 15th } \\
\text { SE Shaver }\end{array}$ & 4 & L-TURN & PDO & Major & Minor & $\begin{array}{l}\text { Vehicle Did Not Yield } \\
\text { ROW }\end{array}$ \\
\hline & $\begin{array}{l}\text { SE 17th } \\
\text { SE Umatilla }\end{array}$ & 4 & L-TURN & PDO & Minor & Minor & $\begin{array}{l}\text { Vehicle Did Not Yield } \\
\text { ROW }\end{array}$ \\
\hline & $\begin{array}{l}\text { NE } 42^{\text {nd }} \\
\text { NE Alberta Ct }\end{array}$ & 4 & ANGL & INJ-B & Minor & Major & $\begin{array}{l}\text { Vehicle Did Not Yield } \\
\text { ROW }\end{array}$ \\
\hline & $\begin{array}{l}\text { SW Barbur } \\
\text { SW Hooker }\end{array}$ & 3 & L-TURN & INJ-B & Major & Major & $\begin{array}{l}\text { Bicycle passed veh } \\
\text { improperly, struck by } \\
\text { opposing L-Turn vehicle }\end{array}$ \\
\hline \multirow{3}{*}{ 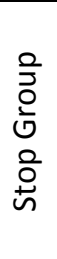 } & $\begin{array}{l}\text { N Lombard } \\
\text { N Leavitt }\end{array}$ & 4 & L-TURN & PDO & Major & Major & $\begin{array}{l}\text { Vehicle Did Not Yield } \\
\text { ROW }\end{array}$ \\
\hline & $\begin{array}{l}\text { SE Tacoma } \\
\text { SE 16th }\end{array}$ & 4 & ANGL & INJ-B & Major & Minor & $\begin{array}{l}\text { Bicycle Did Not Yield ROW } \\
\text { No Lighting on Bicycle }\end{array}$ \\
\hline & $\begin{array}{l}\text { SE } 17^{\text {th }} \\
\text { SE Linn }\end{array}$ & 4 & $\begin{array}{l}\text { L-TURN } \\
\text { R-TURN }\end{array}$ & INJ-A & Major & Minor & $\begin{array}{l}\text { Vehicle took L-Turn sharp } \\
\text { and struck R-turning bike }\end{array}$ \\
\hline
\end{tabular}

The crash that happened at SE Tacoma and SE $16^{\text {th }}$ in the stop group where the bicyclist did not presumably have a safe opportunity to cross the major street and thus took a risk is the type of crash that half-signals and signalized intersections are designed to prevent.

Table 34 shows bicycle crash results comparing half-signal and fully signalized groups. 
Table 34: Crashes Involving Bicycles at Half and Signal Group (2002-2011)

\begin{tabular}{|c|c|c|c|c|c|c|c|}
\hline & Location & $\begin{array}{l}\text { Int } \\
\text { Legs }\end{array}$ & $\begin{array}{l}\text { Collision } \\
\text { Type }\end{array}$ & Severity & $\begin{array}{l}\text { Vehicle } \\
\text { Street }\end{array}$ & $\begin{array}{l}\text { Bicycle } \\
\text { Street }\end{array}$ & Description \\
\hline $\begin{array}{l}\text { Half } \\
\text { Group }\end{array}$ & $\begin{array}{l}\text { NE Sandy } \\
\text { NE 50th }\end{array}$ & 4 & ANGL & PDO & Minor & Major & $\begin{array}{l}\text { Bicycle Riding Opposite } \\
\text { Traffic on Street }\end{array}$ \\
\hline \multirow{4}{*}{ 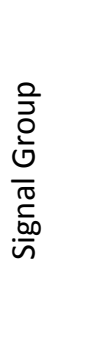 } & $\begin{array}{l}\text { SE Bybee } \\
\text { SE 17th }\end{array}$ & 4 & L-TURN & INJ-B & Major & Major & $\begin{array}{l}\text { Vehicle Did Not Yield } \\
\text { ROW }\end{array}$ \\
\hline & $\begin{array}{l}\text { SE Bybee } \\
\text { SE 17th }\end{array}$ & 4 & L-TURN & INJ-B & Major & Major & $\begin{array}{l}\text { Vehicle Did Not Yield } \\
\text { ROW }\end{array}$ \\
\hline & $\begin{array}{l}\text { N Lombard } \\
\text { N Wabash }\end{array}$ & 4 & ANGL & INJ-B & Minor & Major & $\begin{array}{l}\text { Vehicle Did Not Yield } \\
\text { ROW }\end{array}$ \\
\hline & $\begin{array}{l}\text { NE US Grant } \\
\text { NE 33rd }\end{array}$ & 4 & ANGL & INJ-C & Minor & Major & Vehicle Disregard Signal \\
\hline
\end{tabular}

Pedestrian crashes are presented in Table 35. 
Table 35: Pedestrian Crash Detail at Matched Stop Group (2002-2011)

\begin{tabular}{|c|c|c|c|c|c|c|}
\hline & Location & $\begin{array}{l}\text { Int } \\
\text { Legs }\end{array}$ & $\begin{array}{l}\text { Severity } \\
\text { (\# Ped) }\end{array}$ & Vehicle Movement & $\begin{array}{l}\text { Ped Location } \\
\text { or Crossing Rd }\end{array}$ & $\begin{array}{l}\text { Failure to Yield } \\
\text { Right of Way Fault }\end{array}$ \\
\hline \multirow{4}{*}{$\begin{array}{l}\frac{0}{7} \\
0 \\
0 \\
1 \\
\frac{4}{\pi} \\
\text { I }\end{array}$} & $\begin{array}{l}\text { N Fesenden } \\
\text { N Burr }\end{array}$ & 4 & INJ-B & Backing & Sidewalk & Driver \\
\hline & $\begin{array}{l}\text { N Lombard } \\
\text { N John }\end{array}$ & 4 & INJ-B & Left Turn from MNR & Inside X-Walk & Driver \\
\hline & $\begin{array}{l}\text { N Lombard } \\
\text { N John }\end{array}$ & 4 & INJ-B & Left Turn from MNR & Inside X-Walk & Driver \\
\hline & $\begin{array}{l}\text { SE 17th } \\
\text { SE Umatilla }\end{array}$ & 4 & $\begin{array}{l}\text { INJ-B } \\
(2)\end{array}$ & Left-Turn from MNR & Inside X-Walk & Driver \\
\hline \multirow{6}{*}{$\begin{array}{l}\text { 윽 } \\
0 \\
\text { 누 } \\
\text { 음 } \\
\stackrel{4}{n}\end{array}$} & $\begin{array}{l}\text { SE Division } \\
\text { SE 58th }\end{array}$ & 3 & INJ-B & $\begin{array}{l}\text { Right-Turn from } \\
\text { MNR }\end{array}$ & $\begin{array}{l}\text { Minor Rd } \\
\text { (no X-Walk) }\end{array}$ & Driver \\
\hline & $\begin{array}{l}\text { SE Foster } \\
\text { SE 54th }\end{array}$ & 6 & FAT & Straight on Major & $\begin{array}{l}\text { Major Rd } \\
\text { (no X-Walk) }\end{array}$ & Driver \\
\hline & $\begin{array}{l}\text { N Lombard } \\
\text { N Curtis }\end{array}$ & 3 & INJ-C & Straight on Major & $\begin{array}{l}\text { Major Rd } \\
\text { (no X-Walk) }\end{array}$ & $\begin{array}{l}\text { Ped between } \\
\text { Intersections }\end{array}$ \\
\hline & $\begin{array}{l}\text { SE } 17^{\text {th }} \\
\text { SE Linn }\end{array}$ & 4 & INJ-A & Straight on Major & $\begin{array}{l}\text { Major Rd } \\
\text { (no X-Walk) }\end{array}$ & $\begin{array}{l}\text { Ped did not yield } \\
\text { ROW }\end{array}$ \\
\hline & $\begin{array}{l}\text { SE } 39^{\text {th }} \\
\text { SE Francis }\end{array}$ & 4 & INJ-B & Straight on Minor & $\begin{array}{l}\text { Minor Rd } \\
\text { (no X-Walk) }\end{array}$ & Driver \\
\hline & $\begin{array}{l}\text { SE } 39^{\text {th }} \\
\text { SE Francis }\end{array}$ & 4 & INJ-B & Left-Turn from MNR & $\begin{array}{l}\text { Major Rd } \\
\text { (no X-Walk) }\end{array}$ & Driver \\
\hline
\end{tabular}

The three crashes that occur at half-signalized intersections are the types of pedestrian crashes that the FHWA is concerned with in their Final Rule (16) where it is claimed that motorists on the minor road do not give adequate attention to pedestrians crossing the street. However, this type of crash is not exclusive to half-signals as the same type of crash happened at $39^{\text {th }}$ and Francis at a minor stop controlled intersection. It does appear that the signalization at half-signals reduces the possibility of what 
appear to be more severe crashes along the major road. We do not have enough data to obtain statistically significant results on this hypothesis.

Crashes involving pedestrians at half-signals and the signalized control group are shown in Table 36.

Table 36: Pedestrian Crash Detail at Matched Signalized Group (2002-2011)

\begin{tabular}{|c|c|c|c|c|c|c|}
\hline & Location & $\begin{array}{l}\text { Int } \\
\text { Legs }\end{array}$ & $\begin{array}{l}\text { Severity } \\
\text { (\# Ped) }\end{array}$ & Vehicle Movement & $\begin{array}{l}\text { Ped Location } \\
\text { or Crossing Rd }\end{array}$ & $\begin{array}{l}\text { Failure to Yield } \\
\text { Right of Way Fault }\end{array}$ \\
\hline \multirow{5}{*}{$\begin{array}{l}0 \\
0 \\
0 \\
\frac{0}{0} \\
\frac{4}{\pi} \\
\frac{\pi}{1}\end{array}$} & $\begin{array}{l}\text { N Lombard } \\
\text { N John }\end{array}$ & 4 & INJ-B & $\begin{array}{l}\text { Left Turn from } \\
\text { MNR }\end{array}$ & Inside X-Walk & Driver \\
\hline & $\begin{array}{l}\text { N Lombard } \\
\text { N John }\end{array}$ & 4 & INJ-B & $\begin{array}{l}\text { Left Turn from } \\
\text { MNR }\end{array}$ & Inside X-Walk & Driver \\
\hline & $\begin{array}{l}\text { NE Sandy } \\
\text { NE 50th }\end{array}$ & 4 & INJ-C & $\begin{array}{l}\text { Left-Turn from } \\
\text { MNR }\end{array}$ & Inside X-Walk & Driver \\
\hline & $\begin{array}{l}\text { NE Sandy } \\
\text { NE 50th }\end{array}$ & 4 & INJ-C & $\begin{array}{l}\text { Left-Turn from } \\
\text { MNR }\end{array}$ & Inside X-Walk & Driver \\
\hline & $\begin{array}{l}\text { NE Sandy } \\
\text { NE 50th }\end{array}$ & 4 & $\begin{array}{l}\text { INJ-B } \\
(2) \\
\end{array}$ & $\begin{array}{l}\text { Left-Turn from } \\
\text { MNR }\end{array}$ & Inside X-Walk & Driver \\
\hline $\begin{array}{c}\text { Sig } \\
\text { Group }\end{array}$ & $\begin{array}{l}\text { NE US Grant } \\
\text { NE 33rd }\end{array}$ & 4 & INJ-B & Straight on Major & $\begin{array}{l}\text { Inside X-Walk } \\
\text { (on Major) }\end{array}$ & $\begin{array}{l}\text { Pedestrian } \\
\text { disregard signal }\end{array}$ \\
\hline
\end{tabular}

In the signalized comparison group, all pedestrian crashes occurred as a vehicle was turning left from the minor street. The fully-signalized group does not have these types of crashes in this sample. There may be evidence that these left-turn from the minor street crashes are more of a risk at half-signalized intersections. However, there is not enough data to test this hypothesis and also caution that all of the observed crashes at half-signals in this sample occurred at two intersections. 


\subsubsection{Summary of Crash History and Rates at Matched Comparison Sites}

From this matched comparison, results yielding statistical significance are shown

\section{in Table 37.}

Table 37: Significant Findings from Matched Comparison

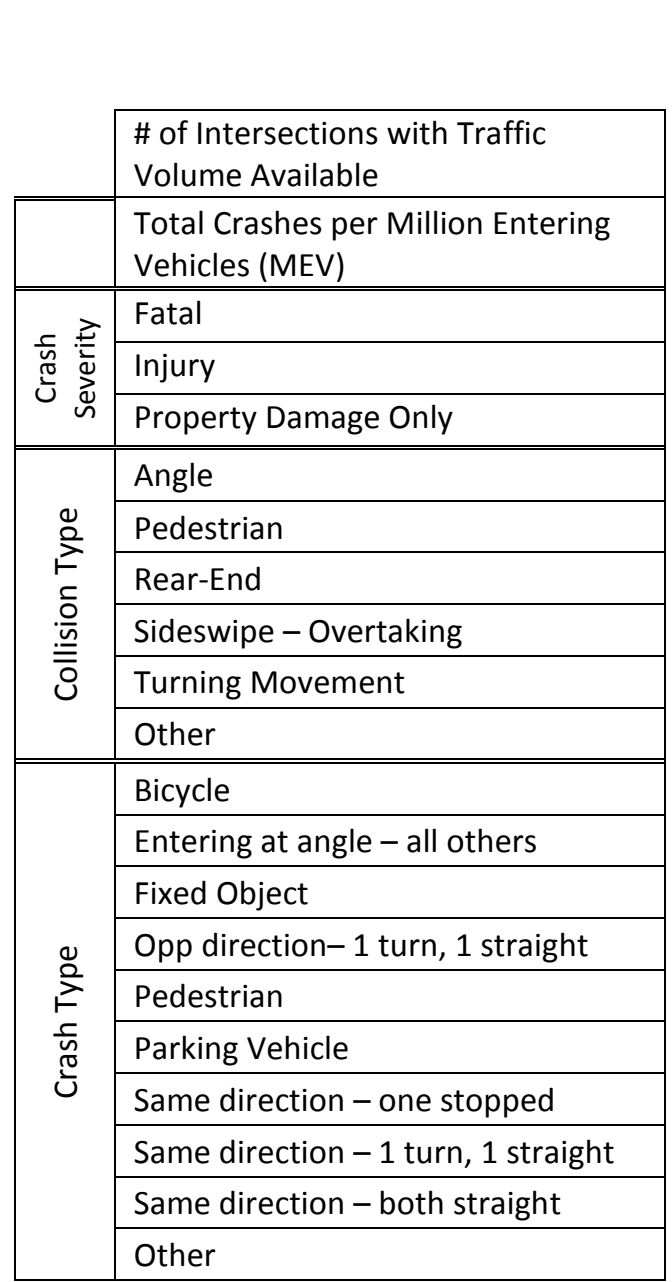

+Significant findings with total crashes
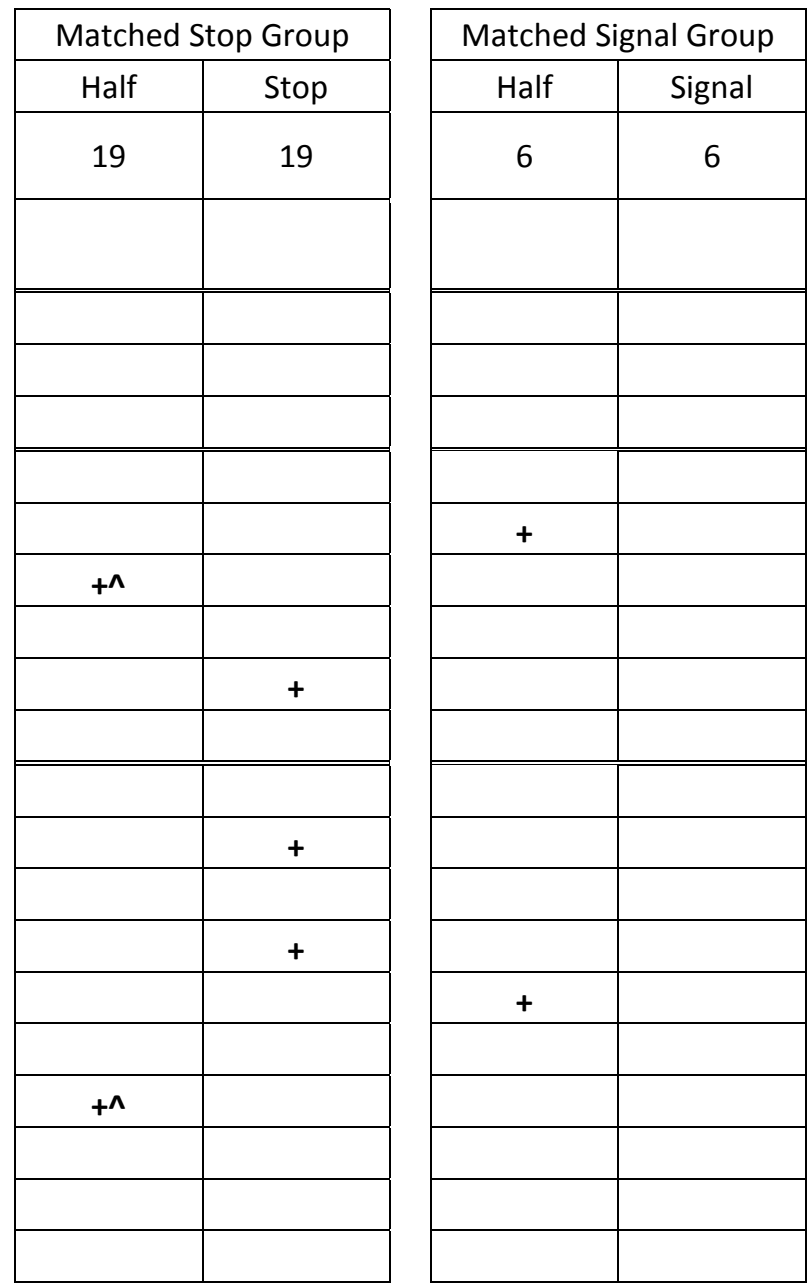

^Significant findings with crash rate (per MEV) 
Results from the matched comparison showed that the half-signalized group had more rear-end crashes when compared with the minor stop controlled group. This was the only result that held significance when crash rates were considered. It was also observed that the minor stop controlled group had a higher proportion of angle crashes when compared with the half-signal group. There was no observed increase in crash severity due to more angle crashes. Also, pedestrian crashes were more prevalent in the half-signal group when compared with the fully-signalized group. Pedestrian volumes were not available which would be used to determine if this significant measure is a result of higher pedestrian use at half-signals.

Crash rates generated through this matched group comparison are shown in Table 38.

Table 38: Matched Comparison Crash Rates (2002-2011)

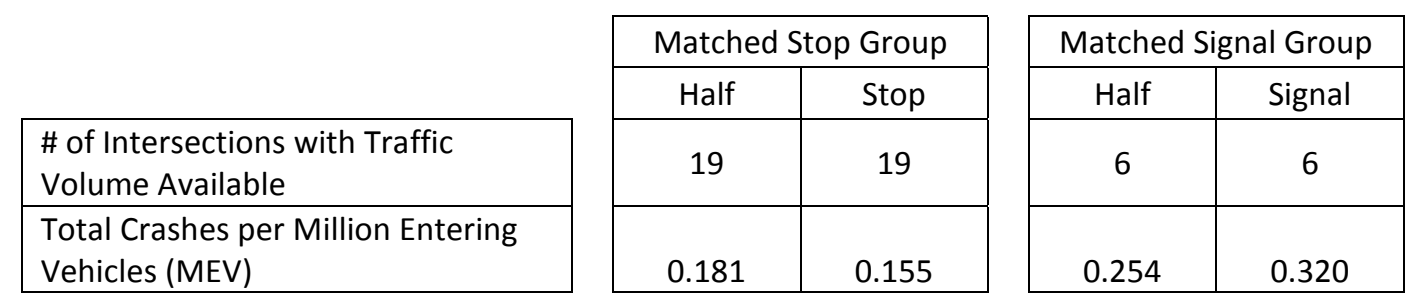

The half-signal group has a slightly higher crash rate than the matched minor stop controlled group and a slightly lower crash rate than the matched signalized group, 
These results do not suggest that converting half-signals to minor stop controlled intersections will lower crash rates nor do they suggest that converting a half-signal to a fully signalized intersection will increase crash rates at that site.

Crash rates have similar characteristics to what was found in Tucson (24) at pedestrian hybrid beacons (PHB). In Tucson at PHBs there were 0.223 crashes per million entering vehicles and pedestrians compared to nearby minor stop controlled intersections with 0.150 crashes/MEV\&P. The crash rate at pedestrian hybrid beacon sites ( 0.223 crashes/MEV\&P) was lower than the crash rate at signalized intersections ( 0.716 crashes/MEV\&P). The inclusion of pedestrian counts into developed rates accounted for approximately $0.5-1.0 \%$ of the total intersection traffic. Converting crash rates from million entering vehicles and pedestrians to million entering vehicles would be expected to increase crash rates shown here approximately $0.5-1.0 \%$. In the PHB study, sites for minor stop controlled and signalized intersections were subjectively chosen in an attempt to closely match conditions at pedestrian hybrid beacons. 


\subsection{VIDEO ANALYSIS}

Recognizing that crash data alone, and specifically pedestrian crash data, would be insufficient to determine safety performance at half-signalized intersections due to the rarity of pedestrian crash events, video footage was collected by the Portland Bureau of Transportation (PBOT) at five half-signalized intersections in Portland,

Oregon. The sites are listed in Table 39 and were chosen for a variety of reasons not limited to crash history, whether it was commercial or school crossing, PBOT needs, and potential future needs.

Table 39: Video Analysis Half-Signal Intersections

\begin{tabular}{|l|l|l|l|l|}
\hline Location & Date & $\begin{array}{l}\text { Hours of } \\
\text { Footage }\end{array}$ & Weather & $\begin{array}{l}\text { Temperature } \\
\left(\text { High/Low }^{\circ} \mathrm{F} \text { ) }\right.\end{array}$ \\
\hline $\begin{array}{l}\text { SE Tacoma } \\
\text { SE 15th }\end{array}$ & $02 / 11 / 11$ & 24 & Overcast & $51 / 34$ \\
\hline $\begin{array}{l}\text { SE Division } \\
\text { SE 28th }\end{array}$ & $03 / 09 / 11$ & 72 & $\begin{array}{l}\text { Light } \\
\text { Rain }\end{array}$ & $57 / 39$ \\
\hline $\begin{array}{l}\text { SE 33rd } \\
\text { SE Hancock }\end{array}$ & $03 / 15 / 11$ & 24 & $\begin{array}{l}\text { Light } \\
\text { Rain }\end{array}$ & $53 / 43$ \\
\hline $\begin{array}{l}\text { N Lombard } \\
\text { N Drummond }\end{array}$ & $03 / 17 / 11$ & 24 & $\begin{array}{l}\text { Light } \\
\text { Rain }\end{array}$ & $50 / 38$ \\
\hline $\begin{array}{l}\text { NE Sandy } \\
\text { NE 50th }\end{array}$ & $04 / 05 / 11$ & 36 & $\begin{array}{l}\text { Mostly } \\
\text { Cloudy }\end{array}$ & $53 / 41$ \\
\hline
\end{tabular}

Video cameras were pole mounted close to each of the five half-signal intersections along the major street. It was requested that the signal head, pedestrian 
movements, and vehicles from major and minor roads be visible. A screen capture from each half-signal intersection is shown in Figure 13.

Page 91 


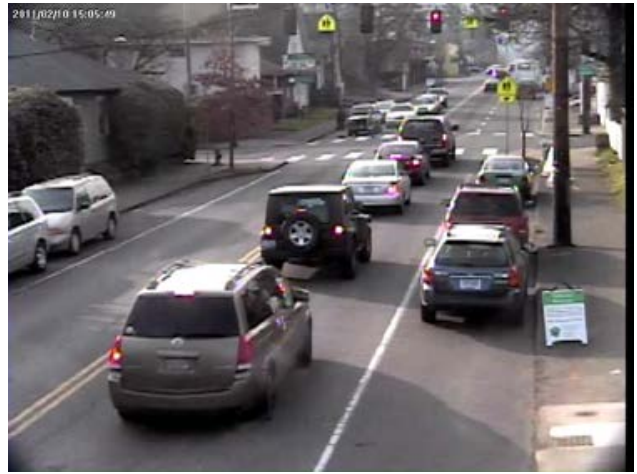

SE Tacoma and SE 15th

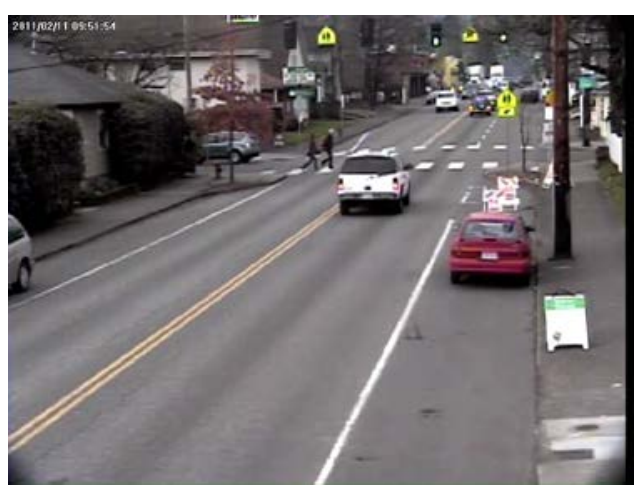

SE 33rd and SE Hancock

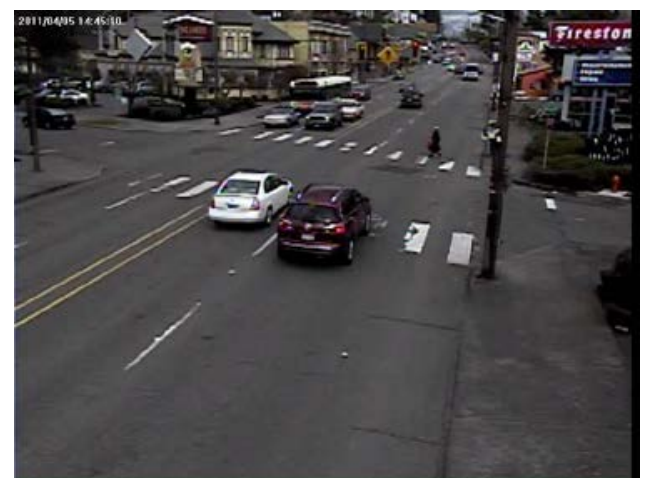

NE Sandy and NE 50th

Figure 13: Sample Screen Captures from Half-Signals

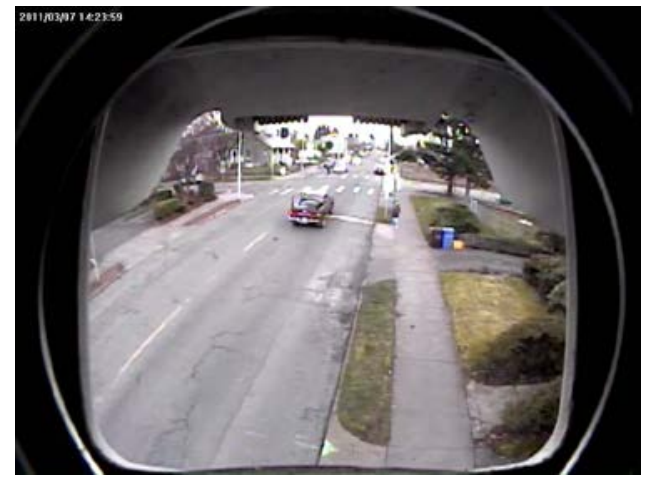

SE Division and SE 28th

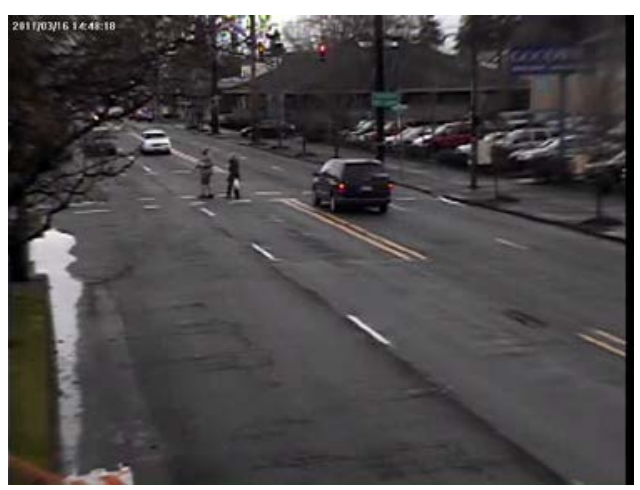

N Lombard and N Drummond 
The analysis of video allows for two aspects of half-signals to be evaluated.

Driver expectancy issues at half-signals are addressed via a conflict study. Motorist stop sign compliance on the minor road is evaluated using a logistic regression model. Safety concerns for pedestrians and vehicles crossing the major road are why half-signals are not currently an accepted policy in most of the United States (16) and these concerns are what prompted the development of a stop sign compliance logistic regression model.

\subsection{Conflict and Compliance Study}

A conflict is an instance where a sudden change of direction or speed by a road user occurs due to the actions of another road user and without this sudden change a collision would have occurred. In conflict studies, conflicts are generally grouped into mild, moderate, and severe types depending on the intensity of the sudden change of direction or speed. Avoidance maneuvers are typically in the same realm as conflicts but these are changes of direction or speed that are not necessarily sudden and would not necessarily result in a collision but are actions taken by one road user in reaction to the presence of another (40). An example of an avoidance maneuver would be a vehicle yielding to a pedestrian crossing the roadway. In pedestrian conflict studies it is oftentimes difficult to separate conflicts from avoidance maneuvers for certain types of 
actions from pedestrians. This is in contrast to vehicles and sometimes bicycles where changes in speeds or direction are clearly noticed.

A conflict study has already been performed in 1977 in Seattle, WA and Lincoln, NE at two half-signal locations (8). This study took six hours of data over three days at the two locations and looked at pedestrian conflicts dealing with hesitation or reversal on part of the pedestrian. Angle, turning, and rear-end conflicts between automobiles were analyzed. Compliance measures studied included pedestrian adherence to the Walk/Do Not Walk signal and vehicle compliance of the traffic signal. The conflict study here expands on this analysis.

In looking at conflicts at half-signals the goal here is to expand upon trends in the crash data analysis and to determine what types of safety problems exist at half-signals. From the crash data it was noted that:

- Rear-end crash potential may be high along the major road at half-signal intersections.

- Turning crash potential from the minor road and motorist's failure to yield may be the largest concern for pedestrians crossing the major road

- Red-light violation frequency may be high, 
- Permissive left-turn movements from the major road appear to be the largest cause of turning crashes regardless of traffic control device.

These observations, Oregon State Law, and previous work done by Petzold and Nawrocki (8) assist with the development of conflicts and avoidance maneuvers to analyze and these are listed and explained in Table 40.

\section{Table 40: Half-Signal Conflict Measures}

\begin{tabular}{|c|c|c|}
\hline & Conflict Type & Explanation \\
\hline \multirow{3}{*}{ 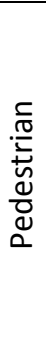 } & $\begin{array}{l}\text { Reversal or } \\
\text { Hesitation }\end{array}$ & $\begin{array}{l}\text { A pedestrian on the road or entering the road reverses direction or } \\
\text { hesitates in response to a vehicle in the traffic lane. }\end{array}$ \\
\hline & Turning Conflict & $\begin{array}{l}\text { A pedestrian is in the path of a turning vehicle in motion with less than } 6 \\
\text { feet separating them. Six feet comes from Oregon Senate Bill 591[29]. }\end{array}$ \\
\hline & $\begin{array}{l}\text { Pedestrian Crossing } \\
\text { Illegal }\end{array}$ & $\begin{array}{l}\text { A pedestrian enters the roadway without right-of-way on the Do Not } \\
\text { Walk or flashing Do Not Walk phase forcing the motorist on major road } \\
\text { to abruptly stop, change direction, or delay accelerating when the signal } \\
\text { changes to green. }\end{array}$ \\
\hline \multirow{3}{*}{ 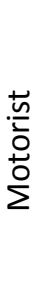 } & Rear-End & $\begin{array}{l}\text { A vehicle traveling straight noticeably and suddenly decelerates in } \\
\text { response to another vehicle or traffic signal condition. }\end{array}$ \\
\hline & $\begin{array}{l}\text { Minor Street Angle } \\
\text { or Turning Conflict }\end{array}$ & $\begin{array}{l}\text { A vehicle on the major road has to change direction or speed abruptly } \\
\text { due to a vehicle from the minor road turning right, left, or straight. }\end{array}$ \\
\hline & Green Trap & $\begin{array}{l}\text { A vehicle entering the intersection from the minor street is caught in the } \\
\text { intersection when the signal on the major street changes from red to } \\
\text { green. }\end{array}$ \\
\hline
\end{tabular}

For rear-end conflicts, the configuration of the video setup was elevated from the intersection and the camera was only focused in one direction and as such any rearend conflicts aside from the most severe of decelerations were not captured. 
In addition to conflicts, compliance measures that are unique to half-signal intersections or affect pedestrian safety are listed in Table 41.

\section{Table 41: Half-Signal Compliance Measures}

\begin{tabular}{|l|l|}
\hline Compliance Type & Explanation \\
\hline Pedestrian Signal Violation & $\begin{array}{l}\text { Instance where a pedestrian leaves the sidewalk during the Do Not Walk } \\
\text { Phase. Pedestrians entering on Flashing Do Not Walk were not counted } \\
\text { as a violation because video cameras were not setup to view the } \\
\text { pedestrian signal head. }\end{array}$ \\
\hline Motorist Signal Violation & $\begin{array}{l}\text { Instance where the motorist enters the intersection, wheels crossing the } \\
\text { pedestrian crossing or stop bar, on red. Oregon is a restrictive yellow } \\
\text { state, however red violations were more accurately measured as a clear } \\
\text { violation of the signal. }\end{array}$ \\
\hline Motorist Actuations & $\begin{array}{l}\text { Instance where that the driver or passenger of a motor vehicle exits } \\
\text { from their car and actuates the pedestrian signal. }\end{array}$ \\
\hline $\begin{array}{l}\text { Motorist Stopping on } \\
\text { Green }\end{array}$ & $\begin{array}{l}\text { Motorist stops on the green signal to wave pedestrians across } \\
\text { intersection. }\end{array}$ \\
\hline
\end{tabular}

\subsubsection{Conflict Study at Half-Signals in Portland, Oregon}

Using the aforementioned conflict measures, twenty-four hours of video at each

of the five half-signal intersections were analyzed. Although slightly more than the twenty-four hours of video at each signal were available, in order to develop rates, this conflict study was limited to twenty-four hours in one day. Vehicle, pedestrian, and bicycle counts were collected along with vehicle turning movements. The number of times that the signal was actuated by pedestrians was also counted. General 
information for the intersection, the number of conflicts, compliance measures, and counts are shown in Table 42.

Table 42: Characteristics, Conflicts, and Counts at Five Half-Signal Locations

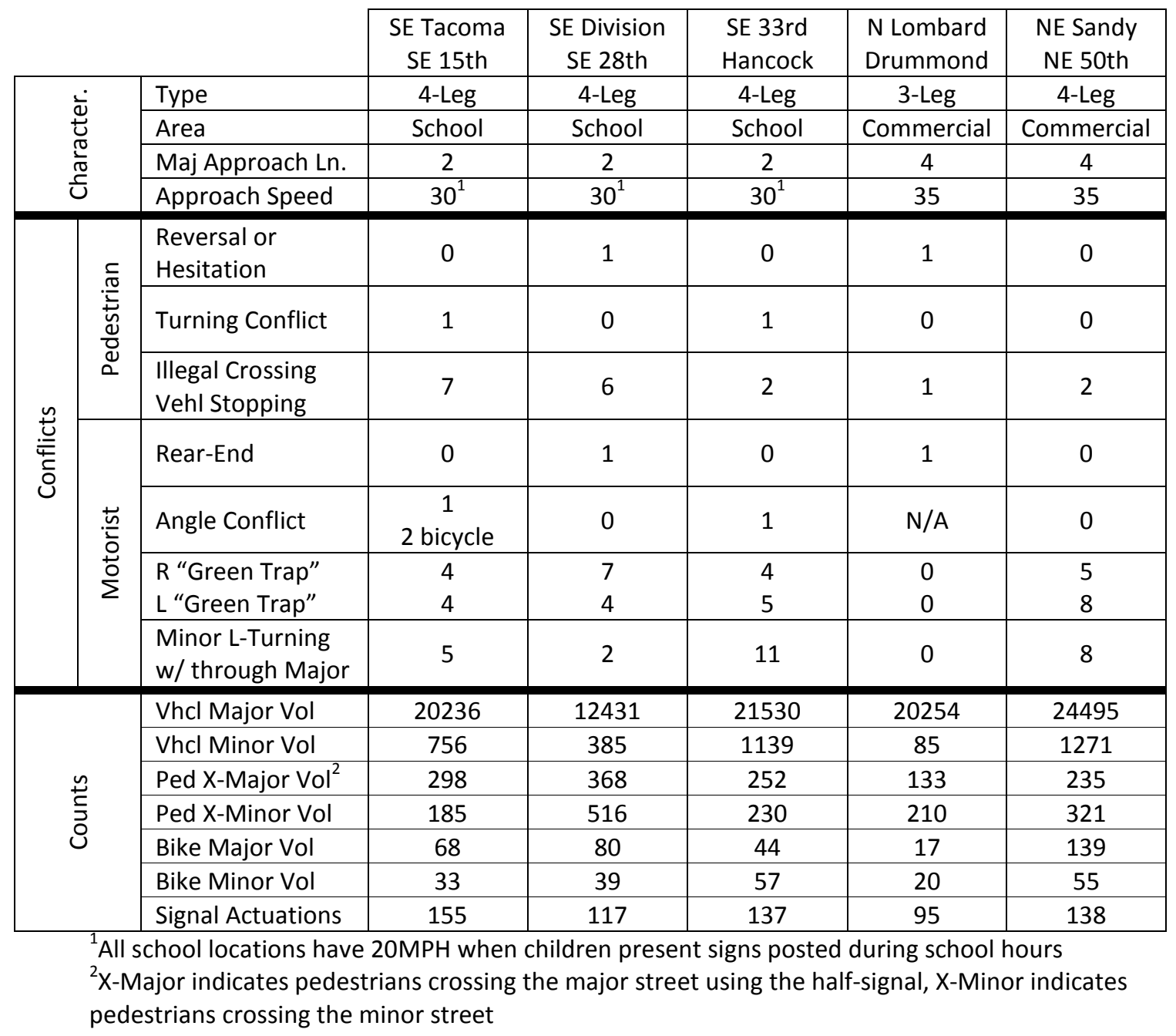

Conflicts occurring when pedestrians used half-signals as intended appeared to occur at very low rates. Four pedestrian-vehicle conflicts were observed involving 
turning vehicles or through vehicles (reversal or hesitation) across 1286 pedestrian crossing events in five days. One location had one pedestrian conflict caused by a motorist running a red light and this led to a conflict rate of $0.7 \%$ measured as the number of pedestrian conflicts divided by the pedestrian volume crossing the major street. Other locations had conflict rates around $0.3 \%$ and these conflicts were caused by right turning vehicles from the minor street. There were no observed vehiclepedestrian conflicts with left-turning vehicles from the minor road. Left-turning vehicles from the minor road involved in crashes with pedestrians were observed in the crash history but were not noticed in this conflict study.

These conflict observations are much lower than what was found in the Petzold and Nawrocki study (8) which observed between 1-2\% of crossing pedestrians having a reversal or hesitation and $1-3 \%$ of crossing pedestrians having a turning vehicle within 10 feet of them. One limitation of this study with video data as compared to being on the ground was that small reversals or hesitations could not be determined with video.

The other type of pedestrian conflict where pedestrians crossed the street without the right-of-way causing a vehicle in traffic to slow, stop, or remain stopped occurred 18 times in 1286 crossings or for $1.4 \%$ of pedestrian crossings. Petzold and Nawrocki used a different metric noting when pedestrians were crossing the street 
without the right-of-way when a vehicle was $1 / 2$ block away. In that study, this instance occurred in $1.4-3.2 \%$ of pedestrian crossings. At semi-actuated signals in the same study this situation happened in $1.4-4.1 \%$ of crossings. It appears that these types of pedestrian violating right-of-way crossing conflicts are to some extent a byproduct of signalization at either half or fully signalized locations. In any case, the crash record at half-signals did not indicate that pedestrian violations are a major concern with respect to crashes.

Looking at motor vehicle conflicts, the green trap was the most observed "conflict" at half-signalized intersections. However, the number of times that vehicles were caught in the green trap was a very small percentage of overall minor street traffic volumes. Furthermore, because of delayed response times by queued vehicles on the major street and relatively low speeds at these intersections, the green trap did not appear to be cause for concern with respect to crashes.

Another observed motor vehicle conflict occurred when left-turning vehicle from the minor road turned into the path of a vehicle on the major road. At two locations, Tacoma and 15th and 33rd and Hancock, these conflicts were more pronounced due to queued vehicles backing up from nearby signals on the major street which obstructed the view of motorists on the minor street to traffic in the far lane on the major street. 
The vehicle on the minor street in many instances decided to proceed after stopping at the stop sign without being able to see traffic in the far lane. After proceeding halfway into the intersection, the vehicle nosed into the far lane and caused conflicts with motorists proceeding through the intersection on a green signal. It is unclear to what extent this is unique with half-signal intersections when compared with minor stop controlled intersections. It was not possible to determine if motorists on the major street were expecting to see a vehicle turning left from the minor road in front of them while having a green signal, however all of these motorists on the major street did avoid this conflict by changing course. These conflicts due to queuing happened to five vehicles and two bicycles at two intersections.

To illustrate this conflict type, a series of still images are shown in Figure 14 from SE Tacoma St and SE 15th Ave. 


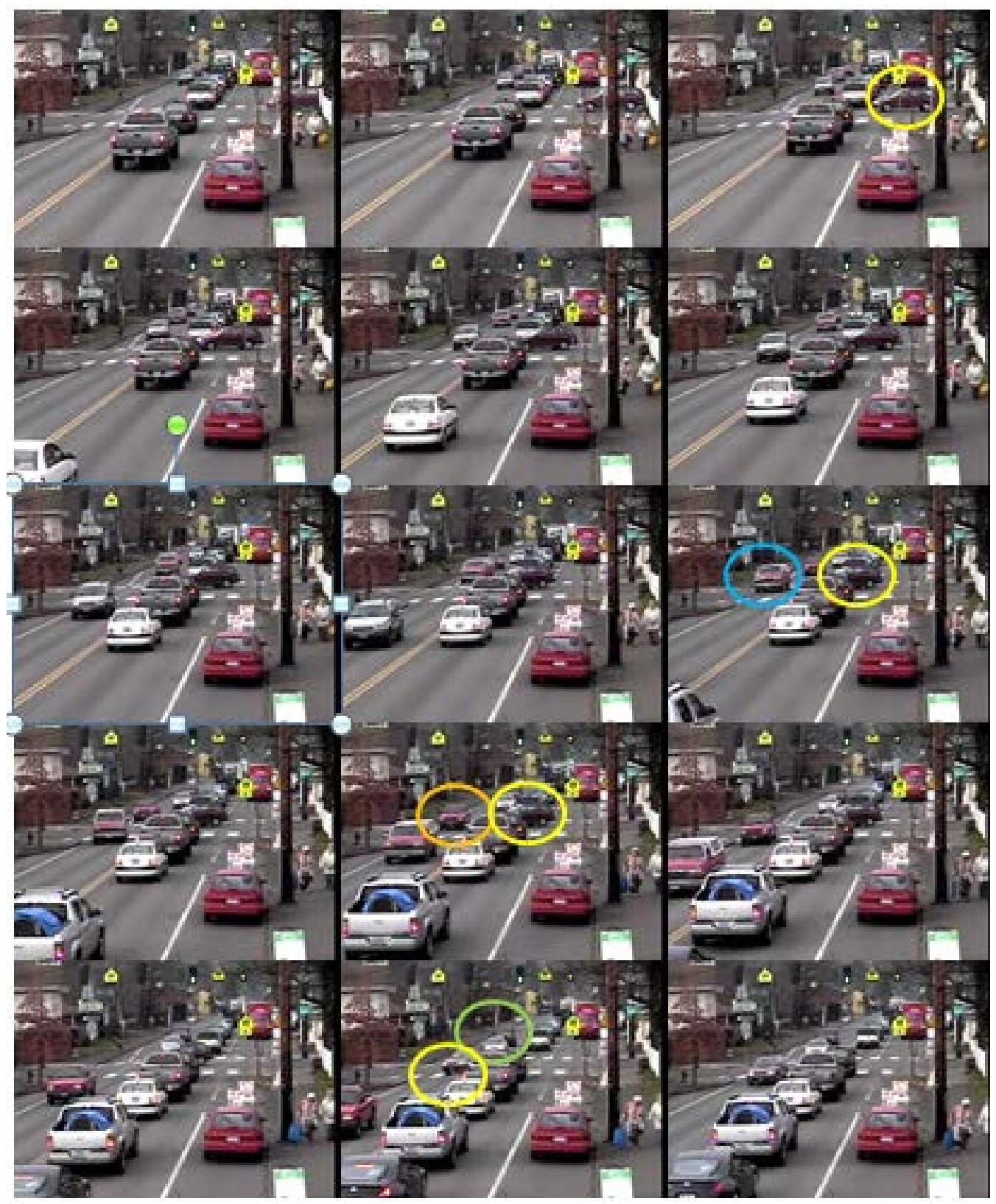

Figure 14: Left-Turning Conflict due to queuing at SE 15th and Tacoma Portland, OR

Page 101 
The vehicle causing a conflict is a red Subaru (circled in yellow) and enters the picture from the minor street on the right side of the photographs. The ninth frame shows an orange and white truck (circled in blue) and the eleventh frame shows a red SUV (circled in orange) both altering their course in response to the red Subaru. The silver car (circled in green) behind these two vehicles stops on the green allowing the red Subaru to complete the left turn. This type of conflict in places where queuing backups are a problem could be eliminated by prohibiting left and through movements at that intersection.

Aside from the aforementioned vehicle-vehicle type of conflict, there were a few left and right turns where motorists on the minor road were willing to accept small gaps in traffic causing major street traffic to adjust to these entering vehicles. No relationship was made between the gap acceptance and motor vehicle delays at half-signals although this is known to be related.

One observed and not understood behavior in Table 42 is that there were a seemingly high number of motorists that turned left onto the minor road from the major road on the red signal after stopping at the red signal. It is unknown to what extent this happens at fully-signalized intersections with permissive left turns. 


\subsubsection{Compliance Study at Half-Signals in Portland, Oregon}

Compliance data and counts are shown in Table 43,

Table 43: Compliance and Counts at Five Half-Signal Locations

\begin{tabular}{|c|c|c|c|c|c|c|}
\hline & & $\begin{array}{l}\text { SE Tacoma } \\
\text { SE 15th }\end{array}$ & $\begin{array}{l}\text { SE Division } \\
\text { SE 28th }\end{array}$ & $\begin{array}{l}\text { SE } 33^{\text {rd }} \\
\text { Hancock }\end{array}$ & $\begin{array}{l}\text { N Lombard } \\
\text { Drummond }\end{array}$ & $\begin{array}{l}\text { NE Sandy } \\
\text { NE 50th }\end{array}$ \\
\hline \multirow{4}{*}{ 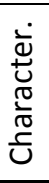 } & Type & 4-Leg & 4-Leg & 4-Leg & 3-Leg & 4-Leg \\
\hline & Area & School & School & School & Commercial & Commercial \\
\hline & Maj Approach Ln. & 2 & 2 & 2 & 4 & 4 \\
\hline & Approach Speed & $30^{1}$ & $30^{1}$ & $30^{1}$ & 35 & 35 \\
\hline \multirow{5}{*}{ 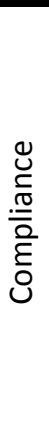 } & $\begin{array}{l}\text { Pedestrian Signal } \\
\text { Violation }\end{array}$ & 84 & 68 & 46 & 8 & 44 \\
\hline & $\begin{array}{l}\text { Motorist Signal } \\
\text { Violation }\end{array}$ & 23 & 9 & 13 & 5 & 21 \\
\hline & L Turn on Red & 1 & 1 & 3 & 1 & 1 \\
\hline & $\begin{array}{l}\text { Motorist Signal } \\
\text { Actuation }\end{array}$ & 1 & 0 & 3 & 0 & 4 \\
\hline & $\begin{array}{l}\text { Motorist stopping } \\
\text { on green for ped }\end{array}$ & 7 & 2 & 1 & 1 & 0 \\
\hline \multirow{7}{*}{\begin{tabular}{l}
$\stackrel{n}{c}$ \\
\multirow{3}{0}{} \\
0
\end{tabular}} & Vhcl Major Vol & 20236 & 12431 & 21530 & 20254 & 24495 \\
\hline & Vhcl Minor Vol & 756 & 385 & 1139 & 85 & 1271 \\
\hline & Ped X-Major Vol ${ }^{2}$ & 298 & 368 & 252 & 133 & 235 \\
\hline & Ped X-Minor Vol & 185 & 516 & 230 & 210 & 321 \\
\hline & Bike Major Vol & 68 & 80 & 44 & 17 & 139 \\
\hline & Bike Minor Vol & 33 & 39 & 57 & 20 & 55 \\
\hline & Signal Actuations & 155 & 117 & 137 & 95 & 138 \\
\hline
\end{tabular}

Signal violations by pedestrians at the five half-signals are upon first inspection seemingly high. Violation rates by pedestrians at the five half-signals are shown in Table 44 and defined as the number of pedestrians leaving the curb during or after the "Do Not Walk" phase divided by the total number of pedestrians using the signal. The 
number of pedestrians entering the intersection during the flashing "Do Not Walk" signal was not collected in this study.

Table 44: Pedestrian Signal Violation Rate

\begin{tabular}{|c|c|c|c|c|c|}
\cline { 2 - 5 } \multicolumn{1}{c|}{} & $\begin{array}{c}\text { SE Tacoma } \\
\text { SE 15th }\end{array}$ & $\begin{array}{c}\text { SE Division } \\
\text { SE 28th }\end{array}$ & $\begin{array}{c}\text { SE 33rd } \\
\text { Hancock }\end{array}$ & $\begin{array}{c}\text { N Lombard } \\
\text { Drummond }\end{array}$ & $\begin{array}{c}\text { NE Sandy } \\
\text { NE 50th }\end{array}$ \\
\hline $\begin{array}{c}\text { Pedestrian Signal } \\
\text { Violation Rate }\end{array}$ & $28 \%$ & $18 \%$ & $18 \%$ & $6 \%$ & $19 \%$ \\
\hline
\end{tabular}

Violation rates are typically associated with the delay that pedestrians experience waiting for a signal to change. Other studies have observed similar violation rates at fully signalized intersection with $6-21 \%$ of pedestrians violating the "Do Not Walk" phase (41). The Petzold and Nawrocki study (8) measured 10.3\%- 22.0\% pedestrian violations at half-signals and $25.7 \%-32.8 \%$ violation rates at reference semiactuated fully signalized control sites. Violation rates are averaged across all five locations and plotted throughout the day with major street traffic and this is shown in Figure 15. 


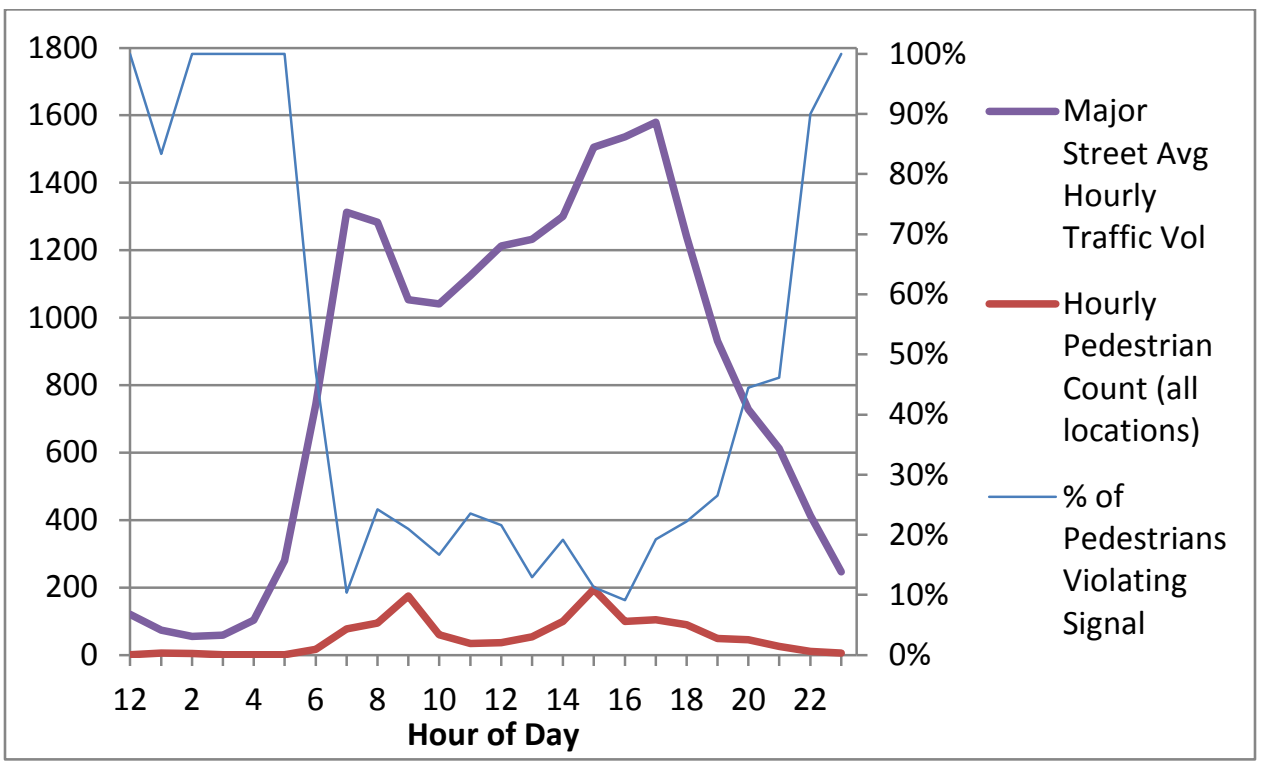

Figure 15: Pedestrian Signal Violation Rate by Hour of Day

From Figure 15, on average, there were not particular peak times during daylight hours such as peak pedestrian times when pedestrian signal violation rates were higher. During the nighttime when there are lower traffic volumes, violation rates were high but pedestrian volumes were also low.

\subsubsection{Vehicle Compliance Observations}

Red-light violation rates ranged from 0.96-4.05 violations per 1000 vehicles at the five half-signals. In other studies at fully signalized intersections, violation rates have 
been found from $0.45-38.50$ violations per 1,000 vehicles but in most cases were around $1-3$ violations per 1,000 vehicles (42).

Another way to measure signal violations is by the number of red light violations compared with the number of signal actuations. These percentages are shown in Table 45. As a comparison, a study at fully signalized intersections found that $35.2 \%$ of signal cycles had at least one red-light violation (42). A benefit of half-signals is the reduction of signal cycles if installed in suitable locations.

Table 45: Percent of Actuated Phases with Half-Signal Red Light Violations by Motor Vehicles

\begin{tabular}{|c|c|c|c|c|c|}
\cline { 2 - 5 } \multicolumn{1}{c|}{} & $\begin{array}{c}\text { SE Tacoma } \\
\text { SE 15th }\end{array}$ & $\begin{array}{c}\text { SE Division } \\
\text { SE 28 }\end{array}$ & $\begin{array}{c}\text { SE 33rd } \\
\text { Hancock }\end{array}$ & $\begin{array}{c}\text { N Lombard } \\
\text { Drummond }\end{array}$ & $\begin{array}{c}\text { NE Sandy } \\
\text { NE 50th }\end{array}$ \\
\hline $\begin{array}{c}\% \text { of Pedestrian } \\
\text { Signals Cycles with } \\
\text { Red Light Violations }\end{array}$ & $14 \%$ & $8 \%$ & $9 \%$ & $5 \%$ & $14 \%$ \\
\hline
\end{tabular}

To get a clearer picture of motor vehicle compliance to the signal, the time after the red light that a motor vehicle went through the signal is shown in Table 46. 
Table 46: Distribution of Red Light Violations by Time Elapsed after Red Onset

\begin{tabular}{|l|l|l|l|l|}
\hline \multicolumn{2}{|l|}{} & \multicolumn{2}{l|}{ Half Signal } & \multicolumn{2}{l|}{$\begin{array}{l}\text { Sacramento Dataset } \\
\text { RITA/Volpe (42) }\end{array}$} \\
\hline After-Red Time & $\begin{array}{l}\text { Counted } \\
\text { Violations }\end{array}$ & $\begin{array}{l}\text { Percent of } \\
\text { Distribution }\end{array}$ & $\begin{array}{l}\text { Counted } \\
\text { Violations }\end{array}$ & $\begin{array}{l}\text { Percent of } \\
\text { Distribution }\end{array}$ \\
\hline$\leq 2.0$ seconds & 61 & $83.5 \%$ & 44,294 & $94.2 \%$ \\
\hline 2.1 to 5.0 seconds & 4 & $5.5 \%$ & 1,270 & $2.7 \%$ \\
\hline$>5.0$ seconds & 8 & $11.0 \%$ & 1,433 & $3.0 \%$ \\
\hline
\end{tabular}

Significant at $\alpha=.05 p=0.0009501$

These results from half signals in Table 46 are not comparable with typical redlight violation data. One thing that did seem unusual at half-signals were the number of vehicles that made a left-turn after being stopped on the major street more than 5 seconds after the signal had been red. These are not vehicles that were making permissive lefts and waited until oncoming traffic was clear. These were vehicles that stopped behind the pedestrian crossing, allowed pedestrians to cross the intersection and then made a left on red. These left turn on red maneuvers occurred at all five intersections where video was captured which included four 4-leg intersections and one 3-leg intersection. It seemed like vehicles performed this maneuver to make it through the intersection before the queued opposing traffic. This maneuver was likely performed by motorists familiar with the intersection and who made the maneuver because there was not as great of a risk in colliding with minor street traffic. It is 
unknown to what condition this exists at fully signalized intersections with lower minor street traffic volumes.

Table 47: Distribution of Red Light Violations by Time Elapsed after Red Onset without Left on Red Violations

Insignificant at $\alpha=.05 \mathrm{p}=0.6335$

\begin{tabular}{|l|l|l|l|l|}
\hline & \multicolumn{2}{|l|}{$\begin{array}{l}\text { Half Signal without } \\
\text { Left Turn on Red } \\
\text { Violations }\end{array}$} & \multicolumn{2}{l|}{$\begin{array}{l}\text { Sacramento Dataset } \\
\text { RITA/Volpe (42) }\end{array}$} \\
\hline After-Red Time & $\begin{array}{l}\text { Counted } \\
\text { Violations }\end{array}$ & $\begin{array}{l}\text { Percent of } \\
\text { Distribution }\end{array}$ & $\begin{array}{l}\text { Counted } \\
\text { Violations }\end{array}$ & $\begin{array}{l}\text { Percent of } \\
\text { Distribution }\end{array}$ \\
\hline$\leq 2.0$ seconds & 61 & $91.6 \%$ & 44,294 & $94.2 \%$ \\
\hline 2.1 to 5.0 seconds & 3 & $4.5 \%$ & 1,270 & $2.7 \%$ \\
\hline$>5.0$ seconds & 2 & $3.0 \%$ & 1,433 & $3.0 \%$ \\
\hline
\end{tabular}

One thing to make clear is that it does not appear that the signal is treated differently than a fully signalized intersection by the majority of motorists. When the abnormal left turn on red violations are removed from this analysis, the signal appears to have compliance equivalent to a regular signal as shown in Table 47. This left turn on red phenomenon at pedestrian beacons has not been studied. With less motorist familiarity with pedestrian hybrid beacons and the same low volumes on cross streets, left turn on red violations may also be present at pedestrian hybrid beacons. 


\subsection{Stop Sign Compliance Logistic Regression Model}

The final aspect of this analysis concerns stop compliance by motorists on the minor street. The MUTCD and Final Rule state that motorists on the minor road, facing the inability to cross the major stream of traffic, could utilize the pedestrian signal, may not come to a complete stop, and not give adequate attention to pedestrians crossing the street $(17,43)$. The assertion that pedestrians are not given adequate attention is specifically what this logistic regression model addresses. Since pedestrian-vehicle conflicts happen almost exclusively during the pedestrian phase, the unique aspect of a half-signal comes about when major street traffic is stopped during the pedestrian phase and a motorist arrives at the minor street. The question beckons, how do motorists on the minor road treat this phase? Are there certain conditions where the motorist is more or less prone to stopping?

\subsubsection{Methodology}

A model of vehicle stop compliance on the minor road during the pedestrian phase was developed. The goal was to determine if pedestrian presence, vehicle movement, queue position, stopped vehicles, and/or vehicle type have any influence on the minor street motorist's decision of stopping. 
A logit model was developed which follows in the vein of other pedestrian safety models that have looked into motorist yielding around crosswalks (44)(45). In this case, the dependent variable is stop sign compliance. Stop sign compliance is a binary result in that either a vehicle stopped or it did not. Stop sign compliance was a somewhat subjective measure, as rolling stops within reason were counted as valid stops. This rolling stop allowance mirrors the definition used be Voss and Parks in their study of stop compliance at half-signals in Vancouver, B.C. (23).

Independent variables included vehicle arrival and departure times, queue position, vehicle movement, pedestrian presence crossing the minor and major streets, if a vehicle was stopped at the signal on the major road, and if there was a vehicle across the intersection on the minor road. Since it was noticed that around school times there is a definite peak for pedestrian activities at the half-signal, an independent variable was included that indicates whether it is one of the two peak school hours. This variable may have colinearity with other independent variables. An example of peak hours associated with school activity is shown below in Figure 16. 


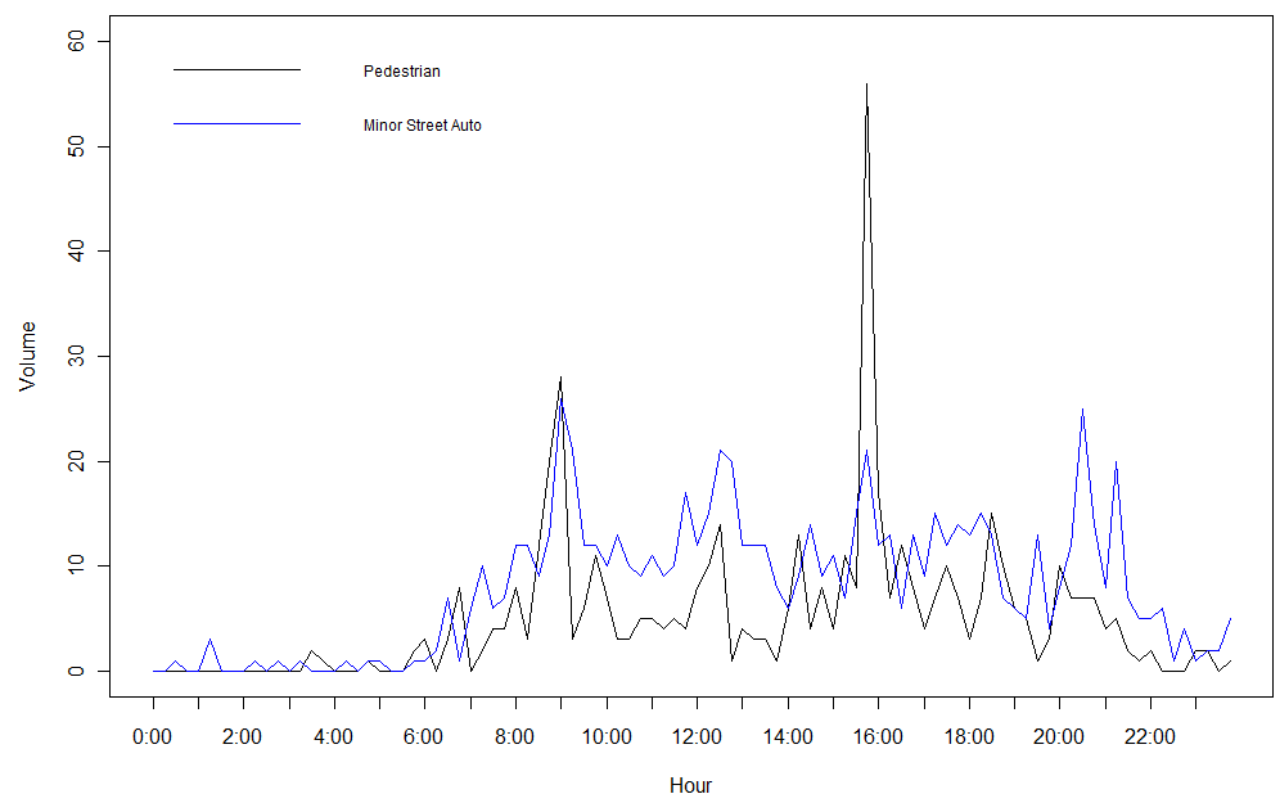

Figure 16: SE Tacoma and SE 15th February 11, 2011 Peak Hours 8:00-9:00 and 14:30-15:30

Pedestrian presence in the roadway was also included as an independent variable. This variable was initially categorized by whether the pedestrian was crossing the major or minor roadways and whether the vehicle yielded to the pedestrian or if the pedestrian yielded to the vehicle. However upon building the model it was realized that these data made sample sizes too small and thus all of these cases were lumped into a two Boolean variables of if a pedestrian was present in the roadway or if a pedestrian was at the curb at the arrival of a vehicle to the stop bar. Independent variables are summarized and described in Table 48. 
Table 48: Description of Independent Variables

\begin{tabular}{|c|c|c|}
\hline Independent Variable & Type & Description \\
\hline $\begin{array}{l}\text { Vehicle Arrival Time } \\
\text { (not in model) }\end{array}$ & Time (Hh:mm:ss) & $\begin{array}{l}\text { Time at which vehicle arrives at stop bar on minor } \\
\text { road }\end{array}$ \\
\hline $\begin{array}{l}\text { Vehicle Departure Time } \\
\text { (not in model) }\end{array}$ & Time (Hh:mm:ss) & $\begin{array}{l}\text { Time at which vehicle departs from stop bar on } \\
\text { minor road }\end{array}$ \\
\hline $\begin{array}{l}\text { Position of Queued } \\
\text { Vehicle }\end{array}$ & Integer & $\begin{array}{l}\text { An integer from } 0 . . . n \text { describing the vehicles } \\
\text { position in queue at the stop sign. The average } \\
\text { queue position is } 1.28 \text {. The maximum observed } \\
\text { queue is } 5 .\end{array}$ \\
\hline $\begin{array}{l}\text { Pedestrian Present } \\
\text { Crossing Major Road at } \\
\text { Vehicle Arrival Time }\end{array}$ & Binary & $\begin{array}{l}0=\text { No } \\
1=\text { Yes a pedestrian is in the major roadway when } \\
\text { vehicle arrived at stop bar and vehicle yielded to } \\
\text { pedestrian }\end{array}$ \\
\hline $\begin{array}{l}\text { Pedestrian Present } \\
\text { Crossing Street at } \\
\text { Vehicle Arrival Time }\end{array}$ & Binary & $\begin{array}{l}0=\text { No } \\
1=\text { Yes a pedestrian is in the major or minor } \\
\text { roadway when vehicle arrived at stop bar and } \\
\text { vehicle yielded to pedestrian or pedestrian is } \\
\text { present at curb and yields first to vehicle prior to } \\
\text { stepping into road }\end{array}$ \\
\hline Peak School Hour & Binary & $\begin{array}{l}0=\text { No } \\
1=\text { Yes it one of two peak pedestrian hours } \\
\text { associated with incoming and outgoing students }\end{array}$ \\
\hline $\begin{array}{l}\text { Vehicle Opposite on } \\
\text { Minor Roadway }\end{array}$ & Binary & $\begin{array}{l}0=\text { No } \\
1=\text { Yes if a vehicle is at the opposing minor roadway } \\
\text { stop bar or if vehicle has not cleared intersection by } \\
\text { time of arrival of vehicle of interest }\end{array}$ \\
\hline $\begin{array}{l}\text { Vehicle Stopped on } \\
\text { Major Road }\end{array}$ & Binary & $\begin{array}{l}0=\text { No vehicle stopped at traffic signal } \\
1=\text { Vehicle(s) is/are stopped at either traffic signal } \\
\text { approach }\end{array}$ \\
\hline Vehicle Type & Binary & $\begin{array}{l}0=\text { Car, Motorcycle } \\
1=\text { Heavy Truck, School bus, Delivery truck, etc... }\end{array}$ \\
\hline Right Turn & Binary & $\begin{array}{l}0=\text { No } \\
1=\text { Yes }- \text { vehicle of interest is making a right turn }\end{array}$ \\
\hline Left Turn & Binary & $\begin{array}{l}0=\text { No } \\
1=\text { Yes - vehicle of interest is making a left turn }\end{array}$ \\
\hline Through Movement & Binary & $\begin{array}{l}0=\text { No } \\
1=\text { Yes - vehicle of interest is making a through } \\
\text { movement }\end{array}$ \\
\hline
\end{tabular}

Page 112 
Major street traffic likely influences the stopping behavior of minor street traffic. This influence is removed by only studying vehicles on the minor street that arrive after the onset of the pedestrian phase where major road traffic, if there is traffic, is stopped at the red signal.

The positioning of cameras at intersections did not allow for the "Walk/Do Not Walk" signals to be observed. Since the traffic signal was visible at half-signals, the onset of the pedestrian phase was determined by using signal timing plans. In signal timing plans, the amber plus all-red time varied from $3.2 \mathrm{~s}$ to $3.8 \mathrm{~s}$ at the five intersections.

For each vehicle to the intersection during the pedestrian phase, dependent and independent variables were recorded. To reduce the influence of red-light running violations from the major street, vehicles whose decision to stop may have been influenced by these red-light violations were removed from this analysis.

This dataset consisted of four intersections. The intersection at Drummond and Lombard was removed from analysis since the video was not set up well to witness the arrival times of vehicles on the minor road. The remaining four four-legged intersections were at SE Tacoma and 15th; SE Division and SE 28th; SE 33rd and Hancock; and NE Sandy and NE 50th. In order to witness enough stopping behavior events and develop a model, all available video totaling 166 hours were observed. 


\subsubsection{Stop Sign Compliance Data Summary}

A summary of the information collected is shown in Table 49.

Table 49: Stop Compliance Model Data

\begin{tabular}{|c|c|c|c|c|c|}
\hline & $\begin{array}{l}\text { SE Tacoma } \\
\text { SE 15th }\end{array}$ & $\begin{array}{l}\text { SE Division } \\
\text { SE 28th PI }\end{array}$ & $\begin{array}{l}\text { NE 33RD } \\
\text { Hancock }\end{array}$ & $\begin{array}{l}\text { NE Sandy } \\
\text { NE 50th }\end{array}$ & All \\
\hline Hours of Footage & 34 & 72 & 24 & 36 & 166 \\
\hline N Observations & 93 & 119 & 128 & 228 & 568 \\
\hline $\begin{array}{l}\text { Stop Sign Violation } \\
\text { (VIOL_STOP) }\end{array}$ & $\begin{array}{l}\text { No }=56 \\
\text { Yes }=37\end{array}$ & $\begin{array}{r}\text { No }=95 \\
\text { Yes }=24\end{array}$ & $\begin{array}{r}\text { No=72 } \\
\text { Yes=56 }\end{array}$ & $\begin{array}{l}\text { No=169 } \\
\text { Yes=59 }\end{array}$ & $\begin{array}{r}\text { No }=392 \\
\text { Yes }=176\end{array}$ \\
\hline $\begin{array}{l}\text { Position of Queued } \\
\text { Vehicle (QUEUE) }\end{array}$ & $\begin{array}{r}0=80 \\
1=11 \\
2=1 \\
3=1 \\
4=0 \\
5=0\end{array}$ & $\begin{array}{r}0=66 \\
1=39 \\
2=8 \\
3=4 \\
4=2 \\
5=0\end{array}$ & $\begin{array}{r}0=56 \\
1=47 \\
2=17 \\
3=6 \\
4=2 \\
5=1\end{array}$ & $\begin{array}{r}0=172 \\
1=36 \\
2=10 \\
3=6 \\
4=3 \\
5=1\end{array}$ & $\begin{array}{r}0=374 \\
1=133 \\
2=36 \\
3=17 \\
4=7 \\
5=2\end{array}$ \\
\hline $\begin{array}{l}\text { Peak Ped Times (for } \\
\text { School) } \\
\text { (SCHOOL_PEAK) }\end{array}$ & $\begin{array}{l}\text { No }=56 \\
\text { Yes }=37\end{array}$ & $\begin{array}{l}\text { No }=56 \\
\text { Yes }=63\end{array}$ & $\begin{array}{r}\text { No=61 } \\
\text { Yes }=67\end{array}$ & $\begin{array}{r}\text { No }=228 \\
\text { Yes }=0\end{array}$ & $\begin{array}{r}\text { No }=401 \\
\text { Yes }=167\end{array}$ \\
\hline $\begin{array}{l}\text { Ped Crossing Maj or } \\
\text { Mnr Road } \\
\text { (PED_PRESENT) }\end{array}$ & $\begin{array}{l}\text { No=83 } \\
\text { Yes }=10\end{array}$ & $\begin{array}{l}\text { No=104 } \\
\text { Yes }=15\end{array}$ & $\begin{array}{r}\text { No }=120 \\
\text { Yes }=8\end{array}$ & $\begin{array}{l}\text { No=194 } \\
\text { Yes }=34\end{array}$ & $\begin{array}{r}\text { No }=501 \\
\text { Yes }=67\end{array}$ \\
\hline $\begin{array}{l}\text { Vehicle Opposite on } \\
\text { Minor Road } \\
\text { (VEHL_OPP) }\end{array}$ & $\begin{array}{l}\text { No=83 } \\
\text { Yes }=10\end{array}$ & $\begin{array}{l}\text { No=106 } \\
\text { Yes }=13\end{array}$ & $\begin{array}{l}\text { No=91 } \\
\text { Yes=37 }\end{array}$ & $\begin{array}{l}\text { No=215 } \\
\text { Yes }=13\end{array}$ & $\begin{array}{l}\text { No }=495 \\
\text { Yes }=73\end{array}$ \\
\hline $\begin{array}{l}\text { Vehicle at Signal on } \\
\text { Major Road (MAJ_ANY) }\end{array}$ & $\begin{array}{r}\text { No=0 } \\
\text { Yes=93 }\end{array}$ & $\begin{array}{r}\text { No=15 } \\
\text { Yes }=104\end{array}$ & $\begin{array}{r}\text { No=4 } \\
\text { Yes }=124\end{array}$ & $\begin{array}{r}\text { No=55 } \\
\text { Yes }=173\end{array}$ & $\begin{array}{r}\text { No=74 } \\
\text { Yes }=494\end{array}$ \\
\hline Vehicle Type (VEH) & $\begin{array}{r}\text { Car } / \text { Mot }=81 \\
\text { Truck }=12\end{array}$ & $\begin{array}{r}\text { Car/Mot }=114 \\
\text { Truck=5 }\end{array}$ & $\begin{array}{r}\text { Car/Mot }=125 \\
\text { Truck=3 }\end{array}$ & $\begin{array}{r}\text { Car/Mot }=226 \\
\text { Truck }=2\end{array}$ & $\begin{array}{r}\text { Car/Mot }=546 \\
\text { Truck }=22\end{array}$ \\
\hline Right Turn (RT) & $\begin{array}{l}\text { No=27 } \\
\text { Yes }=66\end{array}$ & $\begin{array}{l}\mathrm{No}=46 \\
\mathrm{Yes}=73\end{array}$ & $\begin{array}{r}\text { No }=60 \\
\text { Yes }=68\end{array}$ & $\begin{array}{r}\mathrm{No}=84 \\
\text { Yes }=144\end{array}$ & $\begin{array}{r}\text { No }=217 \\
\text { Yes }=351\end{array}$ \\
\hline Left Turn (LT) & $\begin{array}{l}\text { No=83 } \\
\text { Yes }=10\end{array}$ & $\begin{array}{r}\mathrm{No}=83 \\
\mathrm{Yes}=36\end{array}$ & $\begin{array}{r}\text { No=94 } \\
\text { Yes }=34\end{array}$ & $\begin{array}{l}\text { No=158 } \\
\text { Yes }=70\end{array}$ & $\begin{array}{r}\text { No }=418 \\
\text { Yes }=150\end{array}$ \\
\hline $\begin{array}{l}\text { Through Movement } \\
\text { (TH) }\end{array}$ & $\begin{array}{l}\text { No=76 } \\
\text { Yes }=17\end{array}$ & $\begin{array}{l}\text { No=109 } \\
\text { Yes=10 }\end{array}$ & $\begin{array}{l}\text { No=102 } \\
\text { Yes }=26\end{array}$ & $\begin{array}{l}\text { No=214 } \\
\text { Yes }=14\end{array}$ & $\begin{array}{l}\text { No }=501 \\
\text { Yes }=67\end{array}$ \\
\hline
\end{tabular}

Page 114 
In Table 49 one thing to notice is that the pedestrian crossing (PED_PRESENT) has a majority of times that a pedestrian was not crossing the intersection when a vehicle arrived. This means that in most cases, vehicles arrived either before the pedestrian phase and were not considered in this evaluation or late into the pedestrian phase after pedestrians had already crossed the major street.

Because it is unknown if there is a correlation between the dependent variable (VIOL_STOP) and any of the independent variables (QUEUE, SCHOOL_PEAK, PED_PRESENT, VEHL_OPP, MAY_ANY, VEH, RT, LT, TH), each independent variable is tested using Fisher's Exact Test. Dependent variables that exhibit associations with the dependent variable are then used in the Logit model.

\subsubsection{Establishing Dependent Variables for Stop Sign Compliance Model}

Each independent variable collected during the video analysis is separated into a contingency table with the stop compliance dependent variable. Queueing position compared with stop sign compliance is shown in Table 50. 
Table 50: Queuing Position and Stop Compliance

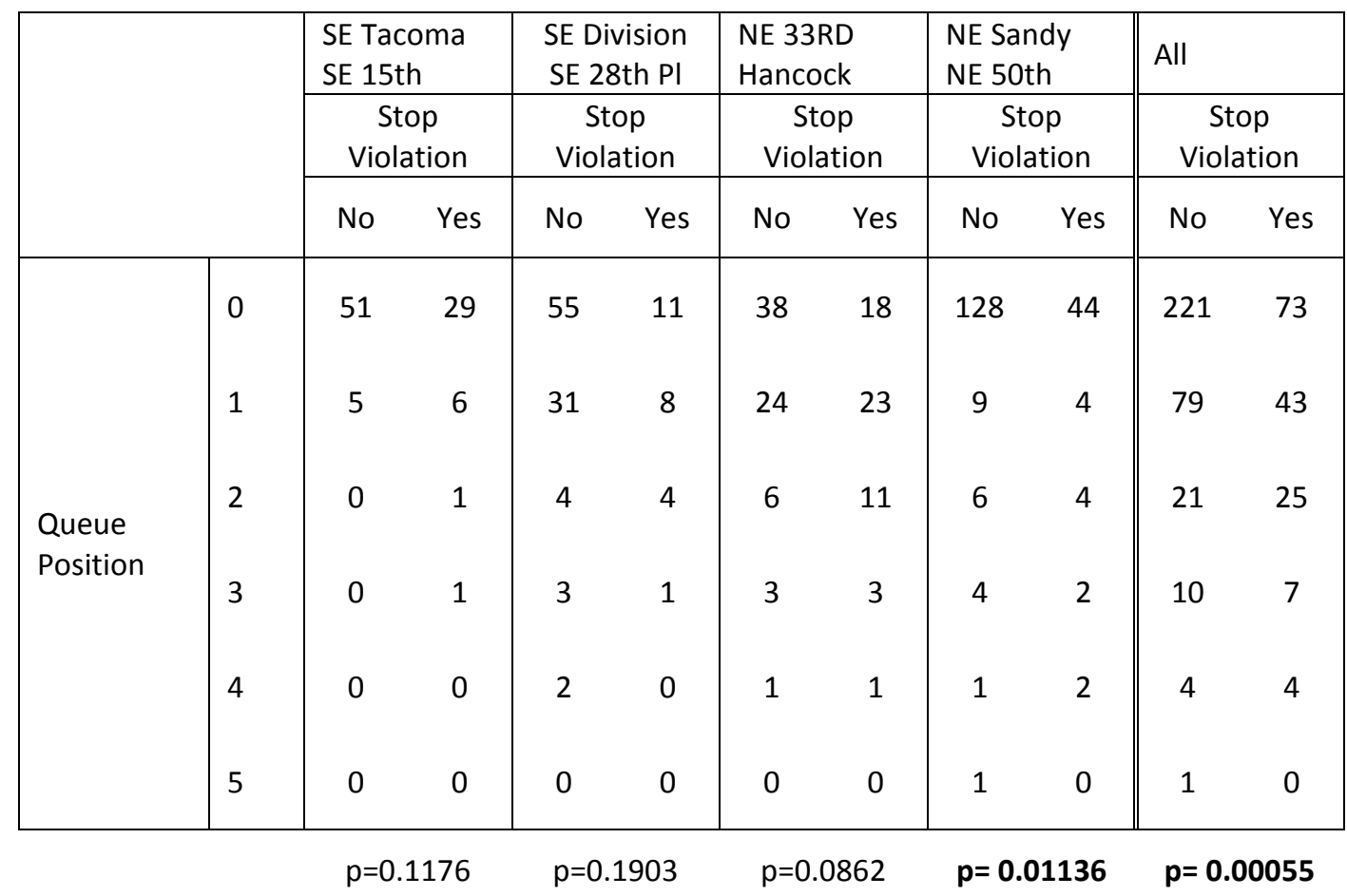

There appears to be a nonrandom relationship between where a vehicle is queued on the minor street and whether or not a stop sign violation occurs. Queueing will be included in the logit model.

There does not appear to be any correlation between whether or not it is the AM and PM peak hour in school zones and stop compliance as shown in Table 51. This variable will not be included in the regression model 
Table 51: AM/PM Peak Hours and Stop Compliance

\begin{tabular}{|c|c|c|c|c|c|c|c|c|c|c|c|}
\hline & \multirow{2}{*}{\multicolumn{2}{|c|}{$\begin{array}{l}\text { SE Tacoma } \\
\text { SE 15th } \\
\text { Stop } \\
\text { Violation } \\
\end{array}$}} & \multirow{2}{*}{\multicolumn{2}{|c|}{$\begin{array}{c}\text { SE Division } \\
\text { SE 28th PI } \\
\text { Stop } \\
\text { Violation }\end{array}$}} & \multirow{2}{*}{\multicolumn{2}{|c|}{$\begin{array}{c}\text { NE 33RD } \\
\text { Hancock } \\
\text { Stop } \\
\text { Violation }\end{array}$}} & \multirow{2}{*}{\multicolumn{2}{|c|}{$\begin{array}{c}\text { NE Sandy } \\
\text { NE 50th } \\
\text { Stop } \\
\text { Violation } \\
\end{array}$}} & \multirow{2}{*}{\multicolumn{2}{|c|}{$\begin{array}{l}\text { All } \\
\begin{array}{c}\text { Stop } \\
\text { Violation }\end{array}\end{array}$}} \\
\hline & & & & & & & & & & & \\
\hline & & No & Yes & No & Yes & No & Yes & No & Yes & No & Yes \\
\hline \multirow{2}{*}{$\begin{array}{l}\text { School } \\
\text { Peak }\end{array}$} & No & 36 & 20 & 37 & 11 & 27 & 18 & 149 & 56 & 100 & 49 \\
\hline & Yes & 20 & 17 & 40 & 7 & 27 & 23 & 0 & 0 & 87 & 47 \\
\hline
\end{tabular}

Note that the intersection at NE Sandy and NE $50^{\text {th }}$ is not included in the All Category since this intersection is not located at a school zone and does not experience this peak pedestrian period

The presence of a pedestrian does appear to have an effect on stop sign

compliance as shown in Table 52 and this independent variable will be included in the logistic regression model.

Table 52: Pedestrian Presence and Stop Compliance

\begin{tabular}{|c|c|c|c|c|c|c|c|c|c|c|c|}
\hline & \multirow{2}{*}{\multicolumn{2}{|c|}{$\begin{array}{l}\text { SE Tacoma } \\
\text { SE 15th } \\
\text { Stop } \\
\text { Violation }\end{array}$}} & \multirow{2}{*}{\multicolumn{2}{|c|}{$\begin{array}{c}\text { SE Division } \\
\text { SE 28th PI } \\
\text { Stop } \\
\text { Violation }\end{array}$}} & \multirow{2}{*}{\multicolumn{2}{|c|}{$\begin{array}{c}\text { NE 33RD } \\
\text { Hancock } \\
\text { Stop } \\
\text { Violation }\end{array}$}} & \multirow{2}{*}{\multicolumn{2}{|c|}{$\begin{array}{l}\text { NE Sandy } \\
\text { NE 50th } \\
\text { Stop } \\
\text { Violation }\end{array}$}} & \multirow{2}{*}{\multicolumn{2}{|c|}{$\begin{array}{l}\text { All } \\
\begin{array}{c}\text { Stop } \\
\text { Violation }\end{array}\end{array}$}} \\
\hline & & & & & & & & & & & \\
\hline & & No & Yes & No & Yes & No & Yes & No & Yes & No & Yes \\
\hline \multirow{2}{*}{$\begin{array}{l}\text { Pedestrian } \\
\text { Present }\end{array}$} & No & 47 & 36 & 81 & 23 & 67 & 53 & 138 & 56 & 333 & 168 \\
\hline & Yes & 9 & 1 & 14 & 1 & 5 & 3 & 31 & 3 & 59 & 8 \\
\hline
\end{tabular}

Page 117 
Whether or not a vehicle is present on the opposite side of the minor road across the intersection does not seem to have an impact on stop sign compliance as shown in Table 53. This variable will not be included in the logit model.

Table 53: Vehicle Opposite on Minor Street and Stop Compliance

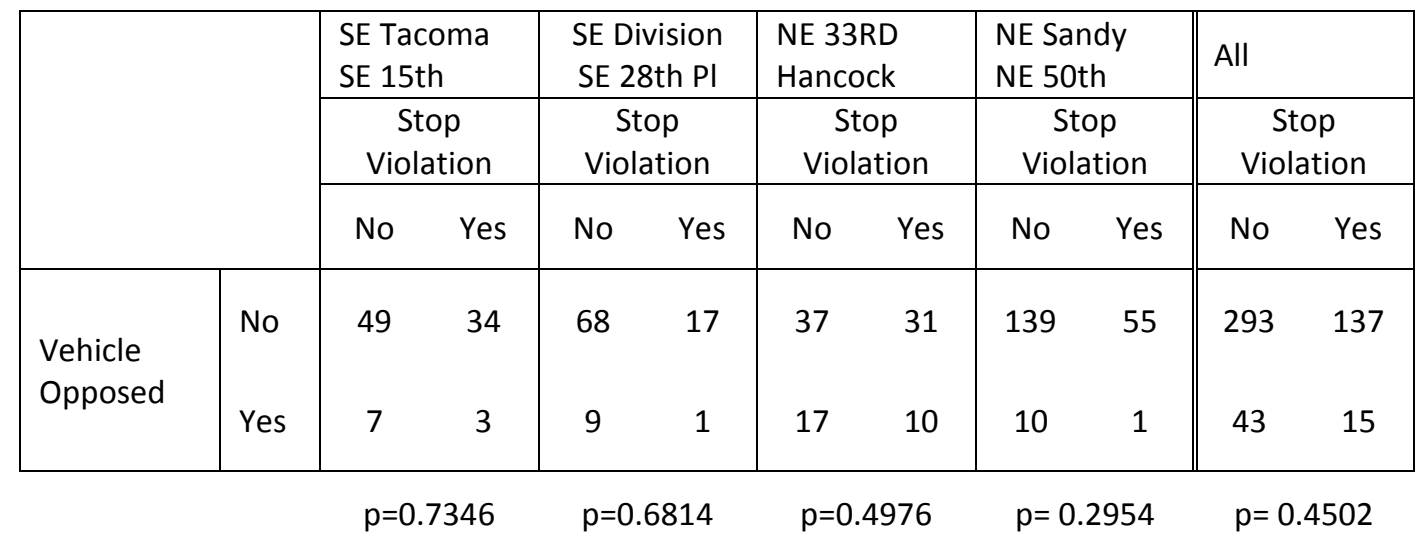

A vehicle stopped at the signal may have an influence on a minor street vehicle's stopping behavior as shown in Table 54. While this variable will be included in the logit model, it must be noted that very few situations were observed where there were no vehicles queued at the red traffic signal on the major street while a vehicle departed from the minor street. The location that did have a lot of pedestrian signal cycles without queued vehicles at NE Sandy and NE $50^{\text {th }}$ achieved this by having coordinated signalization along Sandy Boulevard. 
Table 54: Vehicle Stopped at Signal on Major Street and Stop Compliance

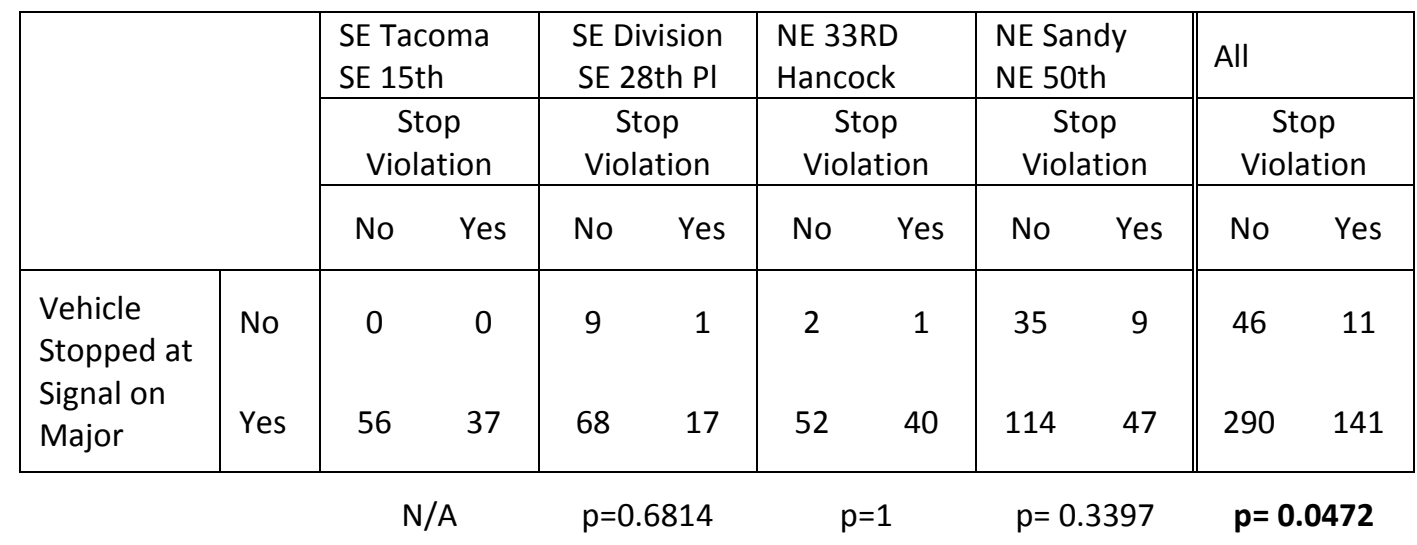

From Table 55 there does not appear to be a correlation between whether the vehicle type is a truck or car and compliance at the half-signal but it should be cautioned that the number of observations with heavy vehicles were low. Even though the number of observed heavy vehicles was low, this independent variable will not be used in the logit model. 
Table 55: Vehicle Type and Stop Compliance

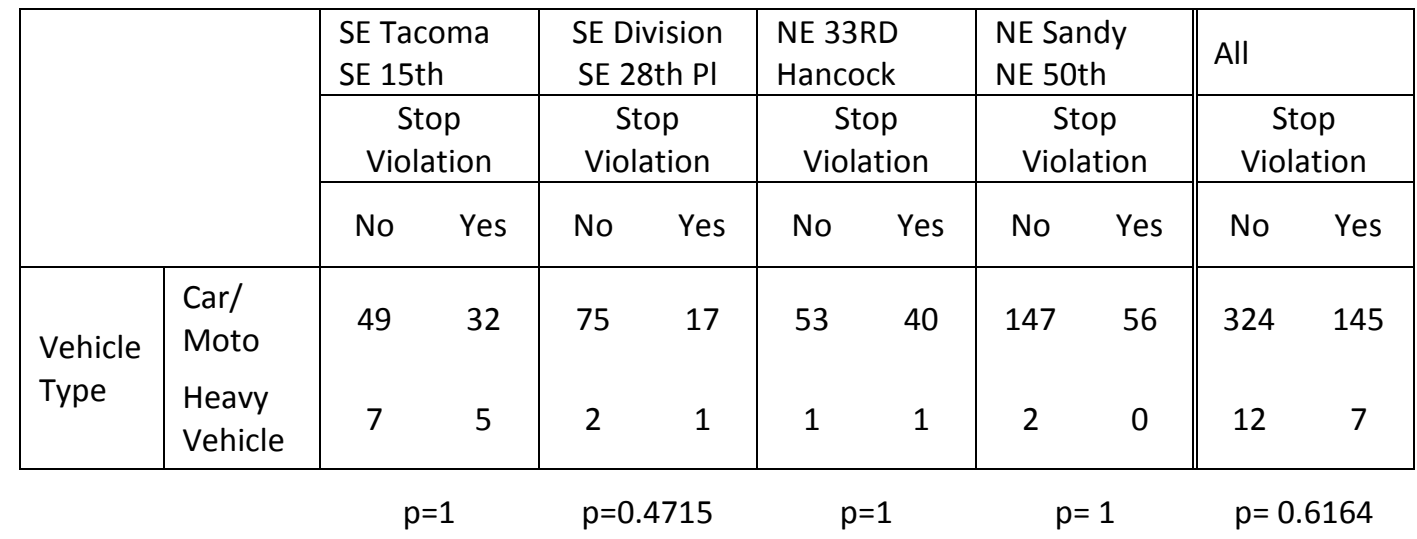

In Table 56, there may be an association with right turning vehicles and stop compliance and this will be included in the logit model. However, it should be cautioned that there are more observations from the intersection at NE Sandy and NE $50^{\text {th }}$ and this intersection may have an unbalanced bias on the other results. 
Table 56: Vehicle Turning Right and Stop Compliance

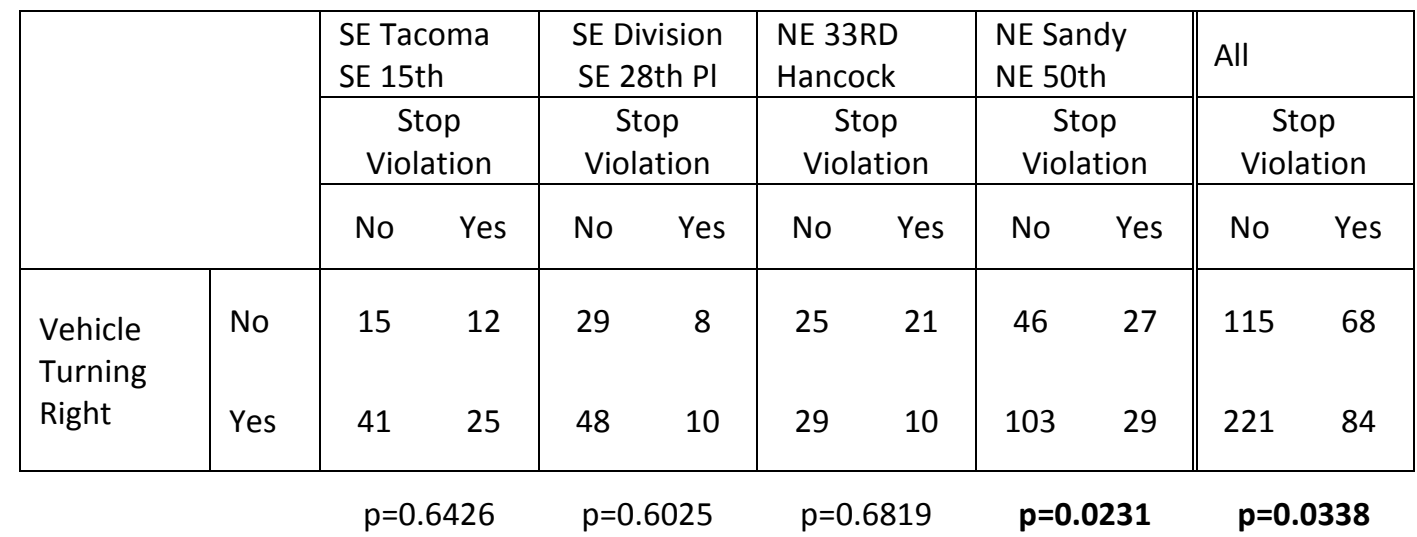

From Table 57 there does not appear to be any compelling reason to include left turning vehicles in the logit model.

Table 57: Vehicle Turning Left and Stop Compliance

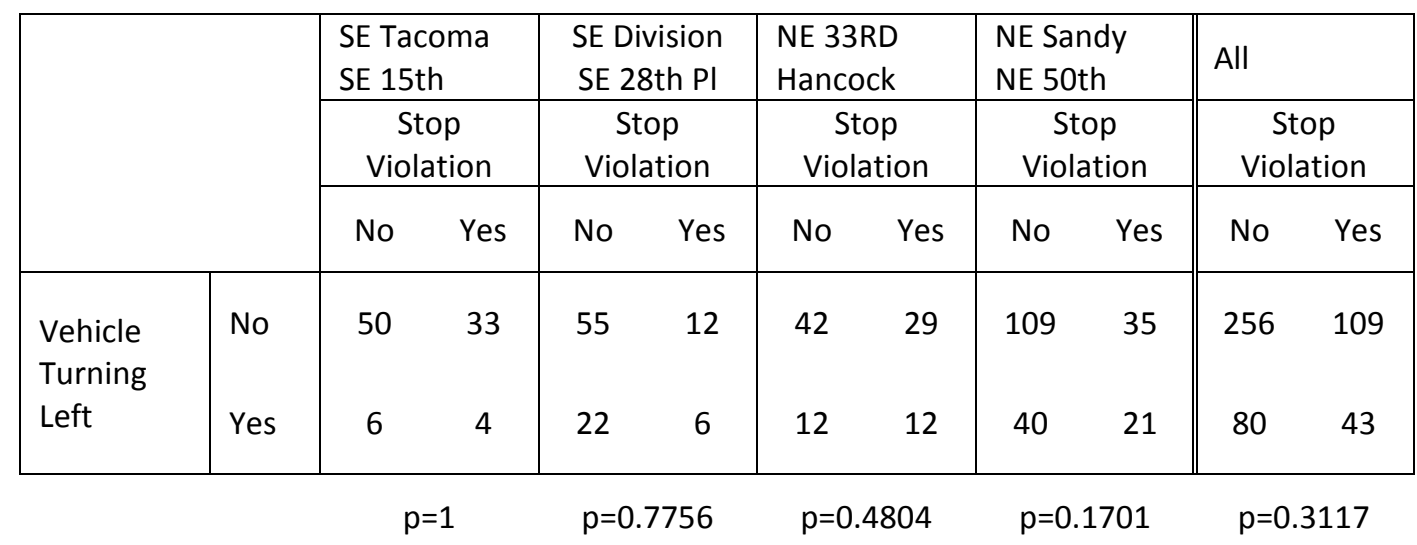

Page 121 
In Table 58 there does not appear to be a relationship between through movements from vehicles on the minor street and stop sign compliance.

Table 58: Vehicle Making Through Movement and Stop Compliance

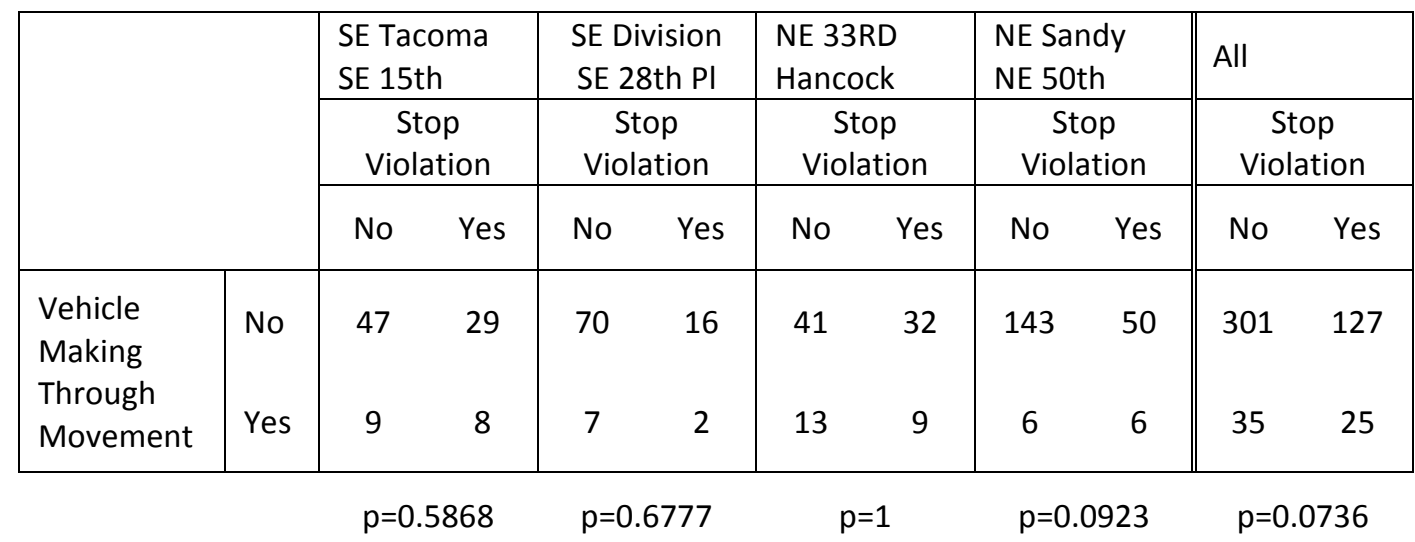

Based on this analysis, the independent variables queueing position, pedestrian presence, the presence of stopped vehicles on the major street, and right-turning vehicles will be used in the logistic regression model.

\subsubsection{Logistic Regression Model at Four Half-Signals in Portland, Oregon}

This regression model was run in $\mathrm{R}$ and $\mathrm{p}$-values and whether the independent variable estimate was found significant is shown below in Table 59. 
Table 59: Logistic Regression Model and Estimates

\begin{tabular}{|c|c|c|c|c|c|}
\hline & $\begin{array}{l}\text { SE Tacoma } \\
\text { SE 15th }\end{array}$ & $\begin{array}{l}\text { SE Division } \\
\text { SE 28th PI }\end{array}$ & $\begin{array}{l}\text { NE 33RD } \\
\text { Hancock }\end{array}$ & $\begin{array}{l}\text { NE Sandy } \\
\text { NE 50th }\end{array}$ & All \\
\hline \multirow{3}{*}{ Intercept } & $\beta=-1.368^{\wedge}$ & $\beta=-2.005^{\wedge}$ & $\beta=-0.298$ & $\beta=-0.577$ & $\beta=-1.034^{* *}$ \\
\hline & SE $\beta=0.788$ & SE $\beta=1.117$ & SE $\beta=1.380$ & SE $\beta=0.370$ & SE $\beta=0.283$ \\
\hline & $e^{\beta}=0.255$ & $e^{\beta}=0.135$ & $e^{\beta}=0.743$ & $e^{\beta}=0.561$ & $e^{\beta}=0.355$ \\
\hline \multirow{3}{*}{$\begin{array}{l}\text { Position of Queued } \\
\text { Vehicle (QUEUE) }\end{array}$} & $\beta=0.986^{\wedge}$ & $\beta=0.175$ & $\beta=0.405^{*}$ & $\beta=0.242$ & $\beta=0.336 * *$ \\
\hline & SE $\beta=0.561$ & SE $\beta=0.253$ & SE $\beta=0.203$ & SE $\beta=0.173$ & SE $\beta=0.104$ \\
\hline & $e^{\beta}=2.680$ & $e^{\beta}=1.191$ & $e^{\beta}=1.450$ & $e^{\beta}=1.274$ & $e^{\beta}=1.399$ \\
\hline \multirow{3}{*}{$\begin{array}{l}\text { Ped Crossing Maj or Mnr } \\
\text { Road (PED_PRESENT) }\end{array}$} & $\beta=-1.893^{\wedge}$ & $\beta=-16.142$ & $\beta=-0.613$ & $\beta=-1.612^{*}$ & $\beta=-1.405^{* *}$ \\
\hline & SE $\beta=1.087$ & SE $\beta=1310$ & SE $\beta=0.976$ & SE $\beta=0.767$ & SE $\beta=0.487$ \\
\hline & $e^{\beta}=0.151$ & $e^{\beta}=0$ & $e^{\beta}=0.542$ & $e^{\beta}=0.199$ & $e^{\beta}=0.245$ \\
\hline \multirow{3}{*}{$\begin{array}{l}\text { Vehicle at Signal on } \\
\text { Major Road (MAJ_ANY) }\end{array}$} & & $\beta=0.710$ & $\beta=-0.196$ & $\beta=0.076$ & $\beta=0.175^{\wedge}$ \\
\hline & $\mathrm{N} / \mathrm{A}$ & SE $\beta=1.108$ & SE $\beta=1.416$ & SE $\beta=0.144$ & SE $\beta=0.1022$ \\
\hline & & $e^{\beta}=2.034$ & $e^{\beta}=0.822$ & $e^{\beta}=1.079$ & $e^{\beta}=1.191$ \\
\hline \multirow{3}{*}{ Right Turn (RT) } & $\beta=-0.075$ & $\beta=-0.144$ & $\beta=-0.132$ & $\beta=-0.808^{*}$ & $\beta=-0.4577^{*}$ \\
\hline & SE $\beta=0.491$ & SE $\beta=0.541$ & SE $\beta=0.435$ & SE $\beta=0.333$ & SE $\beta=0.2064$ \\
\hline & $e^{\beta}=0.928$ & $e^{\beta}=0.866$ & $e^{\beta}=1.141$ & $e^{\beta}=0.446$ & $e^{\beta}=0.633$ \\
\hline \multirow{2}{*}{ P and Log Liklihood } & 0.030 & 0.271 & 0.278 & 0.005 & $4.9 \mathrm{e}^{-7}$ \\
\hline & -58.03 & -43.54 & -62.41 & -112.7 & -285.3 \\
\hline
\end{tabular}

**Significant .01

* Significant .05

$\wedge$ Significant .1

In interpreting the results, negative estimate values indicate that that

independent variable lends a positive effect to stop compliance. In this model, the presence of a pedestrian and if a vehicle is making a right turn lend to higher likelihood of a vehicle stopping on the minor street. Conversely, a higher queuing position and presence of a vehicle on the major road negatively impact the likelihood of a vehicle stopping on the minor street. 
Looking at Table 59 and the log likelihood estimators, with a pedestrian present at an intersection, a motorist is 4 more times likely to stop at the stop sign. The observed half-signals had a $30 \%$ noncompliance rate on average at stop signs. When pedestrians were present this model suggests that the noncompliance rate drops to 7.5\% when pedestrians are present at the intersection. Whether or not this is an acceptable rate remains to be seen.

Additional findings suggest that vehicles queued any position higher than the first are $40 \%$ more likely to not comply with the stop sign, that having a vehicle queued on the major street increases the likelihood of a vehicle not stopping by $19 \%$, and rightturning vehicles are $60 \%$ times more likely to comply with the stop sign than other movements made at the intersection. 


\subsection{CONCLUSIONS}

A review of pedestrian safety studies at half-signalized intersections in the United States and Canada shows that very few conclusive safety studies have been performed at these intersections. This is likely due to the small number of half-signals still being utilized in the United States. Also, since half-signals are not currently permitted by the MUTCD, there is not much incentive to study them. Seattle is currently the only jurisdiction in the United States that is still installing half-signals.

\subsection{Summary of Findings}

In analyzing the crash history and by looking at conflicts and compliance, it appears that the safety performance at half-signalized intersections is not substantially different from other intersection types with low volumes on the minor approaches.

Concerning whether half-signals are beneficial to pedestrian safety, from video captured and observing yielding behaviors it appears that half-signals are very effective in stopping major street traffic and they provide an opportunity for pedestrians to cross the major street. Although $14 \%$ higher crash rates were found at half-signals when compared with minor stop controlled intersections, lower crash rates involving pedestrian were found without taking into account pedestrian volumes. These results 
suggest that half-signals are more beneficial to pedestrian safety than a simple minor stop controlled intersection without marked pedestrian crossing on an arterial street.

Concerning whether a fully signalized intersection or half-signal are more desirable, a minor safety issue was found when reviewing crash history at half-signals and regarding pedestrians crossing during the pedestrian phase and vehicles from the minor street. This safety concern stems from the operation of half signals and any other types of beacon or signal devices located at an intersection including pedestrian hybrid beacons and rapid flashing beacons. Essentially, a fully signalized intersection operates such that pedestrians and vehicles depart at approximately the same time during the pedestrian and minor street green phase to cross the major street. At any other intersection with beacon or signal in combination with a minor street stop sign, vehicles on the minor street can depart at any time, which sometimes happens just before the pedestrian phase and this could conflict with pedestrian movement. It must be stressed that this is an extremely rare occurrence and eight of these types of crashes occurred at 47 intersections over a period of 10 years. A fully signalized intersection has its own safety concerns as well with $26 \%$ higher crash rates than at comparable half-signalized intersections. Although there were not enough intersections available to prove statistical validity, it is hypothesized that the likely fewer signal actuations at a half- 
signal has a safety benefit and potentially lowers the number of rear-end and angle/turning crashes from what would be expected at a fully signalized intersection. With all of these facts considered, it is still felt that half-signals provide desirable operating characteristics with very high motor vehicle yielding to pedestrians, as expected total crash rates (higher than comparable minor stop controlled and lower than comparable fully signalized intersections), and fewer signal actuations. These desirable characteristics reflect favorably on half-signals being a useful intersection control device when pedestrian demand is moderate and minor street traffic volumes are low.

\subsubsection{Crash History}

Crashes in this report were analyzed over a ten year period from 2002-2011. The reported crash history at half-signals in Portland, OR showed very few measurable differences between the half-signalized intersections and other comparable intersection types. From the crash data, there were proportionally more rear-end crashes at halfsignals when compared with minor stop controlled intersections. These results were expected since minor stop controlled intersections do not stop traffic on the major street. 
In crashes involving pedestrians significant differences were found when comparing the street that the colliding vehicle originated from and which road user could be held at fault for the crash. Eight of the fourteen total crashes involving pedestrians at half-signals occurred when a vehicle departed from the minor road striking a pedestrian within the marked crosswalk. These crashes occurred when pedestrians had the walk phase and this is the concern that the FHWA mentions when stating that "motorists on the minor road facing the inability to cross...may not give adequate attention to pedestrians crossing the street". This phenomenon is not exclusive to half-signals as the same crash type happened at comparison minor stop controlled intersections.

Half-signal intersections were compared with both fully signalized and minor stop controlled intersections in a matched analysis. Comparing nineteen half-signalized intersections with nineteen similar matched stop controlled intersections led to higher crash rates of 0.181 crashes per million entering vehicles at half-signals compared with 0.155 crashes per million entering vehicles for the minor stop controlled intersections. Comparing six half-signalized intersections with six similar fully signalized intersections led to lower crash rates of 0.254 crashes per million entering vehicles at half-signals compared with 0.320 crashes per million entering vehicles for the signalized group. 
These results do not suggest that converting half-signals to minor stop controlled intersections will lower crash rates nor do they suggest that converting a half-signal to a fully signalized intersection will increase crash rates at that site. Significant differences were not identified for crash rates between half-signals and minor stop controlled intersections and between fully signalized intersections and half-signals.

Crash rates at half-signals share similar patterns with crash rates at pedestrian hybrid beacons where in that instance pedestrian hybrid beacons also had slightly higher crash rates than minor stop controlled intersections and slightly lower crash rates than fully signalized intersections (24). Because crash reporting rules and study methodologies vary between the research at pedestrian hybrid beacons in Tucson and the data collected in this paper, relative rates are shown in Table 60. 
Table 60: Comparison of Relative Rates between HAWK (24) and Half Signal

\begin{tabular}{|c|c|c|c|c|c|}
\hline & & \multicolumn{2}{|c|}{$\begin{array}{l}\text { Portland, OR } \\
\text { Half-Signals }\end{array}$} & \multicolumn{2}{|c|}{$\begin{array}{l}\text { Tucson, AZ } \\
\text { Pedestrian Hybrid } \\
\text { Beacons }\end{array}$} \\
\hline & & $\mathrm{N}$ & Crash Rate & $\mathrm{N}$ & Crash Rate \\
\hline \multirow{2}{*}{$\begin{array}{l}\text { 윽 } \\
0 \\
0 \\
0 \\
0 \\
\stackrel{0}{n}\end{array}$} & $\begin{array}{l}\text { Crash Rate at Half } \\
\text { Signal or Pedestrian } \\
\text { Hybrid Beacon }\end{array}$ & 19 & $\begin{array}{l}\text { Half Signal } \\
\text { Baseline }\end{array}$ & 21 & $\begin{array}{c}\text { PHB } \\
\text { Baseline }\end{array}$ \\
\hline & $\begin{array}{l}\text { Crash Rate at Stop } \\
\text { Control }\end{array}$ & 19 & $-14.3 \%$ & 102 & $-32.7 \%$ \\
\hline \multirow{2}{*}{ 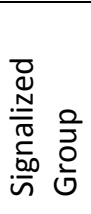 } & $\begin{array}{l}\text { Crash Rate at Half } \\
\text { Signal or Pedestrian } \\
\text { Hybrid Beacon }\end{array}$ & 6 & $\begin{array}{l}\text { Half Signal } \\
\text { Baseline }\end{array}$ & 21 & $\begin{array}{c}\text { PHB } \\
\text { Baseline }\end{array}$ \\
\hline & $\begin{array}{l}\text { Crash Rate at Signalized } \\
\text { Control }\end{array}$ & 6 & $+25.9 \%$ & 36 & $+221.1 \%$ \\
\hline
\end{tabular}

Both half-signals in Portland and pedestrian hybrid beacons in Tucson had more crashes than stop controlled intersections and fewer crashes than fully signalized intersections. The major difference between the research here and the study in Tucson is that the Tucson study's control was used to look at overall crash trends and not directly compared with the group of pedestrian hybrid beacons. It was not critical to find ideal comparison sites for analysis and therefore signalized intersections had much higher volumes (averaging $\sim 25,000$ vehicles/day on the minor street). This explains the much higher proportional crash rate at signalized intersections. 


\subsubsection{Conflict and Compliance}

Tabulating conflicts at half-signals showed a very low rate of occurrence for particular conflict types. The green trap was the most observed "conflict" at halfsignalized intersections happening 41 times. However, the number of times that vehicles were caught in the green trap was a very small percentage of overall minor street traffic volumes happening to $1.14 \%$ of vehicles of the 3636 vehicles observed traveling on the minor street. Four pedestrian-vehicle conflicts were observed involving turning vehicles or through vehicles (reversal or hesitation) across 1286 pedestrian crossing events in five days. One location had one pedestrian conflict caused by a motorist running a red light and this led to a conflict rate of $0.7 \%$ measured as the number of pedestrian conflicts divided by the pedestrian volume crossing the major street. Other locations had conflict rates around $0.3 \%$ and these conflicts were caused by right turning vehicles from the minor street. There were no observed vehiclepedestrian conflicts with left-turning vehicles from the minor road. Left-turning vehicles from the minor road involved in crashes with pedestrians were observed in the crash history but were not noticed in this conflict study. Two locations showed queuing backup from nearby signalized intersections which led to turning conflicts from motorists and bicyclists on the minor street. Tabulating and evaluating conflicts at half- 
signals showed that conflicts happen very seldom between pedestrians legally crossing during the pedestrian phase and motorists. There were two of these conflicts both caused by red light violations in 1034 legal pedestrian crossings taking place during the pedestrian phase.

Motorist and pedestrian compliance at half-signals appears to be comparable to compliance at fully signalized intersections with one exception. Vehicles were observed at all five intersections, consisting of four 4-leg and one 3-leg intersection, making a left turn from red after the onset of the red signal. These were not vehicles that were making permissive lefts and waited until oncoming traffic was clear. These were vehicles that stopped behind the pedestrian crossing, allowed pedestrians to cross the intersection and then made a left on red more than five seconds into the red signal. It appeared that vehicles performed this maneuver to make it through the intersection before the queued opposing traffic. This maneuver was likely performed by motorists familiar with the intersection and who made the maneuver because there was not as great of a risk in colliding with minor street traffic. It is unknown to what extent this exists at fully signalized intersections with lower minor street traffic volumes. 


\subsubsection{Stop Compliance Model}

Developing a model to analyze stop sign compliance showed that pedestrian presence at the intersection during the pedestrian phase of a half-signal had the strongest positive impact on motor vehicle stopping and yielding behavior. Having vehicles that were queued further back on the minor street at a half-signalized intersections and having vehicles stopped at the signal when a vehicle arrived at the stop sign brought about lower compliance rates of the stop sign.

\subsection{Future Work}

In order to figure out whether the combination of a stop sign and traffic signal work safely in conjunction at traffic signals, it is suggested that fully-signalized and minor stop controlled intersections are observed for the same conflict and compliance measures as were performed in this study.

It was also noted that the pedestrian hybrid beacon has become a part of the newest MUTCD. A study that could stem from this research would be to replace signal heads at half-signal locations with pedestrian hybrid beacons and look into the effects on motorist traffic control device compliance on the major street in a before/after study. The left turn on red behavior observed in this research should be analyzed at 
pedestrian hybrid beacons and also at signalized intersections with low minor street traffic volumes.

It is also hypothesized that half-signals exhibit crash rates somewhere between a minor stop controlled intersection and a signalized intersection because they are useful to handle traffic volumes somewhere in the middle of these two alternatives. The pedestrian hybrid beacons may have reduced crashes so substantially because they were precisely targeting intersections not quite meeting warrants for a signal but also experiencing heavy pedestrian and vehicle traffic for a minor stop controlled intersection. Minor stop controlled intersections with volume characteristics meeting those of a half-signal or pedestrian hybrid beacon could be analyzed to support or disprove this hypothesis. Similarly, low volume fully signalized intersections could also be analyzed. It is suspected that many of the patterns and behaviors seen with this analysis will be replicated at low volume fully signalized intersections and high volume minor stop controlled intersections.

As a final note, it was observed through crash history that crashes involving pedestrians caused by a minor street vehicle turning left and colliding with the pedestrian during the pedestrian phase are what differentiate the safety performance at half-signals from fully signalized intersections. It is suspected that the crashes at half- 
signals happen at the beginning of the pedestrian phase. Without detailed information in crash records and without video footage of this conflict type, the time during the pedestrian phase could not be confirmed. At a fully signalized intersection, it is suspected that the conflict type that is especially different from a half-signal is when the signal on the minor street changes back to red at the end of the pedestrian phase and vehicles on the minor street hurry through the signal to complete a movement. It could be of interest to study and compare these two particular scenarios, but it must be cautioned that a lot of footage may need to be collected in order to draw useful conclusions. The "green trap" that occurs at half-signals at the end of the pedestrian phase, from the research here, does not as noted in this paper, appear to be a concern for safety and likely does not warrant further analysis. 


\subsection{REFERENCES}

1. Laurie F. Beck, Ann M. Dellinger, Mary E. O’Neil. Motor Vehicle Crash Injury Rates by Mode of Travel, United States: Using Exposure-Based Methods to Quantify Differences. American Journal of Epidemiology. 2007;Vol. 166(No. 2).

2. Pucher J, Dijkstra L. Promote Safe Walking and Cycling to Improve Public Health: Lessons from the Netherlands and Germany. American Journal of Public Health. 2003 Sep;Vol. 93(No. 9).

3. Pedestrian Injuries: Special Issues. Insurance Institute for Highway Safety: Status Report. 1999 Mar 13;34(3):1-8.

4. Traffic Safety Facts 2009: A Compliation of Motor Vehicle Crash Data from the Fatality Analysis Reporting System and the General Estimates System. Washington D.C.: U.S. Department of Transportation; 2011 Sep. Report No.: DOT HS 811401.

5. Seattle Pedestrian Adivsory Board Meeting Minutes [Internet]. Seattle City Hall Boards and Commissions Room L280; Nov 18, 2009. Available from: http://www.seattle.gov/spab/minutes/SPABminutesNovember2009.pdf

6. Hendrickson J. Half Signal Effectiveness Study Update. City of Seattle Engineering Department: Transportation Division; 1988.

7. Wiatrak. School - Pedestrian Crosswalk Signals at Intersections: A Quantified Evaulation of Performance. Traffic and Transportation Division of the Seattle Engineering Department; 1974.

8. Petzold RG, Nawrocki R. Urban Intersection Improvements for Pedestrian Safety: Volume V-Evaluation of Alternatives to Full Signalization at Pedestrian Crossings. FHWA-RD-77-146. FHWA, US Department of Transportation; 1977.

9. Canadian Institute of Transportation Engineers. A Technical Review of Pedestrian Signals in Canada. 2006 May.

10. Manual on Uniform Traffic Control Devices for Streets and Highways [Internet]. 2009. Available from: http://mutcd.fhwa.dot.gov/

11. Manual on Uniform Traffic Control Devices for Streets and Highways [Internet]. 2003. Available from: http://mutcd.fhwa.dot.gov/

12. Pedestrian Crossing Control Manual. Transportation Association of Canada; 2012.

13. Pedestrian Crossing Control Manual for British Columbia. 2nd Edition. Victoria, B.C.: Ministry of Transportation and Highways; 1994. 159 p. 
14. HDR. HAWK Beacon Signals to Facilitate Pedestrian Crossings: Operational Report [Internet]. 2007. Available from: http://www.ite.org/Membersonly/annualmeeting/2007/AB07H0403.pdf

15. Manual on Uniform Traffic Control Devices for Streets and Highways [Internet]. 1971. Available from: http://www.traffisign.us/1971mutcd.html

16. Department of Transportation; Federal Highway Administration; 23 CFR Part 655; National Standards for Traffic Control Devices; the Manual on Uniform Traffic Control Devices for Streets and Highways; Revision; Final Rule. Federal Register; 1987. Report No.: No. 52 FR 7216.

17. Department of Transportation; Federal Highway Administration; 23 CFR Part 655; National Standards for Traffic Control; Devices: Manual on Uniform Traffic Control Devices for Streets and Highways; Revision; Final Rule. Federal Register; 2003 Nov p. 65536. Report No.: 23 CFR Part 655.Vol 68 No 224.

18. Fitzpatrick K, Turner SM, Brewer M, Carlson PJ, Ullman B, Trout ND, et al. TCRP Report 112/NCHRP Report 562. Improving pedestrian safety at unsignalized crossings: Appendices B to O. Transportation Research. 2006;10:16PM.

19. Fitzpatrick K, Turner SM, Brewer M, Carlson PJ, Ullman B, Trout ND, et al. TCRP Report 112/NCHRP Report 562. Improving Pedestrian Safety at Unsignalized Crossings. Transportation Research Board of the National Academies, Washington, DC. 2006;

20. Kay Fitzpatrick, Shawn Turner, Marcus Brewer, Paul Carlson,Brooke Ullman, Nada Trout, Eun Sug Park, Jeff Whitacre,. Improving Pedestrian Safety at Unsignalized Crossings: Appendicies B to O. Transportation Research Board; 2006 Mar. Report No.: NCHRP 3-71.

21. Thomas, Diane. Half/Pedestrian Signal Report (Intranet Quorum IMA00421970). 2010.

22. Hauer E. Cause, effect and regression in road safety: A case study. Accident Analysis \& Prevention [Internet]. 2010 Jul [cited 2010 Dec 16];42(4):1128-35. Available from: http://www.sciencedirect.com/science/article/B6V5S-4Y64DJB3/2/182f5664c76eef116a6b758b2d131277

23. Voss J, Parks L. A REVIEW OF BRITISH COLUMBIA'S PEDESTRIAN SIGNALS. 2002.

24. Fitzpatrick K, Park ES, United States. Federal Highway Administration. Office of Safety R\&D., Turner-Fairbank Highway Research Center., Texas Transportation Institute. Safety effectiveness of the HAWK pedestrian crossing treatment [Internet]. 2010. Available from: http://purl.fdlp.gov/GPO/gpo7741 
25. Hauer E. Observational Before-After Studies in Road Safety: Estimating the Effect of Highway and Traffic Engineering Measures on Road Safety. Oxford, U. K.:

Pergamon, Elsevier Science Ltd.; 1997.

26. Fitzpatrick K, Park E. Safety Effectiveness of HAWK Pedestrian Treatment (With Discussion and Closure). Transportation Research Board; 2009.

27. Hauer E. Comparison groups in road safety studies: An analysis. Accident Analysis \& Prevention. 1991;23(6):609-22.

28. Hauer E. Observational before-after studies in road safety. Pergamon Press Inc; 1997.

29. Zegeer CV, Stewart RJ, Huang HH, Lagerwey PA, Feaganes J, Campbell BJ. Safety Effects of Marked versus Unmarked Crosswalks at Uncontrolled Locations: Final Report and Recommended Guidelines [Internet]. McLean, VA: Federal Highway Administratioin; 2005 [cited 2012 Jan 30] p. 112. Report No.: FHWA-HRT-04-100. Available from: http://www.fhwa.dot.gov/publications/research/safety/04100/

30. Kononov J. Identifying locations with potential for accident reductions: Use of direct diagnostics and pattern recognition methodologies. Transportation Research Record: Journal of the Transportation Research Board [Internet]. 2002 [cited 2012 Sep 11];1784(-1):153-8. Available from: http://trb.metapress.com/index/9J03J3P76R115R55.pdf

31. Kononov J, Janson BN. Diagnostic Methodology for the detection of safety problems at intersections. Transportation Research Record: Journal of the Transportation Research Board [Internet]. 2002 [cited 2012 Sep 10];1784(-1):51-6. Available from: http://trb.metapress.com/index/c4m31204wxl3417u.pdf

32. Christopher Monsere, Todd Johnson, Karen Dixon, Jianfei Zheng, Ida Van Schalkwyk. ASSESSMENT OF STATEWIDE INTERSECTION SAFETY PERFORMANCE. Oregon Department of Transportation: Portland State University; 2011 Jun. Report No.: FHWA-OR-RD-18.

33. Clopper CJ, Pearson ES. The use of confidence or fiducial limits illustrated in the case of the binomial. Biometrika [Internet]. 1934 [cited 2014 Feb 17];404-13. Available from: http://www.jstor.org/stable/2331986

34. Binomial Confidence Interval and its application in reliability tests [Internet]. http://www.biyee.net/data-solution/resources/binomial-confidence-interval.aspx. 2011 [cited 2014 Feb 16]. Available from: http://www.biyee.net/datasolution/resources/binomial-confidence-interval.aspx 
35. Weisstein EW. Fisher's Exact Test -- from Wolfram MathWorld [Internet]. [cited 2014 May 5]. Available from: http://mathworld.wolfram.com/FishersExactTest.html

36. Statewide Crash Data System: Data Extract and Decode Manual. Oregon Department of Transportation: Transportation Data Section: Crash Analysis and Reporting Unit; 2007.

37. Zegeer, C. V., K. S. Opiela, and M. J. Cynecki. Pedestrian Signalization Alternatives. Federal Highway Administration; 1985 Jul. Report No.: FHWA/RD-83/102.

38. Trans Dev / Transportation Data Traffic Counting Program [Internet]. [cited 2014 May 6]. Available from: http://www.oregon.gov/ODOT/td/tdata/Pages/tsm/tvt.aspx\#Traffic_Volume_Tabl es

39. Crash Modification Factors Clearinghouse [Internet]. [cited 2011 Feb 26]. Available from: http://www.cmfclearinghouse.org/

40. Carter DL, Hunter WW, Zegeer CV, Stewart JR. Pedestrian and Bicyclist Intersection Safety Indices: User Guide. 2007.

41. Analysis of Red Light Violation Data Collected from Intersections Equipped with Red Light Photo Enforcement Cameras [Internet]. Research and Innovative Technology Administration; 2006 Mar. Report No.: DOT HS 810 580. Available from:

http://www.nhtsa.gov/DOT/NHTSA/NRD/Multimedia/PDFs/Crash\%20Avoidance/2 006/810580.pdf

42. HNTB Corp/Wayne State University. EVALUATION OF INNOVATIVE SAFETY TREATMENTS Volume 5: A Study of the Effectiveness of Countdown Pedestrian Signals [Internet]. FDOT; 2008 Jan. Report No.: 40502-PL-009. Available from: http://www.dot.state.fl.us/researchcenter/Completed_Proj/Summary_SF/BD500/BD500_v5_rpt.pdf

43. Department of Transportation; Federal Highway Administration; 23 CFR Part 655; National Standards for Traffic Control Devices; the Manual on Uniform Traffic Control Devices for Streets and Highways; Revision; Final Rule. Federal Register; 2009 Dec p. 66807, 66826-7. Report No.: Vol 74 No 240.

44. Sun D, Ukkusuri SVSK, Benekohal RF, Waller ST. Modeling of motorist-pedestrian interaction at uncontrolled mid-block crosswalks. Urbana. 2002;51:61801.

45. Kaparias I, Bell MGH, Chan C, Biagioli T, Kennedy J, Mount B. Investigating the Willingness of Drivers to Share Space with Pedestrians. 2010; 


\section{APPENDIX A: MUTCD 2003 AND 2009}

2003 MUTCD (11)

- 2B.05: Because the potential for conflicting commands could create driver confusion, STOP signs shall not be installed at intersections where traffic control signals are installed except as noted in Section 4D.01

- 4D.01: STOP signs shall not be used in conjunction with any traffic control signal operation, except in either the following cases:

O A. If the signal indication for an approach is flashing red at all times; or

O B. If a minor street or driveway is located within or adjacent to the area controlled by the traffic control signal, but does not require separated traffic signal control because an extremely low potential for conflict exists.

2009 MUTCD (10)

- 2B.04.10: STOP signs shall not be used in conjunction with any traffic control signal operation, except in either the following cases: 
O A. If the signal indication for an approach is flashing red at all times; or

O B. If a minor street or driveway is located within or adjacent to the area controlled by the traffic control signal, but does not require separated traffic signal control because an extremely low potential for conflict exists.

o C. If a channelized turn lane is separated from the adjacent travel lanes by an island and the channelized turn lane is not controlled by a traffic signal

- 4D.34.07: STOP signs shall not be used in conjunction with any traffic control signal operation, except in either the following cases:

O A. If the signal indication for an approach is flashing red at all times; or

O B. If a minor street or driveway is located within or adjacent to the area controlled by the traffic control signal, but does not require separated traffic signal control because an extremely low potential for conflict exists. 


\section{APPENDIX B: MATCHED STOP CONTROL LOCATIONS}

\begin{tabular}{|c|c|c|c|c|c|c|c|}
\hline \multicolumn{4}{|l|}{ Half-Signal } & \multicolumn{4}{|c|}{ Matched Minor Stop Controlled Intersection } \\
\hline \multicolumn{2}{|r|}{ Vol } & \multicolumn{2}{|c|}{ Vol } & \multicolumn{2}{|c|}{ Vol } & \multicolumn{2}{|c|}{ Vol } \\
\hline N LOMBARD ST & 7431 & N JOHN AVE & 201 & N LOMBARD ST & 7431 & N LEAVITT AVE & 1350 \\
\hline N FESSENDEN ST & 11992 & N BURR AVE & 540 & N FESSENDEN ST & 4515 & N VAN HOUTEN & 275 \\
\hline N LOMBARD ST & 16070 & N HODGE AVE & 804 & N LOMBARD ST & 16070 & N HEREFORD & 193 \\
\hline N WILLIS BLVD & 3780 & N WAYLAND & 402 & N WILLIS BLVD & 3780 & N HAVEN AVE & 835 \\
\hline N LOMBARD ST & 10044 & N DRUMMOND & 201 & N LOMBARD ST & 10044 & N CURTIS AVE & 159 \\
\hline SE MILWAUKIE & 13666 & SE PERSHING ST & 709 & SE MILWAUKIE & 12350 & SE LAFAYETTE ST & NA \\
\hline SE MILWAUKIE & 12350 & SE BUSH ST & NA & SE MILWAUKIE & 12350 & SE BOISE ST & NA \\
\hline NE 15TH AVE & 7673 & NE BRAZEE ST & 996 & NE 15TH AVE & 7673 & NE THOMPSON & 1180 \\
\hline NE 15TH AVE & 6677 & NE SHAVER ST & 1992 & NE 15TH AVE & 6677 & NE FAILING ST & 380 \\
\hline SE TACOMA ST & 20274 & SE 15TH AVE & 890 & SE TACOMA ST & 20274 & SE 16TH AVE & 581 \\
\hline SE MILWAUKIE & 13290 & SE TOLMAN ST & 1316 & SE MILWAUKIE & 13290 & SE CLAYBOURNE & 1441 \\
\hline SE 17TH AVE & 4405 & SE TOLMAN ST & 1686 & SE 17TH AVE & 4892 & SE HAROLD ST & 3918 \\
\hline SE 17TH AVE & 16268 & SE UMATILLA ST & 671 & SE 17TH AVE & 16268 & SE LINN ST & 359 \\
\hline SE DIVISION ST & 13258 & SE 28TH PL & 498 & SE DIVISION ST & 14182 & SE 32ND AVE & NA \\
\hline NE 33RD AVE & 15000 & NE MASON ST & NA & NE 33RD AVE & 15000 & NE SKIDMORE & NA \\
\hline NE GLISAN ST & 6527 & LADDINGTON & 598 & NE GLISAN ST & 7285 & LAURELHURST & NA \\
\hline NE C. CHAVEZ & 19921 & NE ROYAL CT & 199 & NE C. CHAVEZ & NA & LAURELHURST & NA \\
\hline SE C. CHAVEZ & 20245 & SE TAYLOR ST & 709 & SE C. CHAVEZ & NA & SE SALMON ST & NA \\
\hline NE FREMONT ST & 10169 & NE 28TH AVE & NA & NE FREMONT ST & 10383 & NE 40TH AVE & 239 \\
\hline NE 42ND AVE & 10150 & NE ALBERTA CT & 530 & NE 42ND AVE & 10150 & NE SKIDMORE & 322 \\
\hline SE HAWTHORNE & 14043 & SE 41ST AVE & 597 & SE HAWTHORNE & 14043 & SE 44TH AVE & 784 \\
\hline NE SANDY BLVD & 24626 & NE 50TH AVE & 320 & NE SANDY BLVD & 24626 & NE 51ST AVE & NA \\
\hline SE FOSTER RD & 23282 & SE 56TH AVE & 364 & SE FOSTER RD & 18481 & SE 54TH AVE & 530 \\
\hline SE DIVISION ST & 16715 & SE 57TH AVE & 364 & SE DIVISION ST & 16715 & SE 58TH AVE & 304 \\
\hline SE HOLGATE & 15710 & SE 88TH AVE & 178 & SE HOLGATE & 11409 & SE 87TH AVE & 875 \\
\hline SE FOSTER RD & 24148 & SE 87TH AVE & 257 & SE FOSTER RD & 24148 & SE 88TH AVE & NA \\
\hline SE 92ND AVE & 8110 & SE MAIN ST & NA & SE 92ND AVE & NA & SE TAYLOR ST & 895 \\
\hline SE 92ND AVE & 14436 & SE COOPER ST & 405 & SE 92ND AVE & 13509 & SE RURAL ST & 269 \\
\hline NE $102^{N D}$ AVE & 20000 & NE BRAZEE ST & NA & $\mathrm{NE} 102^{\text {nd }} \mathrm{AVE}$ & 19921 & NE KNOTT & 545 \\
\hline SE HOLGATE & 14488 & SE 97TH AVE & 306 & SE HOLGATE & 15394 & SE 107TH AVE & 190 \\
\hline SE C. CHAVEZ & 25252 & SE FRANKLIN ST & 855 & SE C. CHAVEZ & 24836 & SE FRANCIS ST & 1523 \\
\hline N LOMBARD ST & 15066 & N DELAWARE & 1047 & N LOMBARD ST & 18800 & N COMMERCIAL & NA \\
\hline SE POWELL & 20040 & SE 116TH AVE & NA & SE POWELL & 19303 & SE 111TH AVE & NA \\
\hline NE PRESCOTT ST & 8500 & NE 54TH AVE & NA & NEPRESCOTT ST & 6300 & NE 49TH AVE & NA \\
\hline SE FOSTER RD & 20307 & SE 78TH AVE & 202 & SE FOSTER RD & 20307 & SE 76TH AVE & NA \\
\hline
\end{tabular}

Removed from analysis due to incomplete volume data

Page 142 


\section{APPENDIX C: MATCHED SIGNAL CONTROL LOCATIONS}

\begin{tabular}{|c|c|c|c|c|c|c|c|}
\hline \multicolumn{4}{|l|}{ Half-Signal } & \multicolumn{4}{|c|}{ Matched Full Signal } \\
\hline & Vol & & Vol & & Vol & & lol \\
\hline N LOMBARD ST & 7431 & N JOHN AVE & 201 & N LOMBARD ST & 14238 & N BUCHANAN & 1614 \\
\hline N LOMBARD ST & 15066 & N DELAWARE & 1047 & N LOMBARD ST & 15066 & N WABASH AVE & 845 \\
\hline NE 15TH AVE & 7673 & NE BRAZEE & 996 & NE $15 T H$ & 7072 & NE KNOTT & 4444 \\
\hline SE 17TH AVE & 4405 & SE TOLMAN ST & 1686 & SE BYBEE & 12180 & SE 17TH & 3851 \\
\hline SEDIVISION ST & 13258 & SE 28TH PL & 498 & SE DIVISION ST & 13421 & SE 26TH AVE & NA \\
\hline NE GLISAN ST & 6527 & LADDINGTON & 598 & NE GLISAN ST & 6419 & NE 32ND AVE & 2002 \\
\hline NE SANDY BLVD & 24626 & NE 50TH AVE & 320 & NE SANDY BLVD & 18980 & NE 62ND AVE & 685 \\
\hline NE 33RD AVE & 26790 & NE HANCOCK & 1494 & NE 33RD & 23086 & NE US GRANT & 3333 \\
\hline NE 42ND AVE & 10150 & NE ALBERTA CT & 530 & NE 42ND AVE & 10150 & NE PRESCOTT ST & 9561 \\
\hline N LOMBARD ST & 10044 & N DRUMMOND & 201 & N LOMBARD ST & 10044 & N PENINSULAR & 2781 \\
\hline
\end{tabular}

Removed from analysis due to comparatively high minor road volumes at full signal or incomplete volume data

Page 143 